\title{
DETERMINANTES DO ESTADO NUTRICIONAL \\ DE IDOSOS DO MUNICÍPIO DE SÃO PAULO: FATORES SÓCIOECONÔMICOS, REDES DE APOIO SOCIAL E ESTILO DE VIDA
}

\section{TEREZA ETSUKO DA COSTA ROSA}

Tese apresentada ao Departamento de Nutrição da Faculdade de Saúde Pública da Universidade de São Paulo para a obtenção do Título de Doutor em Saúde Pública

Área de concentração: Nutrição

Orientador: PROF. DRA MARIA HELENA

D'AQUINO BENÍCIO

SÃO PAULO

2005

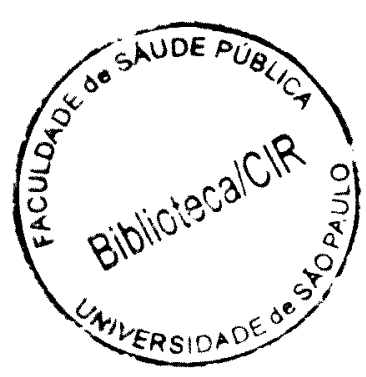


ii

Autorizo, exclusivamente para fins acadêmicos e cientificos, a reprodução total ou parcial desta tese, por processos fotocopiadores.

Assinatura:

Data:

$45657 / 2005$ doe 
Ao Abílio e também Felipe, Clara e Martim. 
“A sobrevivência de cada um está ligada à existência de um ser amado... Ou fica uma imagem, a de um ser que, na sua ausência, faz sonhar e permite, então sobreviver..." M. Dacher e M. Weinstein, Histoire de Louise 


\section{AGRADECIMENTOS}

À Prof Dra MARIA HELENA D'AQUINO BENÍCIO, ao lado de quem tive, o privilégio de desenvolver esta tese, por ter me estimulado a continuar desenvolvendo os meus estudos pós-graduados e por propiciar, mais uma vez, o meu crescimento e amadurecimento profissional como pesquisadora. Propiciar crescimento a outras pessoas é mais do que passar conhecimentos é uma arte de ensinar a aprender e para trabalhar nesta arte é preciso seriedade, profissionalismo, competência, entusiasmo, firmeza, suavidade e ternura; atributos que ela tem em sobejo.

Aos Professores Dra MARIA LÚCIA LEBRÃO e Dr RUY LAURENTI pela brilhante coordenação do Projeto de Pesquisa SABE do qual resultaram os dados utilizados neste estudo.

À Prof Dra MARIA DE FÁTIMA NUNES MARUCCI, coordenadora da seção de avaliação nutricional no Projeto $\mathrm{SABE}$, com quem pude dirimir inseguranças com as minhas primeiras aventuras na área da Nutrição e também pude discutir questões relacionadas com a avaliação de estado nutricional de idosos.

Aos demais componentes da equipe que trabalharam no planejamento e execução do Projeto SABE e em especial ao FERNÃO DIAS DE LIMA que transformou as informações coletadas em banco de dados e incansavelmente tirou todas as minhas dúvidas em relação às variáveis aqui estudadas. 
À Prof Dra MARIA DO ROSÁRIO DIAS DE OLIVEIRA LATORRE, minha grande intérprete da complexa linguagem das modelagens de regressão logística (pela segunda vez), por sua competente orientação técnica da parte estatística do trabalho.

A toda a equipe do Instituto de Saúde da Secretaria de Estado da Saúde de São Paulo, em especial à sua Diretora Técnica Dra MARIA LUCIA ROSA STEFANINI, por seu apoio e carinho em todo o árduo percurso feito para a consecução deste trabalho.

Aos amigos, que mesmo à distância (em geral, por mensagens internetianas, que nem por isso deixou de ser rede de apoio) me encorajaram com amizade, carinho e estímulos, o que tornou este itinerário menos espinhoso. 


\section{LISTA DE TABELAS E FIGURAS}

\section{Capítulo I (Artigo 1)}

Figura 1. Quadro referencial das redes sociais de apoio

\section{Capítulo II (Artigo 2)}

Tabela 1- Associação entre o indice de freqüência de contatos (IFC)/ indice de diversidade de contatos (IDC) dos idosos e os fatores demográficos e sócioeconômicos - modelo de regressão logística múltipla

Tabela 2 - Associação entre status de coabitação/ estado conjugal dos idosos e os fatores demográficos e sócioeconômicos - modelo de regressão

Tabela 3 - Associação entre indice de ajudas recebidas/ indice de ajudas prestadas dos idosos e os fatores demográficos e sócioeconômicos - modelo de regressão logística múltipla

Tabela 4 - Associação entre apoio funcional e apoio estrutural - modelo de regressão logistica múltipla

\section{Capítulo III (Artigo 3)}

Figura 1 - Referencial teórico para a investigação dos fatores determinantes do estado nutricional de idosos, estruturados em níveis hierarquizados

Tabela 1- Prevalência de baixo peso e sua associação com os fatores sócioeconômcios - razão de chances (RC) bruta, intervalo de confiança (IC 95\%) e significância

Tabela 2- Prevalência de baixo peso e sua associação com os fatores de redes sociais de apoio e de estilo de vida - razão de chances ( $\mathrm{RC}$ ) bruta, intervalo de confiança (IC 95\%) e significância. 
Tabela 3 - Prevalência de obesidade e sua associação com os fatores sócioeconômcios - razão de chances ( $\mathrm{RC}$ ) bruta, intervalo de confiança (IC 95\%) e significância.

Tabela 4 - Prevalência de obesidade e sua associação com os fatores de redes sociais de apoio e de estilo de vida - razão de chances $(\mathrm{RC})$ bruta, intervalo de confiança (IC 95\%) e significância.

Tabela 5 - Fatores associados com o baixo peso dos idosos - regressão logística múltipla hierarquizada - razão de chances $(\mathrm{RC})$ ajustada, intervalo de confiança (IC 95\%) e significância.

Tabela 6 - Fatores associados com a obesidade dos idosos - regressão logística múltipla hierarquizada - razão de chances $(\mathrm{RC})$ ajustada, intervalo de confiança (IC 95\%) e significância 


\title{
LISTA DE SIGLAS UTILIZADAS
}

\author{
Capítulo II (Artigo 2) \\ IFC - Índice de freqüência de contatos \\ IDC - Índice de diversidade de contatos \\ IFAR - Índice de freqüência de ajudas recebidas \\ IFAP - Índice de freqüência de ajudas prestadas \\ RC - Razão de chances \\ IC - Intervalo de confiança
}

\section{Capítulo III (Artigo 3)}

IFC - Índice de freqüência de contatos

IDC - Índice de diversidade de contatos

IFAR - Índice de freqüência de ajudas recebidas

IFAP - Índice de freqüência de ajudas prestadas

RC - Razão de chances

IC - Intervalo de confiança 


\section{RESUMO}

\section{Rosa TEC. Determinantes do estado nutricional de idosos do município de São} Paulo: fatores sócioeconômicos, de redes sociais e de estilo de vida. São Paulo; 2004. [Tese de Doutorado - Faculdade de Saúde Pública da USP].

Objetivos: Foram objetivos (1) revisão bibliográfica sobre as redes sociais, (2) descrever a sua distribuição relacionando-a com variáveis socioeconômicas e demográficas em idosos de São Paulo e (3) investigar as redes sociais, além de outros, como determinantes do estado nutricional desses idosos. Método: Realizou-se pesquisa bibliográfica (social network, social support, social integration, social ties e social environment) selecionado-se estudos com idosos e com clara definição do conceito e da operacionalização. Estudou-se amostra probabilística de 2.143 idosos $(60+)$ da cidade de São Paulo (inquérito SABE - Saúde, bem-estar e envelhecimento), focalizando-se as dimensões estruturais (índice de freqüência de contatos - IFC, índice de diversidade de contatos - IDC, coabitação e situação conjugal) e funcionais (índice de frequência de ajudas recebidas - IFAR e indice de freqüência de ajudas prestadas - IFAP) das redes sociais. Adotou-se o índice de massa corporal $\left(\mathrm{MC}-\mathrm{Kg} / \mathrm{m}^{2}\right)$ como indicador de estado nutricional. Utilizou-se análise de regressão logística múltipla em modelos hierarquizados. Resultados: A literatura evidencia que redes sociais levam à redução na mortalidade e à melhora da saúde, entretanto ainda não se têm clareza sobre a natureza dos seus efeitos protetores ou prejudiciais. Idosos paulistanos maiores de 70 anos, solteiros e morando sozinhos tiveram maiores chances para piores niveis nas suas redes sociais. Estado nutricional, com algumas variações, associou-se com idade, raça, escolaridade, renda, IFC, estado civil, tabagismo e atividade fisica. Conclusões: As redes sociais manifestam-se de modos desiguais entre os niveis sóciodemográficos. 
Além das contribuições que podem ser sugeridas por este estudo, outros devem ser realizados incluindo outras dimensões do apoio social, dadas as lacunas existentes sobre as redes sociais como determinantes do estado nutricional de idosos.

Descritores: Idosos, redes sociais, apoio social, obesidade, baixo peso, fatores de risco de estado nutricional de idosos. 


\begin{abstract}
Rosa TEC. Determinants of the nutritional state of elderly people in the city of São Paulo: socioeconomic factors, social networks, and lifestyle. São Paulo (BR); 2005. [Tese de Doutorado - Faculdade de Saúde Pública da Universidade de São Paulo].
\end{abstract}

Objectives: The objectives of this dissertation are (1) review bibliography on social networks, (2) describe their distribution and relate this distribution with socioeconomic and demographic variables of the São Paulo elderly people, and (3) research social networks, as well as other issues, as determinants of the nutritional state of these elderly people. Method: A bibliographic research was carried out (social network, social support, social integration, social ties, and social environment) by selecting studies with elderly people and clearly defining their concept and its application. A probability sample of 2,143 elderly people (60+) from the city of São Paulo was studied (SABE Wealth, Welfare, and Aging query), focusing on structural dimensions [contact frequency index (IFC), contact diversity index (IDC), cohabitation, and conjugal status], and functional dimensions [aid received frequency index (IFAR) and aid granted frequency index (IFAP)] of the social networks. A body mass index was adopted (BMI $\mathrm{Kg} / \mathrm{m}^{2}$ ) as nutritional state indicator. A multiple logistic regression analysis based on hierarchical models was used. Results: Literature shows that social networks reduce mortality and improve health conditions; however, the nature of their protective or damaging effects is not yet clear. Elderly people from São Paulo over 70 years old, single, and living alone tend to show the worst results in their social networks. Nutritional state is related, with some variations, to age, race, education, income, IFC, marital status, smoking habits, and physical activity. Conclusions: Social networks proved to be uneven through different sociodemographic levels. In addition to the contributions that might be suggested by this study, other studies should be conducted to 
include other social support schemes in view of the existing gaps in the current social networks as determinants of the nutritional state de elderly people.

Descriptors: Elderly people, social networks, social support, nutritional state, body mass index, risk factors of the nutritional state of elderly people. 


\section{SUMÁRIO}

LISTA DE TABELAS E FIGURAS

OBJETIVOS

CAPÍTULO I (Artigo 1) ENVELHECIMENTO E REDES DE APOIO SOCIAL: UMA REVISÃO DA LTERATURA

RESUMO

ABSTRACT

INTRODUÇÃO

O CONCEITO DE REDES SOCIAIS DE APOIO

REDES SOCIAIS DE APOIO E SAÚDE: MODELOS EXPLICATIVOS

A MENSURAÇÃO DAS REDES DE APOIO SOCIAL 
IMPORTÂNCIA DAS REDES SOCIAIS DE APOIO EM IDOSOS

RELAÇÃO ENTRE REDES SOCIAIS DE APOIO E NIVEL

SÓCIOECONÔMICO, GÊNERO E IDADE

CONSIDERAÇÕES FINAIS

REFERÊNCIAS

CAPÍtulo II (Artigo 2). REDES SOCIAIS DE APOIO EM IDOSOS DO MUNIĆ́PIO DE SÃo PAULO: ASPECTOS ESTRUTURAIS E FUNCIONAIS

RESUMO

ABSTRACT

INTRODUÇÃO

MÉTODOS 47

RESULTADOS 50

DISCUSSÃO 55

CONCLUSÕES 61

REFERÊNCIAS 63

CAPÍtulo III (Artigo 3). DETERMINANTES DO ESTADO NUTRICIONAL DE IDOSOS DO MUNICÍPIO DE SÃo PAULO: FATORES SOCIOECONÔMICOS, REDES SOCIAIS DE APOIO E ESTILO DE VIDA 69

RESUMO 70

ABSTRACT 72

INTRODUÇÃO 74 
xvi

MÉTODOS

$\begin{array}{ll}\text { RESULTADOS } & 79\end{array}$

$\begin{array}{ll}\text { DISCUSSÃO } & 83\end{array}$

CONCLUSÕES $\quad 92$

REFERÊNCIAS

$\begin{array}{lc}\text { CONCLUSÕES GERAIS } & 106\end{array}$

$\begin{array}{lr}\text { BIBLIOGRAFIA } & 109\end{array}$ 


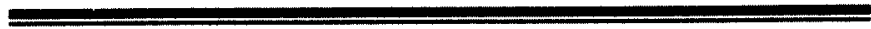

APRESENTAÇÃO 
O fenômeno do envelhecimento populacional, inicialmente ocorrido em países da Europa, da América do Norte e Japão, mais recentemente vem ocorrendo intensamente em países em desenvolvimento, entre os quais o Brasil. Dados recentes mostram que, nos países desenvolvidos, o número absoluto de idosos é menor em comparação com o dos países menos desenvolvidos. Em 1990, mais de 280 milhões de pessoas de 60 anos ou mais viviam nos países em desenvolvimento, o que significa cerca de $58 \%$ de toda a população mundial dos idosos. As projeções para o ano 2020 mostram que teremos mais de $70 \%$ de idosos nas regiões menos desenvolvidas, o que quer dizer mais de 700 milhões de idosos, em números absolutos. Este fato é a evidência da contribuição do imenso contingente de jovens, nascidos até décadas recentes, para o rápido aumento de idosos na população. No Brasil, o número de pessoas com 60 anos de idade ou mais passou de 3 milhões em 1960 para mais de 14 milhões em 2000.

O tão almejado prolongamento da vida pode assumir características catastróficas devidas às conseqüentes alterações no perfil de morbidade e mortalidade. Se por um lado declinam as taxas de mortalidade, por outro aumenta a incidência e prevalência de doenças crônicas e degenerativas, que em geral causam incapacidades e dependência. Dessa forma, manter e melhorar a qualidade de vida com o envelhecimento se torna um dos maiores desafios para a Saúde Pública e outros setores.

Nesse contexto, a nutrição é um aspecto importante porque os idosos constituem-se em um grupo específico que é especialmente vulnerável tanto aos distúrbios nutricionais quanto às inúmeras conseqüências destes, relacionadas aos agravos à saúde.

Outro aspecto importante a ser ressaltado, dentro do contexto do rápido envelhecimento populacional, é a preocupação com relação a mudanças econômicas e sociais que acompanham a modernização das sociedades, porque tal configuração pode 
enfraquecer os tradicionais sistemas de apoio para pessoas idosas, dando lugar à expansão do grupo de idosos em situação de risco.

O propósito fundamental deste estudo é analisar os aspectos do ambiente social, relacionados às redes sociais de apoio, da população idosa do Município de São Paulo e verificar a sua influência sobre o estado nutricional destes idosos.

Este estudo foi apresentado na forma de três artigos que foram desenvolvidos sem a observância da relação de continuidade, independentes, guardando as principais características de um artigo científico e construídos em consonância com o objetivo principal do estudo. Os artigos 1, 2 e 3 fazem parte dos capitulos I, II e III do trabalho, respectivamente.

O primeiro artigo é a revisão da literatura a respeito das redes sociais. A busca bibliográfica privilegiou estudos sobre o tema com a população de idosos, mas principalmente aqueles que apresentavam claramente a definição do conceito e a sua operacionalização no estudo.

$\mathrm{O}$ artigo 2 descreve e analisa a distribuição das redes sociais e verifica a influência das variáveis sóciodemográficas sobre alguns indicadores de apoio social de idosos. Este estudo é parte do inquérito sobre Saúde, Bem-estar e Envelhecimento (Projeto SABE) realizado na cidade de São Paulo em pessoas de 60 anos ou mais. O Projeto é um estudo Multicêntrico (sete paises da América Latina e Caribe) coordenado e financiado pela Organização Pan-Americana de Saúde/Organização Mundial de Saúde (OPAS/OMS). No Brasil este estudo foi executado por equipe da Faculdade de Saúde Pública da Universidade de São Paulo.

No artigo 3, apresentam-se os resultados da análise dos fatores de apoio social como determinantes do estado nutricional em idosos, além de outros fatores 
relacionados a variáveis socioeconômicas e de estilo de vida. A base de dados é a mesma utilizada para o estudo do artigo anterior. 
INTRODUÇÃO 
Entre a fronteira do social e do psicológico, a categoria "apoio social" tem favorecido o desenvolvimento de diversos trabalhos de investigação que buscam explicar algumas das diferenças existentes na distribuição de certas enfermidades tanto fisicas quanto mentais. Esse tipo de investigação iniciou-se com o clássico estudo sociológico sobre o suicídio, onde Émile Durkheim 1951 (citado em MCcAMISHSVENSSON e col 1999 p.302) vê o suicídio como produto de um enfraquecimento da coesão da sociedade, cujos membros se tomaram menos solidários e mais individualistas.

Apoio social tem sido definido como compreendo conforto, ajuda ou informações que um individuo recebe do outro, dentro de uma rede de relações. As redes sociais seriam compostas por uma estrutura e uma função, aspectos e fenômenos distintos que, como tais, devem ser avaliados e examinados. A estrutura se refere ao grau em que um individuo está socialmente conectado com os outros (freqüência, duração, diversidade, densidade e reciprocidade de contatos com quaisquer pessoas com quem se tem uma relação familiar próxima ou com envolvimento afetivo), enquanto a função consiste em conforto, ajuda instrumental ou informações intercambiadas, dentro da estrutura (DUE e col. 1999), bem como em controle social, que uns exercem sobre os outros (UMBERSON 1992).

No campo da epidemiologia, expandem-se as pesquisas sobre apoio social como preditor de saúde (BERKMAN e SYME 1979, HOUSE e col 1982, WALLSTEN e col 1999, LITWIN 1999, McCAMISH-SVENSSON 1999, WU e RUDKIN 2000, LITWIN 2001); de morbidades como doenças cardiovasculares (KAWACHI e col 1996); de incidência de doença isquêmica do coração (VOGT e col 1992) e de mortalidade (SHYE e col 1995, DAVIS e col 1997, PENNINX e col 1997, YASUDA e col 1997, RAHMAN 1999, LUND e col 2000, CERIA e col 2001). Além de outras 
pesquisas que evidenciam efeitos benéficos provindos das redes sociais de apoio sobre a sobrevivência em pacientes com câncer de mama (WAXLER-MORRISON e col 1991), com câncer em geral e em pacientes com acidente vascular cerebral (VOGT e col 1992).

Podemos perceber que temos acumulado grande quantidade de conhecimentos sobre os efeitos do apoio social e saúde fisica, mental e mortalidade. Entretanto, existem poucos estudos que investigam a relação entre dimensões do apoio social e riscos de distúrbios nutricionais. Há que se ressaltar que a relação entre saúde e estado nutricional vem sendo intensamente reconhecida e evidenciada particularmente entre os idosos, que se constituem em um grupo especifico, que são especialmente vulneráveis a inúmeras conseqüências de distúrbios nutricionais relacionadas aos agravos à saúde (McINTOSH e col. 1989).

As pesquisas, indicadas pela literatura anteriormente citada, sugerem que as pessoas que têm formas diversificadas de apoio social ficam doentes menos freqüentemente, recuperam-se de doenças mais rapidamente e engajam-se mais em comportamentos considerados mais saudáveis do que pessoas sem apoio social. Assim, se estado nutricional adequado está associado à saúde, supõe-se que o apoio social teria os mesmos efeitos positivos para o estado nutricional que têm para a saúde. 
OBJETIVOS 
1. Partindo-se da hipótese de que rede social está positivamente relacionado com o estado nutricional adequado de idosos, o principal objetivo deste estudo foi investigar a associação de indicadores de rede social de apoio entre o baixo peso e entre a obesidade da população idosa do Município de São Paulo. Considerouse a relevância do tema tendo os idosos como um grupo específico que é especialmente vulnerável tanto aos distúrbios nutricionais quanto às inúmeras conseqüências destes, relacionadas aos agravos à saúde.

2. A compreensão das estruturas e dos processos sociais amplos, bem como dos processos psicológicos e biológicos, que determinam a quantidade e qualidade das redes sociais e de apoio entre os idosos é tão importante quanto o significado das redes sociais de apoio para a melhoria da saúde. Essas informações são importantes para o planejamento e realização de programas de prevenção e intervenção que pretendam reduzir riscos para diversos desfechos de saúde. Considerando esses aspectos, o presente estudo teve também como objetivo investigar os diferenciais nas redes sociais de apoio em idosos no Município de São Paulo, identificando a influência de algumas características sócioeconômicas e demográficas sobre elas.

3. A despeito de uma grande quantidade de pesquisas e dos resultados que associam a presença do apoio social com a existência de certos níveis de saúde e doença, não existe ainda, um consenso em relação ao conceito de rede social de apoio, o qual apresenta vários problemas de definição e de operacionalização Considerando-se esse aspecto, este estudo contemplou ainda como objetivo a realização de uma revisão da literatura, fazendo uma análise sobre a origem do 
termo, as maneiras pelas quais tem sido definido e as formas em que a investigação recente tem tratado de vincular a disponibilidade de apoio social com bem estar e com saúde. 


\section{CAPíTULO I (Artigo 1)}

ENVELHECIMENTO E REDES DE APOIO SOCIAL:

UMA REVISÃO DA LITERATURA 


\section{RESUMO}

Realizou-se revisão sumária com o objetivo de discutir conceitos atuais sobre as redes sociais ou redes sociais de apoio e identificar as questões não resolvidas acerca da sua conceituação, bem como identificar os problemas metodológicos envolvidos na sua operacionalização. A partir da pesquisa bibliográfica (social network, social support, social integration, social ties e social environment) selecionaram-se estudos que abordavam o tema relacionando-o aos idosos, mas principalmente aqueles que apresentavam claramente a definição do conceito e a sua operacionalização no estudo. Descreveu-se o conceito mais amplamente aceito pelos autores dentro do contexto de estudos epidemiológicos e psicossociológicos, e outros aspectos como trocas sociais, apoio percebido, interações negativas e capital social, discutidos mais recentemente, também foram sucintamente descritos. As medidas de redes sociais mais amplamente empregadas foram descritas e as questões metodológicas não resolvidas, relativas à operacionalização das mensurações, foram debatidas. Analisaram-se também alguns estudos que evidenciam a importância das redes sociais em idosos e outros relacionando redes sociais e nível sócioeconômico, gênero e idade. Seus resultados foram resumidamente compilados. Concluiu-se que, a despeito da existência de uma grande quantidade investigações que atestam a associação entre presença de rede social e certos níveis de saúde e doença, o conceito de redes sociais de apoio ainda apresenta vários problemas de definição e de operacionalização. Outros estudos de atualização bibliográfica centrando-se nas investigações mais recentes, que abordam certos aspectos qualitativos e comportamentais das interações interpessoais, seriam necessários para uma melhor compreensão acerca deste complexo constructo multidimensional.

Descritores: redes sociais, redes sociais de apoio, apoio social, integração social. 


\begin{abstract}
A summary review was carried out for the purpose of discussing the current concepts on the social networks or social support networks and identify and the unresolved issues on their conceptualization, as well as to identify the methodology issues involving their application. Based on the bibliographic research (social network, social support, social integration, social ties and social environment) studies addressing this matter and relating it to elderly people were selected, in particular those that clearly present in the study the definition of the concept and its application. The concept described is the concept more broadly accepted by the authors within the context of epidemiological and psychosociological studies, and other very recently discussed aspects such as social exchanges, support perceived, negative interactions and social capital, were also succinctly described. The most broadly used social network metrics were described and the unsolved methodology issues related to the application of the measurements were debated. There was the analysis of some studies evidencing the importance of social networks among elderly people and others relating social networks to socioeconomic level, gender, and age. Their results were briefly collated. It was also concluded that despite the existence of a large number of research studies attesting the association between the presence of the support network and certain health and sickness levels, the concept of social support network still presents several problems to define and apply. Other bibliography updating studies focusing on the most recent research on this issue, covering certain qualitative and behavioral aspects of interpersonal interactions, would be necessary for better understand this complex multidimensional construct.
\end{abstract}

Descriptors: social networks, social support networks, social support, social integration. 


\section{INTRODUÇÃO}

Entre a fronteira do social e do psicológico, a categoria redes sociais de apoio tem favorecido o desenvolvimento de diversos trabalhos de investigação que buscam explicar algumas das diferenças existentes na distribuição de certas enfermidades, tanto fisicas quanto mentais. Esse tipo de investigação iniciou-se com o clássico estudo sociológico sobre o suicídio, onde Émile Durkheim 1951 (citado em McCAMISHSVENSSON e col. 1999 p.302) vê o suicídio como produto de um enfraquecimento da coesão da sociedade, cujos membros se tornaram menos solidários e mais individualistas. Em seguida surgiram a teoria da ligação ${ }^{1}$ do psiquiatra John Bowlby e as análises das redes sociais dos antropólogos Elizabeth Bott e John Barnes ${ }^{2}$ (citados em BERKMAN e col. 2000) que formaram o alicerce e impulsionaram as investigações empiricas sobre as relações sociais e seus efeitos sobre a saúde.

Em meados da década de 1970, alguns pesquisadores passam a dar atenção especial ao contexto social, a partir da suposição de que há outra categoria de fatores ligados a certos aspectos do ambiente social capazes de produzir efeitos sobre um hospedeiro suscetível a agentes de doenças. Os estudos passam a sugerir que deve existir uma relação entre redes formadas por laços sociais, além de relações com parentes e amigos, e a promoção de saúde, a proteção contra doenças, e mesmo o aumento da sobrevivência em indivíduos. As investigações neste âmbito confirmam que a presença

\footnotetext{
${ }^{1}$ John Bowlby influenciou as teorias do desenvolvimento infantil ao propor o conceito de ligação (attachment theory) afirmando que existe uma necessidade humana universal para formar vínculos afetivos intimos. Esses vinculos intimos, criados na infância, formariam uma base segura e sólida para os relacionamentos duráveis, seguros e afetuosos na vida adulta.

${ }^{2}$ Barnes e Bott desenvolveram, de forma independente, o conceito de redes sociais para analisar vínculos que perpassam os grupos que têm relapōes de parentesco tradicionais, grupos de residência e de classes, e que explicam certos comportamentos relativos a acesso a trabalho, a atividade politica ou a papéis conjugais.
} 
ou ausência de relações sociais afeta diferencialmente a saúde dos individuos (CASSEL 1976).

Essas hipóteses vêm se confirmando a partir de resultados de diversas investigações que destacam as redes sociais de apoio como possível determinante da mortalidade geral. Um desses importantes trabalhos é o estudo longitudinal desenvolvido em amostra populacional de 6928 adultos de Alameda County, realizado entre 1965 e 1974 por BERKMAN e SYME, 1979. Eles observaram que pessoas que não mantinham relações sociais e comunitárias tiveram maior probabilidade de morrer, durante o seguimento, do que aquelas que mantinham contatos mais extensos (contato com parentes e amigos, ser membro de igreja e ser membro de grupos e associações), mesmo após ajuste por idade.

Posteriormente, HOUSE e col., 1982, empregando metodologia semelhante, mas mais aprimorada em relação ao estudo de BERKMAN e SYME, desenvolveram a pesquisa Tecumseh Community Health Study. Esta investigacão permitiu avaliar o impacto de um amplo leque de relações sociais, freqüência e intensidade delas na mortalidade de uma coorte de 1322 homens e 1432 mulheres que foram entrevistados, examinados por médicos e acompanhados por 9 a 12 anos. A associação negativa das variáveis sociais (estado civil, visitar amigos/parentes, ir à igreja; freqüentar salas de leitura, cinema e jogos; ver televisão, ouvir rádio e ler) com mortalidade persistiu, mesmo quando controlada por idade e pelos diversos indicadores de saúde e doenças. É interessante notar que os resultados demonstraram também que atividades mais solitárias, tais como ver televisão, ouvir rádio e ler, estão associadas mais com o aumento da mortalidade do que com a sua diminuição. Este resultado sugere que a mera atividade de diversão, diferente do trabalho ou da rotina da vida cotidiana, não é o que 
tem efeito na redução do risco de morrer. $O$ efeito benéfico parece vir da atividade que envolve algum contato com outras pessoas.

No campo da epidemiologia, expandem-se as pesquisas sobre as redes sociais de apoio como preditor de saúde (WALLSTEN e col., 1999; McCAMISH-SVENSSON 1999; WU e RUDKIN, 2000, LITWIN 2001); de morbidades, como doenças cardiovasculares (KAWACHI e col., 1996); de incidência de doença isquêmica do coração (VOGT e col., 1992) e de mortalidade (SHYE e col., 1995, DAVIS e col., 1997, PENNINX e col., 1997; YASUDA e col,. 1997; RAHMAN 1999; LUND e col., 2000; CERIA e col., 2001). Além de outras pesquisas que evidenciam efeitos benéficos provindos das redes sociais de apoio sobre a sobrevivência em pacientes com câncer de mama (WAXIER-MORRISON e col., 1991), com câncer em geral e em pacientes com acidente vascular cerebral (VOGT e col., 1992).

\section{O CONCEITO DE REDES SOCIAIS DE APOIO}

A despeito de uma grande quantidade de pesquisas e dos resultados que associam a presença das redes sociais de apoio com a existência de certos níveis de saúde e doença, o conceito apresenta vários problemas de definição e de operacionalização.

Considera-se, portanto, oportuno fazer uma análise sobre a origem do termo, as maneiras pelas quais tem sido definido e as formas em que a investigação recente tem tratado de vincular a disponibilidade de redes sociais de apoio com bem estar e com saúde.

O conceito encontra-se designado de diferentes modos dependendo do autor, entretanto os termos mais freqüentemente utilizados são apoio social e redes sociais, também é comum encontrarmos termos como relações sociais, integração social, 
vínculos sociais e ancoragem social sendo empregados indistintamente (CASTRO e col., 1997; DUE e col., 1999). A maioria dos investigadores concorda que as redes sociais de apoio seriam compostas por uma estrutura e uma função (Figura 1), as quais constituem aspectos e fenômenos distintos e, como tais, devem ser avaliados e examinados.

A estrutura das relações sociais de apoio refere-se à organização do vínculo entre pessoas e pode ser descrita sob diferentes aspectos tais como número de relações ou papéis sociais que uma pessoa tem, freqüência de contatos com vários membros de uma rede, densidade de contatos, multiplicidade e reciprocidade de relações entre os membros de uma rede). A estrutura das relações sociais é composta pela rede de relações formais e informais. As relações formais são aquelas mantidas devido à posição e papéis na sociedade e incluem contatos com profissionais como médico, dentista, professor, advogado, etc., e outras pessoas conhecidas. As relações sociais informais - relações tidas como de maior importância pessoal e afetiva do que as relações mais especializadas e formais - são compostas por vínculos com todos os demais indivíduos (família, amigos, vizinhos, col.egas de trabalho, comunidade, etc) e têm como caracteristicas marcantes a familiaridade e proximidade, com envolvimento afetivo. "Medir" a estrutura da rede social permite avaliar o grau em que um indivíduo está socialmente conectado com os outros, seu nivel de isolamento ou de integração social. (THOITS 1995; DUE e col., 1999).

A função das redes sociais de apoio compreende o apoio social, as relações de tensão e a ancoragem social.

O apoio social inclui o nível de recursos fornecidos por outros e pode ser especificada em quatro aspectos (DUE e col., 1999; BERKMAN e col., 2000):

1) apoio emocional, que envolve expressð̃es de amor e afeição; 
2) apoio instrumental, que se refere aos auxílios "concretos" como provimento de necessidades materiais em geral, ajuda para trabalhos práticos (limpeza de casa, preparação de refeição, provimento de transporte) e ajuda financeira;

3) apoio de informação, referente a informações (aconselhamentos, sugestões, orientações) que podem ser usadas para lidar com problemas e sua resolução;

4) interação social positiva, que compreende a disponibilidade de pessoas com quem é possivel se divertir e relaxar.

Ainda não se tem bem esclarecido de que forma os aspectos estrutural e funcional do apoio social estão relacionados entre si. Alguns autores ressaltam ser possível que o número e estrutura de vínculos dos indivíduos importe menos para a percepção de apoio recebido do que possuir no mínimo um vínculo que seja bastante próximo e de confiança (THOITS 1995). Entretanto, outros sustentam que a estrutura da rede é crucial para facilitar o acesso a vários tipos de apoio funcional. Além disso, tem sido evidenciado que o tamanho da rede social de uma pessoa, a coesão da rede e o tipo de relacionamentos na rede (vínculos fortes ou fracos) são fatores que influenciam o recebimento de vários tipos de apoios sociais (BARRERA 1986; WELLMAN e WORTLEY, 1990, citado em THOITS 1995).

Desde que as primeiras investigações sobre a influência das relações sociais na saúde foram realizadas entre as décadas de 1970 e 1980, avançou-se nos conhecimentos e na compreensão sobre a riqueza e complexidade do apoio social, ganhando relevo a literatura que associa o apoio social à saúde mental. Alguns pesquisadores têm concluído que apoio social é um constructo multidimensional e têm descrito diferentes tipos ou categorias de apoio social que devem ser considerados e que podem ter diferentes conseqüências para a saúde física e mental dos indivíduos (TURNER e MARINO, 1994). 
Outros aspectos das redes sociais de apoio: trocas sociais, apoio percebido (ou avaliação subjetiva de apoio), interações negativas e o conceito de capital social

Além do nivel de recursos fornecidos por outros, a função das relações sociais de apoio abrange os aspectos qualitativos e comportamentais das interações interpessoais que ocorrem dentro da estrutura das redes sociais como a ancoragem social e as relações de tensão (DUE e col., 1999). A ancoragem social está relacionada com o "grau de enraizamento" ao grupo formal ou informal e a um senso mais qualitativo de seu "sentimento como membro desse grupo". As relações de tensão referem-se à dimensão em que a função das relações sociais causa tensão emocional ou instrumental por conflitos ou demandas excessivas, ou ambos. Por causa do aspecto negativo e prejudicial que pode estar presente nas funções das relações sociais, alguns pesquisadores passaram a considerar nas escalas de avaliação do apoio social o apoio percebido, ou a avaliação subjetiva do apoio. A inclusão de interações negativas e do apoio percebido ajudam a explicar as conseqüências desejáveis, bem como as indesejáveis, das redes sociais de apoio sobre o bem estar.

Como uma outra importante faceta do processo envolvido nas redes sociais de apoio, as trocas sociais são vistas, por diversos autores, como fator crítico para o bem estar, ou seja, os efeitos do receber apoio, do oferecer apoio e os da reciprocidade sobre o bem estar são de crucial e decisiva importância. Além das trocas sociais, outro conceito subjacente às redes sociais de apoio é a norma da solidariedade nas relações próximas, tais como as encontradas entre membros de uma família. A norma da solidariedade está refletida no compromisso das pessoas com entes queridos e amados, apesar do custo ou do que vai retomar a elas. (LIANG e col., 2001). 
A literatura sobre as redes sociais de apoio dificilmente enfoca o idoso como cuidador ou provedor de apoio. No entanto, LIANG e col. (2001) ressaltam que o idoso faz parte de um elenco de pessoas cujo papel não é somente receber, mas também prover ajuda para os outros. HUGHES e WAITE (2002) teorizam que a percepção que os indivíduos têm sobre o equilíbrio dos recursos e das demandas é o fator que tem mais conseqüèncias sobre a saúde deles. Isso significa que o apoio informal, dentro das redes sociais dos idosos, é governado também pelo critério da reciprocidade.

A incapacidade de explicar o perfil de saúde em áreas pobres com base somente nas características dos seus habitantes tem levado pesquisadores a investigarem a possibilidade de que a relação entre nivel sócioeconômico e saúde seja mediada pelo número e pela natureza dos relacionamentos entre as pessoas. Como exposto anteriormente, quando diz respeito à dimensão individual esse conceito é avaliado como "apoio social" (número e tipo de relações que um indivíduo possui); quando referido ao âmbito populacional esse conceito é medido como "capital social" (neste sentido "organização social" e "eficácia coletiva" são conceitos próximos): uma designação que permite avaliar a qualidade dos relacionamentos entre os moradores de determinada área. ( COHEN e col., 2003).

O conceito de capital social tem sido colocado na vanguarda como uma das explicações do porquê algumas comunidades prosperam e têm instituiç̃es políticas efetivas e cidadãos saudáveis, enquanto outras comunidades não (KAWACHI e col., 1999; McCULLOCH 2001). Capital social se refere a sistemas horizontais de participação cívica que podem ser associações comunitárias, grupos de música, cooperativas, grêmios desportivos, partidos políticos, etc.. As características centrais dessas redes de intercâmbio social são a confiança, a reciprocidade e a cooperação 
(LABRA 2002). Fontes de capital social incluem não só trocas recíprocas, mas também e principalmente valores culturais e solidariedade de classes e étnica (PORTES 1998, citado em LIANG e col., 2001).

As redes sociais informais e formais são componentes essenciais do capital social, um recurso que se produz com a habilidade dos atores para assegurar beneficios a partir dos membros de uma rede social ou dos recursos de uma estrutura social. As trocas sociais diferenciam-se das trocas puramente econômicas em dois aspectos. 1) A moeda com a qual as obrigações serão pagas pode ser diferente daquela utilizada na economia e pode ser algo tão dificil de apreender como aprovação e lealdade; 2) o tempo do pagamento é inespecifico (CATTELL 2001; LIANG e col., 2001).

Características da sociedade não devem ser reduzidas aos atributos dos indivíduos que nela vivem, por isso é mais provável encontrar individuos socialmente isolados concentrados em comunidades que são fracas em capital social, porque tais lugares provêem menos oportunidades para que os individuos estabeleçam vínculos locais (KAWACHI e col., 1999). Segundo os mesmos autores, a influência do capital social na saúde individual é plausivel, pelo menos, de três modos: 1) promovendo maior rapidez na difusão de informações em saúde; 2) aumentando a probabilidade de que hábitos de comportamentos saudáveis sejam adotados (por exemplo, atividade fisica); e 3) exercendo controle social sobre comportamentos desviantes relacionados com a saúde.

A teoria da difusão de inovações sugere que comportamentos inovadores (por exemplo, utilização de serviços preventivos) se difundam mais rapidamente em comunidades que são coesas e nas quais seus membros se conheçam e confiem uns nos outros. 


\section{REDES SOCIAIS DE APOIO E SAÚDE: MODELOS EXPLICATIVOS}

Os mecanismos através dos quais o apoio social influencia a saúde ainda não estão suficientemente esclarecidos. De um lado tem-se o modelo do efeito amortecedor. Este sustenta que o apoio social protege os indivíduos dos efeitos patogênicos ligados aos eventos estressantes. O mecanismo explicativo proposto está relacionado com processos psicobiológicos que influenciariam os sistemas neuroendócrino e imunológico (BERKMAN e SYME, 1979). O apoio social permitiria aos indivíduos redefinirem a situação estressante e enfrentá-la mediante estratégias não estressantes ou capazes de inibir os processos psicopatológicos que poderiam desencadear-se na ausência do apoio social. Em suma, segundo estes autores, o apoio social enfraquece ou amortece os efeitos do estresse evitando que os individuos definam e vivenciem uma situação como estressante. Embora o papel que as redes sociais de apoio ocupam na diminuição da influência do estresse sobre a saúde tenha recebido considerável atenção na literatura, sabe-se muito pouco sobre a natureza desses processos (KRAUSE e MARKIDES, 1990).

Por outro lado, tem-se o modelo do efeito direto. Aqui postula-se que o apoio social favorece os níveis de saúde, independentemente dos níveis de estresse do indivíduo. Essa explicação sugere que o apoio social atuaria através da regulação social de certos hábitos tais como o do uso fumo e o do consumo de álcool (UMBERSON 1992); através do fornecimento de informações e recursos adequados relacionados com ajuda econômica, cuidados com a casa e meios de transporte (COHEN 1988, citado por PENNINX e col., 1997, p.510); e através das influências na acessibilidade ao cuidado à saúde e às práticas saudáveis (BERKMAN e SYME, 1979). 
É importante mencionar algumas implicações teóricas do modelo do efeito direto. Dado que se postula que o apoio social tem repercussões sobre o indivíduo, independentemente da presença de estresse, implicitamente aceita-se que não há interação entre o estresse e o apoio social. Nessa perspectiva, se os outros fatores se mantiverem constantes, os individuos que diferem em seus níveis de apoio social diferirão, na mesma medida, em seu bem estar fisico e mental, independentemente de que experimentem baixos ou altos níveis de estresse.

\section{A MENSURAÇÃO DAS REDES SOCIAIS DE APOIO}

A maioria dos estudos, que passou a dar atenção ao contexto social, realizada entre as décadas de 1970 e 1980, utilizou, como medida, informações sobre o número de amigos próximos e parentes, sobre o estado conjugal e sobre afiliações a instituições religiosas e associações voluntárias. Essas medidas foram unanimemente definidas como "enraizamento social" (social embeddedness), que avalia o grau em que um indivíduo está socialmente conectado ou integrado com outros. As avaliações não eram padronizadas e, muitas vezes, medidas de vínculos "fortes" e "fracos" não eram avaliadas diretamente, mas inferidas a partir da freqüência a organizações voluntárias e religiosas (BERKMAN e col., 2000). Entretanto, as medidas que avaliam o grau de integração, pelo seu alto poder de predizer desfechos em saúde, continuam a ser empregadas na grande maioria dos estudos.

Uma segunda onda de pesquisas desenvolvidas em reação aos trabalhos anteriores é o conjunto de pesquisas em saúde mental, que transformou toda a orientação do campo de diversas maneiras (BERKMAN e col., 2000). Nestas, a ênfase é dada mais 
aos aspectos qualitativos das relações sociais (apoio funcional e aspectos prejudiciais das relações) do que à elaboração de aspectos estruturais das redes.

“Apoio realmente recebido" (enacted support), afere a quantidade de assistência que foi realmente fornecida pelos membros da rede social. Empregando esse tipo de medida enfoca-se a quantidade dos apoios emocional, instrumental e de informação que é intercambiada na rede social KRAUSE e MARKIDES, 1990 LIN e col., 1999). Os autores abrangem todos os aspectos do apoio funcional incluindo em suas medidas questões como "Com que freqüência alguém formeceu transporte limpeza pesada de casa, compras) que necessitou ?" (apoio instumental); "Tem amigos/pares com quem você pode falar sobre seus problemas? (apoio emocional); e assim sucessivamente.

Outra dimensão freqüentemente incluída nas medidas, o "apoio percebido" (perceived support), captura avaliações subjetivas do apoio, examinando a satisfação com a quantidade de ajuda recebida de outros ou o sentimento de que o apoio está disponível, quando necessário (DUE 1999; LIN e col., 1999; CHOR e col., 2001). Incluem questões como "Você teria alguém que lhe desse dinheiro para pagar uma conta muito importante se você precisasse? (sim; sim, com dificuldade e não).

Outro aspecto subjetivo e qualitativo do apoio social que tem sido mensurado é o número de pessoas consideradas de muita confiança ou confidentes. (OLSEN e col. 1991).

As interações negativas também são consideradas, uma vez que há recentes evidências de que o apoio fornecido também pode ser fonte de desprazer ou de trocas não positivas. (KRAUSE e BORAWSKI-CLARK, 1995; DUE e col., 1999). O primeiro autor incluiu questões como "Com que freqüência você sente que os outros tem feito demandas excessivas a você?" e "Os outros criticam coisas em você ou em coisas que 
wocê faz?", enquanto DUE pergunta diretamente: "Você experiência conflitos no seu dia-a-dia (em questões separadas para parceiro, familia, e colegas? "

Há uma pequena, mas crescente, literatura que utiliza um constructo complexo para analisar o fenômeno das redes sociais de apoio, a dos tipos de redes. 0 desenvolvimento da tipologia das redes baseia-se em determinados aspectos estruturais ou funcionais para efetuar a classificação. Por exemplo, LITWIN (2001) empregou seis aspectos estruturais - tamanho, composição, percentual de vinculos íntimos, freqüência de contatos, duração dos vínculos e proximidade geográfica - como critérios discriminantes. Os tipos identificados foram: rede formada por amigos, vizinhos e familiares; rede formada por amigos e vizinhos; rede formada por familiares muito próximos; rede formada somente por membros da igreja; e por fim, a rede formada somente pelos filhos (em geral, único).

Os indicadores aqui enumerados são exemplos de medidas que aparecem comumente na literatura relacionada com as redes sociais de apoio. De modo geral, os pesquisadores têm reconhecido que apoio social é um constructo multidimensional com diferentes aspectos ou dimensões, ainda não totalmente elucidados. Uma revisão da literatura sobre escalas ou índices de apoio social sugere que nenhuma é inteiramente adequada e que a confiabilidade, validade e fatores estruturantes dos instrumentos existentes são desconhecidos (KRAUSE e MARKIDES, 1990).

ORTH-GOMÉR e UNDÉN (1987) realizaram uma revisão da literatura a respeito de instrumentos de mensuração do apoio social comparando sistematicamente seus referenciais teóricos, suas capacidades preditoras, reportadas nos estudos, e suas propriedades psicométricas. O estudo compreendeu 18 escalas utilizadas em levantamentos populacionais diversos analisando características quanto ao conteúdo das questões, à aplicabilidade, às propriedades relacionadas à validade e confiabilidade, à 
capacidade de generalização e à capacidade preditiva da escala. As autoras concluem que não há um consenso na definição conceitual de apoio social e que não é possivel, ainda, identificar um questionário que possa descrever perfeitamente o conceito. Entretanto, fazem a recomendação de que "um estudo ideal" deve incluir em seu instrumento medidas da estrutura da rede social, bem como das suas funções.

\section{FAMÍLIA: ARRANJO DOMICILIAR E APOIO}

Paralela à extensa literatura em que são abordadas as inúmeras dimensões das redes sociais de apoio e suas influências sobre a saúde, toma-se visível uma bibliografia, não tão extensa, mas significativa, com investigações sobre o impacto da estrutura familiar ou do arranjo domiciliar sobre a saúde. Nesse âmbito, duas são as principais razões que impulsionaram as investigações: 1) A familia é o contexto social mais próximo no qual os individuos estão envolvidos, e os relacionamentos mantidos pelos co-residentes em seus arranjos domiciliares têm grande relevância para a saúde; 2) Focase o arranjo domiciliar pela necessidade de se conhecer o processo social pelo qual as novas estruturas familiares dos idosos demandam e fornecem sistemas de apoio formal e informal.

As pesquisas que compõem o grupo da primeira vertente têm mostrado que a mortalidade (RAHMAN 1999) e certos desfechos de saúde (HUGHES e WAITE, 2002) variam segundo a composição familiar. $\mathrm{O}$ estado conjugal, em outros termos, a presença de cônjuge, considerada a dimensão mais importante do arranjo domiciliar, tem sido variável importante em diversos estudos. A maior longevidade das pessoas casadas quando comparada com a das não casadas tem sido repetidamente evidenciada (HU e 
GOLDMAN, 1990; MURRAY 2000). Pessoas com melhores desfechos de saúde também são encontradas entre as pessoas que vivem com o cônjuge (UMBERSON 1992; BENZEVAL 1998).

Na vertente que considera a segunda razão, as investigações sobre a relação entre as características dos arranjos domiciliares dos idosos e o apoio familiar, em países desenvolvidos, tem chamado a atenção para importantes mudanças nos padrões de e hábitos e valores, bem como para transformações em comportamentos demográficos, hábitos e comportamentos, que se mantiveram estáveis na Europa durante muitas décadas. Entre as mudanças mais importantes nos aspectos demográficos são citadas as elevadas chances de uma pessoa nunca se casar e as altas freqüências de divórcios e coabitações sem casamento. Além disso, nos países desenvolvidos são encontradas elevadas freqüências de idosos vivendo sós, sendo as mulheres idosas e as viúvas aquelas que mostraram maiores chances para viverem nesta situação. Algumas dessas diferenças nos arranjos domiciliares dos idosos são associadas com diferenciais encontrados na mortalidade dos mais velhos. (UNITED NATIONS 2001).

Por outro lado, considerando-se as dimensões do apoio social informal (apoio emocional, apoio instrumental, apoio de informação e interações sociais positivas), observa-se que o predomínio da família na atenção às pessoas idosas é muito forte. A investigação gerontológica transcultural também vem demonstrando essa constatação a partir da alta prevalência do apoio familiar na vida dos idosos, tanto na vida cotidiana como em momentos de crise. (BAZO e OÑATE, 1999; YAZAKI e col., 1991). A família continua envolvida nos cuidados de saúde, educação, provisão econômica e de bem estar dos seus membros, e a interdependência é possível graças ao componente afetivo de suas relações e à garantia de estabilidade, coesão e equilíbrio, derivados do apego que se estabelece. Além disso, a família como fonte fundamental provedora de 
apoio ao idoso está intimamente relacionada ao dever indiscutível que os filhos se colocam no que diz respeito ao cuidado dos pais (BAZO e ONÃTE, 1999). Uma questão levantada, ainda sem resposta, é: de que forma se articulam as relações entre a família e as organizações formais no que se refere ao tipo de cuidado a ser prestado às pessoas idosas incapacitadas e portadoras de doenças crônicas, aspecto que é de crucial importância na atualidade?

\section{IMPORTÂNCIA DAS REDES SOCIAIS DE APOIO EM IDOSOS}

Do mesmo modo como as redes sociais de apoio influenciam as condições de saúde e mortalidade da população em geral, a presença de apoio social tem sido fortemente associada com desfechos positivos, também para os idosos.

O efeito protetor das relações sociais sobre a mortalidade tem sido amplamente reconhecido através de estudos epidemiológicos longitudinais realizados com idosos em diversos locais, como Estados Unidos (DAVIS e col., 1997; YASUDA e col., 1997), Europa (SHYE e col., 1995; PENNINX e col., 1997, LUND e col., 2000), Ásia (CERIA e col., 2001) e na África (RAHMAN 1999).

Redes sociais diversificadas foram consistentemente associadas com algumas medidas da saúde (capacidade funcional, incontinência urinária, auto-avaliação de saúde e problemas visuais) em idosos (LITWIN 2001).

Além das investigações relacionando a presença de redes sociais com a redução da mortalidade, a importância deste fator, em idosos, tem sido evidenciada principalmente no campo da saúde mental. Tais trabalhos mostram que sintomas depressivos estão inversamente associados com o tamanho das redes sociais 
(PALINKAS e col., 1990); mostram também que existe uma relação direta entre grau de incapacidade e sintomas depressivos; além disso indicam que o suporte social mitiga o efeito da incapacidade dos idosos com depressão, quando a rede de apoio é avaliada positivamente por eles (WALLSTEN e col., 1999).

Outros estudos relacionam altos escores de satisfação com a vida e melhor estado de saúde na auto-avaliação de idosos - importantes preditores de mortalidade - com a frequêencia de contatos com irmãos (McCAMISH-SVENSSON e col., 1999) e com outros com familiares e amigos (PINQUART e SÖRENSEN, 2000).

Na população de idosos têm-se observado, também, a associação positiva entre redes sociais formadas por grande número de amigos e escores de estado de ânimo (LITWIN 2001) e de auto-estima (LEE e SHEHAN, 1989).

Outro grupo de autores, interessados em verificar os efeitos da integração social em comportamentos alimentares, observou que os idosos que estavam satisfeitos com a freqüência de visitas recebidas por parentes e amigos registraram menos problemas com suas dietas (LEARNER e KIVETT, 1981); foi observado também que aqueles que eram mais ativos fisica e socialmente tinham dietas alimentares mais diversificadas e adequadas (KRONDL e col., 1982); constatou-se, ainda, que amplas redes de amigos têm conseqüências positivas no apetite e na ingestão adequada de nutrientes e além disso, constatou-se que a magnitude dos efeitos negativos do estresse financeiro sobre o apetite foi reduzida pelo relacionamento com amigos, pelo estado conjugal e pela presença de companhia (McINTOSH e col., 1989).

A hipótese de que os tipos de apoio mais eficazes são aqueles que combinam com as necessidades do individuo, não foi definitivamente confirmada até o momento (CUTRONA e RUSSEL 1990, citado em THOITS 1995). Entretanto a idéia de 
"combinação" também tem produzido diversos esforços para especificar se fontes de apoio (cônjuge, amigos, colega de trabalho, profissionais) são mais eficazes em proteger dos impactos de certas situações estressantes. Em decorrência disso a preferência dos idosos por diferentes tipos de apoio tem se tornado o foco da atenção de pesquisas gerontológicas. PINQUART e SÖRENSEN (2002) observaram, numa população americana e canadense, que os idosos preferem apoio informal e misto (formal/informal) para necessidades de cuidados em curto prazo e preferem assistência mais formal para necessidades de cuidados de longo prazo. Um estudo realizado na China, contexto cultural e económico totalmente diverso do estudo anterior, evidencia resultados guardando certa semelhança: enquanto os idosos chineses esperam que os programas de pensão do Estado resolvam uma boa parte das suas necessidades financeiras, a família permanece preferencialmente como fonte de apoio social e emocional, tanto nas áreas urbanas quanto nas rurais (PEI e PILLAI, 1999).

\section{RELAÇÃO ENTRE REDES SOCIAIS DE APOIO E NIVEL SÓCIOECONÔMICO, GÊNERO E IDADE}

A maioria dos estudos enfoca o papel das redes sociais de apoio na determinação dos diferentes níveis de saúde e bem-estar dos indivíduos, entretanto alguns poucos investigadores sociais têm voltado seus interesses para os determinantes dos niveis de integraça social, ou seja, das redes sociais de apoio.

Entre os poucos estudos que enfocam as relações sociais de apoio como variável desfecho observam-se algumas diferenças marcantes. Pessoas que trabalham em 
ocupações prestigiadas socialmente recebem maiores niveis de apoio social ${ }^{3}$ (TURNER e MARINO, 1994); idosos com renda e nível educacional mais altos têm mais contatos com amigos, maior freqüência de apoio fornecido a outros e maior satisfação com apoio recebido dos membros da rede de apoio (KRAUSE e BORAWSKI-CLARK, 1995).

Algumas pesquisas têm fornecido fortes evidências para uma importante diferença quanto ao gênero nos níveis de apoio social: as redes sociais das mulheres são maiores e mais amplas do que a dos homens (TURNER e MARINO, 1994), que tendem a se relacionar exclusivamente com seus cônjuges (DUE e col., 1999).

Os evidentes efeitos benéficos que a presença de cônjuge tem sobre diversos desfechos, vistos anteriormente, levaram alguns estudiosos ao pressuposto de que o estado conjugal diferenciaria os níveis do apoio social. Entretanto, TURNER e MARINO (1994) não encontraram nenhuma diferença importante no apoio social associada com estado civil, exceto em relação ao apoio proveniente da família, onde são observadas diferenças significativas favorecendo os casados, tanto para os homens quanto para as mulheres.

Os estudos, em geral, reportam diferenças na estrutura, na qualidade e na percepção que as pessoas têm das redes sociais de apoio, quando consideradas as diferentes faixas etárias, entretanto seus achados são inconsistentes entre si. Portanto, a relação entre idade e nível de apoio social permanece, ainda, não totalmente estabelecida (TURNER e MARINO, 1994). Investigações mais recentes têm indicado que existem pessoas-chave nas redes sociais, e que estas diferem muito de acordo com a faixa etária. Esses resultados levam à hipótese de que a importância relativa que pessoas como pais, filhos, parentes e amigos têm dentro das redes sociais sofre modificaç̃̃es ao longo da vida, conforme os ciclos de vida. (OLSEN e col., 1991; DUE e col., 1999).

\footnotetext{
${ }^{3}$ TURNER e MARINO utilizaram uma medida escalar de apoio, cujos escores foram somados em uma medida global assumindo que quanto maior o número alcançado maior o nível do apoio.
} 


\section{CONSIDERAÇÕES FINAIS}

O objetivo desta revisão foi discutir sucintamente os conceitos atuais sobre as redes sociais e identificar as questões não resolvidas acerca da sua conceituação, bem como identificar os principais problemas envolvidos na sua operacionalização. A principal dificuldade encontrada para alcançar o propósito foi compreender e integrar os diversos trabalhos com orientações teóricas procendentes de diversas disciplinas, que foram fundamentais para o avanço das pesquisas nessa área, dentre elas a Sociologia e a Psiquiatria. Assim, mais do que uma revisão de vasta quantidade de trabalhos a respeito dos desfechos de saúde, a proposta aqui foi descrever o estado da arte sobre as redes sociais de apoio e desenvolver um quadro referencial conceitual que pudesse nortear futuros trabalhos.

Por um lado, a rede social de apoio é considerada como um recurso moderador ou amortecedor dos efeitos do estresse sobre a saúde fisica e mental (modelo moderador/amortecedor). Por outro lado, especialmente entre os estudos epidemiológicos, a rede social de apoio é considerada um recurso, por si, capaz de influenciar diretamente os mais variados desfechos de saúde (modelo do efeito direto). Muitas das investigações acumulam evidências empíricas em favor de algum desses dois modelos. A comparação dos dois modelos parece não aumentar significativamente a compreensão acerca da natureza dos processos pelos quais a rede social de apoio evita a doença ou fortalece a saúde.

Em síntese, é importante considerar a rede social de apoio como um constructo de extrema complexidade composto por várias dimensões, algumas bastante exploradas 
e outras ainda muito pouco estudadas. $\mathrm{O}$ modo como o contexto social mais amplo (fatores sócioeconômicos, culturais, políticos e mudanças sociais) determina a distribuição e disponibilidade do apoio social não tem sido suficientemente explorado.

Cabe esperar novas investigações que sejam capazes de distinguir diversas formas de apoio social e as diversas fontes de cada uma delas.

Além disso, parece pertinente esperar que seja possível combinar métodos estatísticos com métodos qualitativos de alto nível de conceituação.

\section{REFERÊNCIAS}

Barrera M Jr. Distinctions between social support: concepts, measures, and models. Am J Community Psychol. 1986; 14:117-28.

Bazo MT, Oñate CM. Sociologia de la vejez. In: Bazo MT (coord.). Envejecimiento y sociedad: una perspectiva internacional Madri: Editorial Medica Panamericana; 1999. p. 47-102

Benzeval M. The self-reported health status of alone parents. Soc Sci Med. 1998; 46:1337-53

Berkman LF, Glass T, Brissette I, Seeman TE. From Social integration to health: Durkheim in the new millennium. Soc Sci Med. 2000; $51: 843-57$. 
Berkman LF, Syme SL. Social networks, host resistance, and mortality: a nine-year follow-up study of Alameda County residents. Am J Epidemiol. 1979; 186-204.

Cassel J. The contribution of the social enviroment to host resistance. Am J Epidemiol. $1976,107-23$.

Castro R, Campero L, Hernández B. La investigación sobre apoyo social en salud: situación actual y nuevos desafios. Rev Saúde Pública. 1997; 4: 425-35.

Cattell V. Poor people, poor places, and poor health: the mediating role of social networks and social capital. Soc Sci Med. 2001, 52:1 501-16.

Ceria CD, Masaki KH, Rodriguez BL, Chen R, Yano K, Curb JD. The relationship of psychosocial factors to total mortality among older Japanese-American men: the honolulu heart program. Am J Geriatr Soc. 2001 ; 49:725-31.

Chor D, Griep RH, Lopes CS, Faerstein E. Medidas de rede e apoio social no Estudo Pró-Saúde: pré-teste e estudo piloto. Cad Saúde Pública. 2001;17:887-96.

Cohen AD, Farley TA, Mason K. Why is poverty unhealthy? Social end physical mediators. Soc Sci Med. 2003; 57: 631 - 41 .

Davis MA, Moritz DJ, Neuhaus JM, Barclay JD, Gee L. Living arrangements, changes in living arrangements, and survival among community dwelling older aldults. Am $\mathbf{J}$ Public Health. 1997; 87:371-7. 
Due P, Holstein B, Lund R, Modvig J, Avlund K. Social relations: network, support and relational strain. Soc Sci Med. 1999; 48: 661-73.

House JS, Robbins C, Metzner HL. The association of social relationships and activities with mortality: prospective evidence from the Tecumseh community health study. Am J Epidemiol. 1982; $123-40$.

Hu Y, Goldman N. Mortality differentials by marital status: an international comparison. Demography. 1990; 27: 233-50.

Hughes ME, Waite LJ. Health in household context: living arrangements and health in late middle age. J Health Soc Behavior. 2002; 43:1-21.

Kawachi I, Col.ditz GA, Ascherio A, Rimn EB, Giovannucci E, Stampfer MJ, Willett WC. A prospective study of social networks in relation to total mortality and cardiovascular disease in men in the USA. J Epidemiol Community Health. 1996; $50: 245-51$

Kawachi I, Kennedy BP, Glass R. Social capital and self-rated health: a contextual analysis. Am J Public Health. 1999; 8:1187-93.

Krause N. Borawski-Clark E. Social class differences in social support among older adults. Gerontologist. 1995; 35:498-508. 
Krause N, Markides K. Measuring Social Support Among Older Adults. Int J Aging and Human Development. 1990; 30: 37-53.

Krondl M, Lau D, Yurkiw MA, Col.eman PH. Food use and perceived food meanings of the elderly. J Am Diet Assoc. 1982; 80:523-9.

Labra ME. Capital social y consejos de salud en Brasil. Un círculo virtuoso? Cad Saúde Pública. 2002; 18 (suplemento): 47-55

Learner RM, Kivett VR. Discriminators of perceived dietary adequacy among the rural elderly. J Am Diet Assoc. 1981; 78:330-7.

Lee G R, Shehan CL. Social relations and the self-esteem of older persons. Research Aging. $1989 ; 11: 427-42$.

Litwin H. Social network type and morale in old age. Gerontol. 2001; 41:516-24.

Liang J, Krause NM, Bennett JM. Social exchange and well-being: is giving better than receiving? Psychology Aging. 2001, 3:511-23.

Lin N, Ye X, Ensel WM. Social support and depressed mood: a structural analysis. J Health Soc Behavior 1999; 40:344-59. 
Lund R, Modvig J, Due P, Holstein BE. Stability and change in structural social relations as preditor of mortality among elderly women and men. Euro $\mathbf{J}$ Epidemiol. $2000 ; 16: 1087-97$.

McCulloch A. Social environments and health: cross sectional national survey. Br Med J. $2001 ; 323: 208-9$.

McIntosh WA, Shifflett PA, Picou J. Social support, stressful events, strain, dietary intake, and the elderly. Med Care. 1989; 27:140-53.

McCamish-Svensson C, Samuelsson G, Hagberg B, Svensson T, Dehlin O. Social relationships and health as predictors of life satisfation in advanced old age: results from a swedish longitudinal study. Int J Aging and Human Development. 1999; 301-24.

Murray E J. Marital protection and marital selection: evidence from a historicalprospective sample of American men. Demography. 2000; $37: 511-21$.

Olsen O, Iversen L, Sabroe S. Age and the operationalization of social support. Soc Sci Med $1991 ; 32: 767-71$.

Orth-Gomér C, Udén AL. The measurement of social support in population surveys. Soc Sci Med 1987; 24: 83-94.

Palinkas AL, Wingard D L, Barrett-Connor, E. The biocultural context of social networks and depression among the elderly. Soc Sci Med. 1990; 30: 442-447. 
Pei X, Pillai V. Old Age support in China: The role of state and the family. Int J Aging and Human Development. 1999; 49: 197- 212.

Penninx BWJH, Tilburg T van, Kriegsman DMW, Deeg DJH, Boeke AJP, Eijk JThM van. Effects of social support and personal coping resources on mortality in older age: the longitudinal aging study Amsterdam. Am J Epidemiol. 1997; 146:510-9.

Pinquart M, Sörensen S. Influences of socioeconomic status, social network, and competence on subjective well-being in later life: a meta-analysis. Psychology and Aging. 2000; 15:187-224.

Pinquart M, Sörensen S. Older adults' preferences for informal, formal, and mixed support for future care needs: a comparison of Germany and the United States. Int J Aging Human Development. 2002; 54:291-314.

Rahman MO. Age and gender variation in the impact of household structure on elderly mortality. Int J Epidemiol. 1999; 28:485-91.

Shye D, Mullooly JP, Freebom DK, Pope CR. Gender differences in the relationship between social network support and mortality: a longitudinal study of an elderly cohort. Soc Sci Med. 1995; $41: 935-47$.

Thoits PA. Stress, coping, and social support processes: Where are we? What next? J Health Soc Behavior. 1995; (Extra Issue): 53-79. 
Tumer RJ, Marino F. Social support and social structure: a descriptive epidemiology. J Health Soc Behavior. 1994; 35:193-212.

Umberson D. Gender, marital status and the social control of health behavior. Soc Sci Med. 1992; 8:907-17.

UNITED NATIONS. Living Arrangements of older persons: critical issues and policy responses. New York:United Nations; 2001. (Special Issue, 42/43)

Vogt TM, Mullooly JP, Emst D, Pope CR, Holles JF. Social networks as predictors of ischemic heart disease, cancer, stroke and hypertension: incidence, survival and mortality. J Clin Epidemiol. 1992; 45:659-66.

Wallsten SM, Tweed DL, George LK. Disability and depressive symptoms in the elderly: the effects of instrumental support and its subjective appraisal. Int $\mathbf{J}$ Aging Human Development. 1999; 48:145-59.

Waxler-Morrison N, Hislop TG, Mears B, Kan L. Effects of social relationships on survival for women with breast cancer: a prospective study. Soc Sci Med. 1991; 33: 177-83.

Wu ZH, Rudkin L. Social contact, socioeconomic status, and the health status of older Malaysians. Gerontologist. 2000; 40:228-34. 
Yasuda N, Zimmerman SI, Hawkes W, Fredman L, Hebel JR, Magaziner J. Relation of social network characteristics to 5-year mortality among young-old versus old-old white women in an urban community. Am J Epidemiol. 1997; 145:516-23.

Yazaki LM, Melo AV, Ramos LR. Perspectivas atuais do papel da família frente ao envelhecimento populacional: um estudo de caso. In: Fundação SEADE. A população idosa e o apoio familiar. São Paulo: 1991. p. 11-86. (Informe Demográfico, 24) 
Figura 1. Quadro referencial das Redes Sociais de Apoio
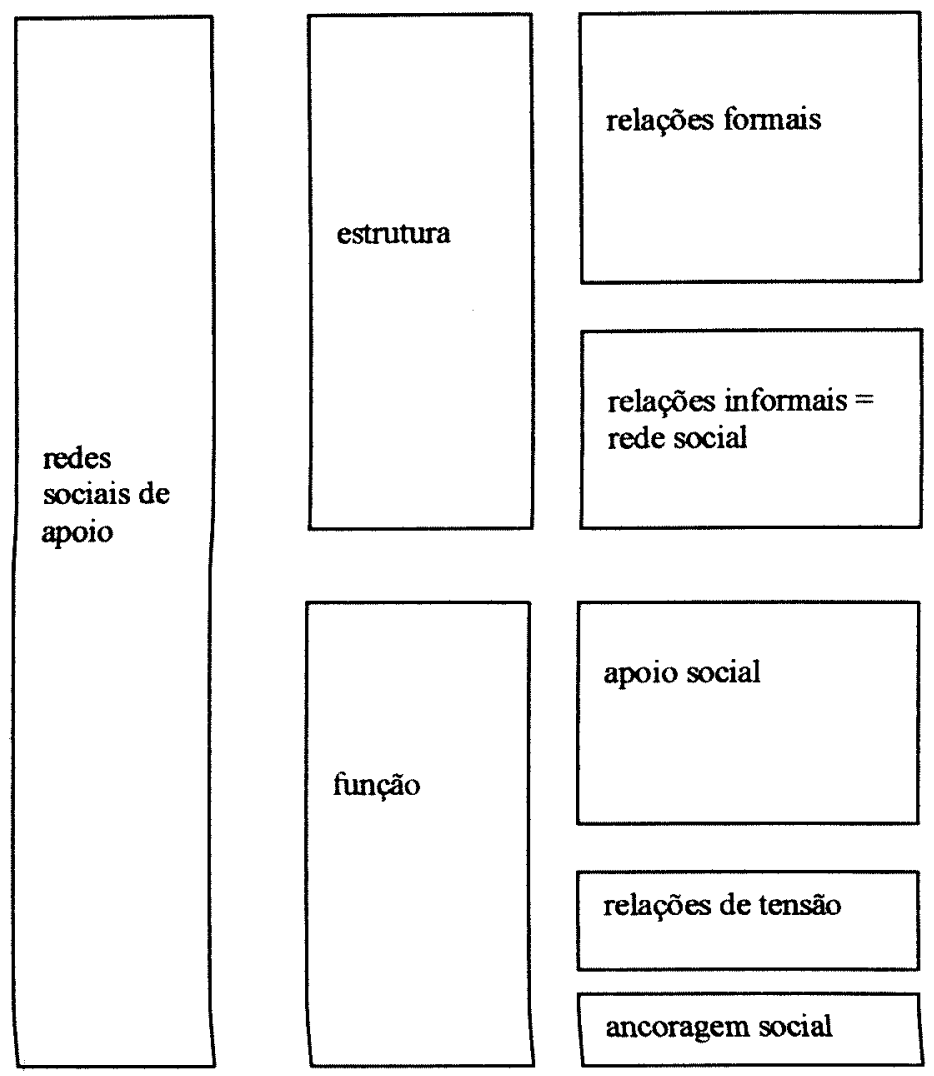

n. ${ }^{\circ}$ e tipo de relações freqüência de contatos

duração dos contatos diversidade dos contatos

densidade

reciprocidade

apoio emocional apoio instrumental apoio de informaçðes interação social positiva

relações de tensão

conflitos

demanda excessiva

ancoragem social

integração social

Fonte: DUE e col., 1999 


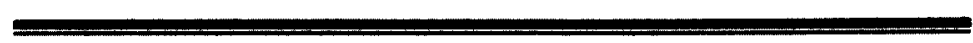

\section{CAPÍTULO II (Artigo 2)} REDES SOCIAIS DE APOIO EM IDOSOS DO MUNICÍPIO dE SÃO PAULO: ASPECTOS ESTRUTURAIS E FUNCIONAIS 


\section{RESUMO}

Objetivo: O presente estudo teve como objetivo descrever a distribuição das redes sociais e de apoio em idosos no Município de São Paulo, segundo algumas características sócioeconômicas e demográficas. Método: Estudou-se amostra probabilística de 2.143 idosos (60+) da cidade de São Paulo (inquérito SABE - Saúde, bem-estar e envelhecimento), focalizando-se as dimensões estruturais (índice de freqüência de contatos - IFC, indice de diversidade de contatos - IDC, coabitação e situação conjugal) e funcionais (indice de frequêencia de ajudas recebidas - IFAR e índice de freqüência de ajudas prestadas - IFAP) das redes sociais. Para a análise dos dados utilizou-se o teste quiquadrado e a regressão logística univariada e múltipla. Resultados: As melhores condições nas redes sociais foram observadas nos menores patamares de renda e as piores, entre os mais velhos e os não casados, para ambos os gêneros. A escolaridade mostrou pouca influência nas redes, exceto para as mulheres cujas chances de estarem não casadas aumentaram significativamente quanto pior era $o$ seu nivel educacional. $O$ aspecto estrutural da rede que mais influenciou o apoio funcional foi o status de coabitação, onde "morar só" aumentou significativamente as chances de ocorrerem as trocas sociais, para homens e mulheres. Conclusões: Os modelos de regressão logística múltipla construídos separadamente por gênero sugerem que idade, estado civil, renda per capita e escolaridade estão associados com as redes sociais entre os idosos. No entanto, essas relações manifestam-se de modos desiguais entre gêneros e entre as características sóciodemográficas para as diferentes dimensões da rede social.

Descritores: idosos, redes sociais, apoio social, redes sociais de apoio. 


\begin{abstract}
Objective: The purpose of this study is to describe the distribution of social and support networks for the elderly people of the City of São Paulo, pursuant to some socioeconomic and demographic characteristics. Method: A probability sample of 2,143 elderly people $(60+)$ from the city of São Paulo was studied (SABE - Wealth, Welfare, and Aging query), focusing on structural dimensions (contact frequency index (IFC), contact diversity index (IDC), cohabitation, and conjugal status) and functional dimensions [aid received frequency index (IFAR) and aid granted frequency index (IFAP)] of the social networks. In order to analyze the data, the chi-square test and univariate and multiple logistic regression were used. Results: The best conditions in the social networks were observed in the lowest income levels and the worst among the older and unmarried people, from both genders. Education showed little influence on the networks, except for women, whose chances of not being married increase significantly when their education level is lower. The most influencing structural aspect of the network was the cohabitation status, where "living alone" increases significantly the chances of social exchanges, both for men and women. Conclusions: The multiple logistic regression models separately built by gender suggest that age, marital status, income per capita, and education are associated to the social networks among elderly people. However, these relationships are uneven in the different genders and depending on the sociodemographic characteristics of the different dimensions of the support network.
\end{abstract}

Descriptors: elderly people, social networks, social support, social support networks. 


\section{INTRODUÇÃO}

É amplamente reconhecido que as redes sociais têm poderosos efeitos sobre as saúde fisica e mental das pessoas.

As redes sociais seriam compostas por uma estrutura e uma função, as quais são aspectos e fenômenos distintos e que, como tais, devem ser avaliados e examinados. A estrutura se refere ao grau em que um indivíduo está socialmente conectado com os outros (freqüência, duração, diversidade, densidade e reciprocidade de contatos com quaisquer pessoas com quem se tem uma relação familiar próxima ou com envolvimento afetivo), enquanto a função (apoio social) consiste em conforto, ajuda instrumental ou informações que um recebe do outro, dentro da estrutura (DUE e col. 1999), bem como em controle social, que uns exercem sobre os outros (UMBERSON 1992).

Se, nas últimas décadas, as redes sociais de apoio têm sido extensivamente estudadas como variável independente, interveniente ou moderadora associada a diversos desfechos de saúde, por outro lado, quase nenhuma atenção tem sido dada a elas como variável dependente. A compreensão das estruturas e dos processos sociais amplos, bem como dos processos psicológicos e biológicos, que determinam a quantidade e qualidade das relações sociais e de apoio na sociedade, pode ser considerada tão importante quanto o significado das relações sociais para a melhoria da saúde (HOUSE e col. 1988).

Entre os poucos estudos que enfocam as redes sociais como variável desfecho observam-se algumas diferenças marcantes. Pessoas que trabalham em ocupações prestigiadas socialmente recebem maior número de apoio social (TURNER e MARINO 1994); idosos com renda e nivel educacional mais altos têm mais contatos com amigos, maior freqüência de apoio fomecido a outros e maior satisfação com apoio recebido dos membros da rede social de apoio (KRAUSE e BORAWSKI-CLARK 1995); as redes sociais das mulheres são maiores e mais amplas do que a dos homens, que tendem a se relacionar exclusivamente com seus cônjuges (DUE e col. 1999). Além disso, foram 
observadas diferenças significativas, quanto ao apoio proveniente da familia, favorecendo os casados, tanto para os homens quanto para as mulheres (TURNER e MARINO 1994). Finalmente, diferenças marcantes na estrutura e função das redes sociais segundo a idade foram encontradas por DUE e col. 1999, os contatos com seus pares são os mais freqüentes entre as pessoas de 25 anos de idade, enquanto as de 70 anos têm mais contatos com filhos, amigos e pessoas conhecidas em associações formais.

Paralela à extensa literatura abordando a relação entre redes sociais e saúde, toma-se visível uma bibliografia onde a ênfase é dada ao arranjo domiciliar, pela necessidade de se conhecer o processo pelo qual as novas estruturas familiares dos idosos demandam sistemas de apoio formal e informal. $O$ envelhecimento populacional associado às modificações econômicas e sociais que acompanham a modernização das sociedades tem afetado a constituição das famílias em todo o mundo, independentemente do contexto cultural em que ocorreu este processo de modernização. Pesquisadores e formuladores de políticas públicas têm expressado preocupação com relação a essas mudanças econômicas e sociais que acompanham a modernização das sociedades, porque essa configuração pode enfraquecer os tradicionais sistemas de apoio para pessoas idosas, dando lugar à expansão do grupo de idosos em situação de risco.

Portanto, informações sobre as redes sociais e sobre a disponibilidade de apoio instrumental informal em função de características socioeconômicas e demográficas de idosos residentes em uma grande metrópole como São Paulo são importantes para o planejamento e programas de prevenção e intervenção que pretendam reduzir riscos para diversos desfechos de saúde. Nesse contexto o presente estudo teve como objetivo investigar os diferenciais nas redes sociais e de apoio em idosos no Município de São Paulo, identificando a influência de algumas características sócioeconômicas e demográficas sobre elas. 


\section{MÉTODOS}

Este estudo é parte do inquérito sobre Saúde, Bem-estar e Envelhecimento (SABE) realizado na cidade de São Paulo em pessoas de 60 anos ou mais, durante o período de janeiro de 2000 a março de 2001. Trata-se de um estudo Multicêntrico (em sete países da América Latina e Caribe) coordenado e financiado pela Organização PanAmericana de Saúde (OPAS) e Organização Mundial de Saúde (OMS) e executado, no Brasil, por equipe da Faculdade de Saúde Pública da Universidade de São Paulo.

A amostra probabilística foi formada por 1.568 entrevistas realizadas entre os 1.852 idosos identificados nos domicílios sorteados. Em seguida, para compensar a mortalidade na população de maiores de 75 anos e completar o número desejado de entrevistas nesta faixa etária, foi feito um acréscimo de 575 entrevistas realizadas com residentes nos distritos sorteados anteriomente. A amostra final foi composta de 2.143 pessoas de 60 anos e mais. A taxa de resposta ao levantamento foi de $84,7 \%$, dentro do esperado estatisticamente. Os motivos principais pelos quais as entrevistas não foram realizadas foram a recusa em participar do estudo e a não possibilidade de localizar o entrevistado em pelo menos três visitas ao domicílio

Como variáveis dependentes foram estudados quatro aspectos estruturais da rede social:

1. O índice de freqüência de $\operatorname{contatos}^{1}$ (IFC) - número de contatos mensais - para avaliar o grau em que o idoso está conectado socialmente com outros, foi construído com base em questões relacionadas com a freqüência de contatos com filhos, irmãos, outros familiares e com amigos, com um máximo de 301 contatos por mês e

\footnotetext{
${ }^{1}$ Levando em consideração que a literatura (KRAUSE e col 1995) fornece indicativos de que os contatos com amigos e não familiares são mais favoráveis, o indice de contatos, foi, inicialmente, construído e analisado diferenciando contatos com familiares dos contatos com outras pessoas. Entretanto, não foi possivel observar tais diferenças, provavelmente pela pequena proporção de idosos que relataram relacionamentos fora do âmbito familiar, sendo, portanto considerados para esta variável todos os contatos.
} 
um mínimo de zero, dicotomizado em quartil inferior $(<12$ contatos) e demais $(>=12$ contatos $)$

2. $\mathrm{O}$ indice de diversidade de contatos (IDC), para avaliar a amplitude da rede social, foi construido a partir das mesmas questões, mas foi calculado como número de diferentes tipos de contatos ocorridos mais de duas vezes em um mês, com um máximo de quatro tipos de contatos e um mínimo de zero. Ou seja, foi considerado contato regular de determinado tipo (contatos com filho, com irmão, com pais, com sogros, com genro/nora, com neto, com sobrinho, com outro familiar e com amigos) quando o contato ocorreu pelo menos duas vezes por mês com estas pessoas. Se nenhuma das questões sobre a freqüência de contatos (contatos com filhos, irmãos, etc.) foi respondida, os indices foram considerados "não resposta". Por outro lado, se as respostas eram disponíveis para pelo menos um tipo de contato, a "não resposta", individualmente, foi tratada como se não tivesse havido contato e conseqüentemente codificada como zero. Os indices foram expressos em quartis e depois dicotomizados: quartil inferior $(<1$ contato regular) e demais $(>=1$ contato regular). Os índices de contato e de diversidade foram construídos segundo sugestão de LUND e col. 2000.

3. O status de coabitação foi uma variável dicotômica indicando se o idoso vivia só ou não.

4. A situação conjugal foi analisada como índice de rede social (casados; nãocasados), uma vez que diversos autores concordam na suposição de que "estar casado" normalmente indica a existência de um relacionamento estável, condição mínima para que se experiencie um apoio social.

Além dessas variáveis dependentes, outras duas, dimensões da rede social de apoio funcional foram estudadas com base nas respostas às questões relativas à freqüência de ajudas recebidas (IFAR) e à freqüência de ajudas prestadas (IFAP) a quaisquer pessoas que moram junto e também outras que não moram junto como filhos, irmãos, outros 
familiares e amigos: apoio efetivamente recebido (máximo de 280 e mínimo de zero) e apoio efetivamente prestado (máximo de 336 e mínimo de zero). Similarmente aos índices de frequêencia de contatos, estes indices foram dicotomizados em quartil inferior $(<28$ ajudas) e demais ( $>=28$ ajudas). Coincidentemente, não houve diferença no ponto de corte do quartil inferior nos índices de ajudas recebidas e prestadas.

Entre as variáveis independentes foram estudadas as seguintes caracteristicas sociodemográficas: idade em anos (faixas de 60 a 64, 65 a 69, 70 a 74, 75 a 79 e 80 anos e mais); renda mensal do idoso per capita em reais - soma dos rendimentos declarados pelo entrevistado dividido pelo número de pessoas que dependia desta renda - (ordenada de forma crescente e estratificada em quartis, $1 .^{\circ}-<\mathrm{R} \$ 75,50 ; 2 .^{\circ}-\mathrm{R} \$ 75,50<=$ renda percapita $<\mathrm{R} \$ 151,00$ e $3 \% 4^{\circ}->=R \$ 151,00$ ); e escolaridade em número de anos de estudo (nunca foi à escola, 1 a 3 anos, 4 anos e 5 anos ou mais). $O$ estado conjugal foi tratado, primeiro, como indice de apoio social e, segundo, como variável demográfica, independente, de modo a estimar as diferenças dos outros aspectos do apoio social segundo as características relacionadas ao casamento. Como variável demográfica, o estado conjugal foi categorizado em casado, solteiro, separado/divorciado e viúvo.

Os dados já se encontravam codificados e informatizados em forma de banco de dados e todos os procedimentos estatísticos foram realizados pelo Programa SPSS.

Cada um dos aspectos da rede social foi analisado como uma variável dependente e os fatores demográficos e sócioeconômicos (gênero, estado civil, idade, renda e escolaridade) como variáveis independentes.

Para a identificação da associação individualizada entre cada aspecto das redes sociais e as variáveis demográficas e socioeconômicas foi realizada análise de regressão logística múltipla. Iniciou-se o processo a partir da análise de regressão univariada e as variáveis cujo nivel de significância foi igual ou menor que 0,20 foram mantidos na análise 
múltipla como variável de controle. Para a interpretação dos resultados, considerou-se como associação estatisticamente significativa o nível de significância menor que 0,05 .

\section{RESULTADOS}

Nas Tabelas 1, 2 e 3 estão apresentados os resultados obtidos na análise de cada uma das variáveis de rede social para mulheres e homens separadamente. Modelos separados por gênero foram construídos com base na literatura que mostra diferenças importantes entre homens e mulheres (DUE e col. 1999). Note-se que foram apresentadas nas Tabelas somente as variáveis independentes que evidenciaram associação na análise univariada, cujos resultados não estão aqui representados.

\section{IFC (índice de freqüência de contatos) e IDC (índice de diversidade de contatos)}

As mulheres de 80 anos ou mais, comparadas com as mais jovens que 64 anos, apresentaram probabilidade significativamente maior de ter baixas freqüências de contatos, enquanto para os homens a idade não exerceu influência alguma sobre o número de contatos. Quanto ao estado conjugal, relativamente aos casados, mulheres e homens solteiros, além dos homens viúvos, tiveram chance significativamente maior de ter baixas freqüências de contatos. Para as mulheres, os fatores sócioeconômicos não mostraram efeitos sobre o IFC, tmabém foi constatado que os homens de renda mais baixa têm probabilidade significativamente aumentada para menores freqüências de contatos, comparativamente aos de rendas do $3 .^{\circ}$ e $4 .^{\circ}$ quartis.

Os resultados em relação ao IDC foram muito semelhantes aos do IFC,

destacando ai apenas o fato de que as mulheres na faixa etária de 80 anos e mais, praticamente têm dobrada a chance de terem pequena diversidade de contatos, comparandose à chance de terem baixa freqüência de contatos. 


\section{Status de coabitação}

Notou-se que o estado conjugal tem associação muito intensa com o status de coabitação, tendo as categorias solteiro, separado/divorciado e viúvo apresentado, na análise univariada, razões de chances maiores que 70 para as mulheres e maiores que 300 para os homens, de morarem sós. Por esta razão, essa variável não foi mantida na regressão múltipla.

A idade tem efeito sobre o status de coabitação, independentemente das outras variáveis demográficas e sócioeconômicas, para ambos os gêneros, sendo a chance de morar só significativamente maior a partir dos 70 anos de idade, comparando-se com a faixa de 60 a 64 anos.

Por outro lado, para ambos os gêneros, a probabilidade de morar só foi significativamente menor em rendas mais baixas, comparadas com rendas do $3^{\circ}$ e $4^{\circ}$ quartis. Curiosamente, para os homens, a relação observada com a renda se inverte na associação com a escolaridade, constatando-se que em níveis mais baixos de escolaridade é maior a probabilidade do idoso morar só, embora estatisticamente não significativa. Os homens que tinham quatro anos de freqüência à escola apresentaram chances significativamente menores de morarem só.

Para as mulheres, a escolaridade não teve influência significativa no status de coabitação, não tendo sido inserida no modelo ajustado.

\section{Estado conjugal (não-casado)}

O estado conjugal dos idosos variou significativamente com a idade, sendo a relação entre as grupos etários e a condição "não-casado" significativa e positiva para ambos os gêneros. Vale salientar que a probabilidade de ser "não casado" aumenta significativamente, a partir dos 70 e 75 anos, para mulheres e homens, respectivamente. Além disso, a probabilidade de ser "não casado" dobra entre as pessoas de mais de 80 anos de idade, para ambos os gêneros. 
Comparando-se com rendas mais altas $\left(3 .^{\circ}\right.$ e $4 .^{\circ}$ quartil), todos os outros níveis de renda apresentaram probabilidades significativamente menores de serem não-casados, exceto o $1 .^{\circ}$ quartil de renda nos homens. Chama a atenção que as mulheres do patamar mais baixo de renda tenham apresentado a menor probabilidade (muito próxima de zero) de serem não-casadas, quando comparadas intra e inter-gêneros.

A escolaridade mantém associação independentemente com o estado conjugal, tanto para as mulheres quanto para os homens, porém a relação é bastante distinta entre os gêneros. Para as mulheres, a probabilidade de ser não-casada aumenta significativamente conforme diminui o grau de escolaridade. Por outro lado, para os homens com 4 anos de estudo essa probabilidade é significativamente menor, relativamente à dos que têm 5 anos e mais de estudo.

\section{IFAR (indice de freqüência de ajudas recebidas)}

A idade manteve associação positiva com o IFAR, após ajuste pelas outras variáveis demográficas e socioeconômicas. Comparando-se com a faixa mais jovem (60 a 64 anos), todas as outras faixas etárias mostraram menor probabilidade de terem baixa freqüência de ajudas recebidas. Essas probabilidades são estatisticamente significativas somente para as faixas mais velhas: 80 anos e mais, para as mulheres, e 75 a 79 e 80 anos e mais, para os homens.

Ao contrário, as probabilidades de ter baixa freqüência de ajudas recebidas aumentam consistentemente, tanto para mulheres quanto para homens, no estado conjugal “solteiro", "separado/ divorciado" e "viúvo", quando comparado à categoria casado.

Entre as mulheres, rendas inferiores indicaram probabilidades significativamente menores de se ter baixa freqüência de ajudas recebidas em comparação com as rendas do $3 .^{\circ}$ e $4^{\circ}$ quartil. Para os homens, a renda não influencia significativamente o IFAR, mantendo a tendência à significância após o ajustamento com as outras variáveis sóciodemográficas. 
A escolaridade, que na análise univariada mantinha relação estatisticamente significativa para as mulheres, no modelo ajustado perdeu a significância $(p=0,52)$, ou seja, esta variável não se associou independemente com o IFAR $\mathrm{O}$ efeito da escolaridade para os homens apresentou-se de forma distinta da apresentada para as mulheres. Para eles, essa variável manteve tendência à significância $(p=0,06)$. Para a categoria de quatro anos de escolaridade, a razão de chances foi significativamente menor em relação ao nível mais alto de escolaridade.

\section{IFAP (índice de freqüência de ajudas prestadas)}

Observaram-se diferenças notáveis entre homens e mulheres no que se refere ao IFAP. Entre as mulheres, a faixa etária afeta o índice de tal maneira que quanto mais avançada é a idade, significativamente maiores são as probabilidades de se ter baixas freque ências de ajudas prestadas. Distintamente, entre os homens, a idade perdeu a significância quando ajustada com as outras variáveis, o que significa que ela não se associou independentemente $(p=0,60)$ com o índice de ajudas prestadas.

Para ambos os gêneros, o estado civil apresentou forte associação com este tipo de apoio funcional. Solteiros, separados ou divorciados e viúvos têm chances ignificativamente maiores de apresentarem baixa freqüência de ajudas prestadas.

Entre as mulheres, a renda afeta o IFAP, independemente; sendo que para níveis le rendimento mais baixos as probabilidades são significativamente menores de se ter baixas freqüências, tomando como referência rendas do $3 .^{\circ}$ e $4 .^{\circ}$ quartis. Para os homens, a renda perdeu a associação significativa $(\mathrm{p}=0,66)$, após o ajuste para as outras variáveis.

Em relação à escolaridade, para ambos os gêneros, não houve associação com IFAP, entretanto para os homens ocorreu tendência à significância. 


\section{Apoio funcional e rede social (estrutural)}

Para testar o efeito dos aspectos estruturais das redes sobre o apoio funcional incluiram-se, na análise de regressão múltipla, as variáveis relativas à estrutura (IFC, IDC e status de coabitação) e as sóciodemográficas (variáveis de controle), que se associaram na análise univariada com o apoio social funcional (IFAR e IFAP). Esses resultados estão apresentados na Tabela 5 .

Para as mulheres, o IFC e o IDC não se associaram ao IFAR, não foram, portanto, incluídos na regressão múltipla. O fator estado civil, que indicou forte associação independente com o IFAR, perdeu sua significância quando ajustado com a variável status de coabitação. As mulheres que moravam sós apresentaram probabilidade maior, altamente significativa, de ocorrência de baixas freqüências de ajudas recebidas, estatisticamente controladas para os efeitos das variáveis sóciodemográficas.

Para os homens, o IDC não foi incluído no modelo de regressão múltipla por não ter se associado significativamente com o IFAR O IFC não foi significativo na análise univariada, entretanto foi mantido como variável de controle por ter apresentado significância menor que 0,20 . A categoria separado/divorciado da variável estado civil perdeu significância $(\mathrm{IC}=0,55-3,82)$, quando ajustada pelos fatores relacionadas à estrutura da rede. A variável status de coabitação manteve forte associação independente com o IFAR, sendo que a chance daqueles que moravam sós de apresentarem baixas freqüências de ajudas recebidas foi de $R C=6,91$ (IC=4,52 - 10,57) e $R C=10,82$ (IC=4,78 24,52), para mulheres e homens, respectivamente.

No caso das mulheres, o IFC associou-se positivamente com o IFAP. A probabilidade de ter baixa freqüência de ajudas prestadas foi significativamente maior para as mulheres que apresentaram baixas frequeências de contatos, independentemente das outras variáveis. Embora o IDC tenha mantido associação significativa com o IFAP na análise univariada, isto não se manteve quando foi controlado por outras variáveis. Chama 
I atenção o efeito do status de coabitação que evidencia uma probabilidade muito alta, para ıquelas que moram sós, de terem freqüências baixas de ajudas prestadas.

Algumas diferenças entre mulheres e homens são notáveis no que diz respeito às ijudas prestadas. Observou-se que o IFC associou-se a este tipo de apoio funcional, no intanto foi retirado do modelo por não manter a mesma associação após o ajuste com as sutras variáveis. O IDC manteve relação independente com o IFAP, sendo significativamente maior a probabilidade dos homens com pequena diversidade de contatos apresentarem baixas freqüências de ajudas prestadas. Esse tipo de relação também foi observado com os fatores status de coabitação (morar só) e em todas as categorias do estado conjugal. Chamou a atenção o fato dos idosos que moravam sós apresentarem elevadas chances de possuírem baixas freqüências de ajudas prestadas, $\mathrm{RC}=10,38(\mathrm{IC}=6,56$ - 16,43) e RC=5,07 (IC=2,71-9,50), para mulheres e homens, respectivamente.

\section{DISCUSSÃO}

A relevância do presente estudo consiste no fato de que se tem pouco conhecimento a respeito da distribuição das redes sociais nos diferentes níveis sócioeconômicos e nas características demográficas, e sobre o impacto que certos fatores da estrutura social podem ter sobre elas. Tal fato, deve-se a que uma expressiva maioria dos estudos que abordam a integração social tenham investigado somente a relação entre as redes sociais e mortalidade ou certos desfechos de saúde. Este é um dos poucos estudos em que a relação entre fatores sóciodemográficos e um abrangente conjunto de medidas do apoio social foi avaliada, com referência nos dados de uma pesquisa de base populacional e representativa do Município de São Paulo. 
Procurou-se discutir os resultados enfatizando diferenças e similaridades com a literatura, entretanto esta tarefa foi dificultada pela exigüidade de investigações deste tipo e pela característica do apoio social, um constructo multifacetado, que contém diferentes dimensões, o que torna dificil a comparabilidade dos resultados.

Diversos estudos confirmam a existência de diferenças na estrutura das relações sociais conforme a idade (DUE e col. 1999, OLSEN e col. 1991). Em termos gerais, pessoas mais jovens tendem a ter mais contatos e mais apoio instrumental do que os mais idosos. Esses achados foram consistentes com os desta investigação somente no caso das mulheres, nas quais as chances de terem baixas freqüências de contatos e de pequena diversidade de contatos aumentaram significativamente nas mais velhas (80+). Nestes grupos etários mais avançados, o nivel dos contatos piora, provavelmente pela diminuição do número de irmãos e amigos vivos, que constituíam sua rede social potencial (OLSEN e col. 1991).

Em contrapartida, para ambos os gêneros, o aumento da idade piorou os outros tipos de apoio. Ou seja, as chances dos idosos morarem sós, de serem "não casados" e de apresentarem baixa freqüência no IFAP aumentam significativamente, sobretudo na faixa acima de 70 anos. A morte de um dos cônjuges é a principal razão que pode levar o idoso a morar sozinho e naturalmente, esta é mais provável de ocorrer em idades mais avançadas, o que pode explicar a maior proporção das condições "não casado" e "morar só" entre os mais velhos. Estas condições em que estão os idosos mais velhos são preocupantes, pois a condição de viver sozinho significa ausência de uma relação próxima, imediata, que pode constituir-se em apoio social. Porém, em uma pesquisa qualitativa realizada no Município de São Paulo com o objetivo de analisar de forma mais profunda os aspectos peculiares das relações entre a família e o idoso, foi observado que "morar só" é uma condição desejável pelos próprios idosos, se o grau de dependência física e/ ou econômica permite ao idoso manter o poder de decisão sobre o arranjo domiciliar que lhe convém. Ter distância física 
dos filhos significa condição de independência fisica e econômica, o que lhes permite uma inserção numa convivência familiar e social mais ampla (YAZAKI e col. 1991).

A elevação observada nos níveis de ajudas recebidas conforme o aumento da idade, para ambos os gêneros, parece estar relacionada com a necessidade do idoso de receber algum tipo de ajuda, porque nessa faixa etária é esperado que o idoso passe a ser menos independente funcionalmente. Esses achados são consistentes com a observação de alguns estudos de coorte onde o aparecimento de incapacidades funcionais no idoso contribui para a formação de uma rede de apoio (OXMAN e HULL 1997, citado por LITWIN 1998). Em relação à diminuição nos níveis de ajudas prestadas, pode ser inferido que a incapacidade funcional, em conseqüência da idade, impede o fornecimento de ajudas.

Homens e mulheres na condição conjugal "solteiro" experienciam piores níveis de apoio social no que diz respeito à freqüência de contatos, à diversidade desses contatos e ao número de ajudas recebidas e prestadas.

A explicação para esses niveis encontrados nos solteiros poderia estar relacionada à maneira como foi construído o questionário. Como a resposta para os contatos fora do âmbito familiar foi obtida a partir da questão "Existe algum outro familiar ou amigo do qual o sr. recebe ou dá ajuda e que não mora na sua casa?", e em, seguida inquiriu-se "Com que freqüência vê ou fala com...", privilegiaram-se as trocas sociais (recebe ou dá ajuda em dinheiro, em comida, em roupa ou em serviços) e não os contatos sociais em si (visitas sociais, amigos com quem faz passeios ou alguma outra atividade de lazer) e portanto, os contatos que não envolviam apoio instrumental não foram somados. Por outro lado, como o número de idosos que responderam relacionar-se com não-parentes ou com amigos foi muito baixo, supõe-se que as relações dos idosos devem limitar-se essencialmente à familia nuclear. Portanto, o principal diferencial entre o idoso solteiro e os outros (casado, separado/divorciado, viúvo) pode ser o fato de ter ou não ter filhos. Ao mesmo tempo pode-se supor que os filhos são pessoas chaves no apoio a estes idosos. $\dot{E}$ 
possível que a presença ou ausência de filhos na rede de apoio tenha um forte impacto sobre o apoio estrutural e funcional desta população.

Parcialmente contrários a essa idéia, os resultados observados por SAAD 2003 mostram que o número de filhos tem pouco efeito sobre as transferências de apoio entre os idosos do Município de São Paulo. No entanto, há que se ressaltar dois aspectos levantados no estudo desse autor, que podem explicar tal discordância: 1) ele investigou somente a ajuda recebida em dinheiro e não considerou que $78 \%$ dos idosos recebem ajudas em serviços; 2) o idoso que não tinha filhos apresentou menor probabilidade estatisticamente significativa de receber esse tipo de ajuda. Portanto, parece que o diferencial não é tanto o número de filhos, mas a condição de ter ou não filhos.

Estudos anteriores observaram que, entre os idosos, melhores niveis de apoio associam-se com melhores niveis de rendas, independentemente do gênero (KRAUSE e BORAVSKI-CLARK 1995). Entretanto, os resultados do presente estudo concordaram com os dos autores acima somente em relação aos homens, estes, quando apresentaram rendas inferiores, tiveram significativamente maiores chances de terem baixas freqüências de contatos e de pequena diversidade de contatos.

Embora homens idosos que tinham rendas nos patamares mais baixos tenham apresentado piores níveis de integração social (menores níveis de contatos com outras pessoas), pode-se dizer que renda mais baixa é fator que "protege" o idoso, notoriamente, em relação à coabitação e ao apoio funcional. A explicação para esses resultados poderia estar relacionada com os motivos que levam à conformação nos arranjos familiares dos idosos. Situações como incapacidade física ou financeira; dependência econômica dos filhos para constituição de novo domicílio; necessidade de um responsável pelos netos e pela própria casa, em virtude do trabalho extemo dos filhos (YAZAKI e col. 1991) são apontadas como fatores que levam mais da metade dos idosos do Município de São Paulo, em geral de baixo nivel sócioeconômico, a residir com filhos (SAAD 2003, ROSA e col. 2003). Estas informações permitem concluir que as familias intergeracionais cumpririam 
lupla função: 1) reunir renda para satisfazer melhor as possibilidades de utilização de bens : serviços e 2) facilitar, pela proximidade fisica, as transferências de apoio. SAAD 2003 zonfirma essa hipótese mostrando que "os idosos em condições mais favoráveis parecem ser os que vivem com cônjuge sem filhos, enquanto a proporção dos que declaram possuir três ou mais doenças ou que apresentam dificuldades em exercer atividades básicas da vida diária é significativamente maior entre os que moram com filhos casados; no entanto, são os idosos que moram com filhos casados os que recebem, com maior freqüência, ajuda nas atividades básicas da vida diária e os que apresentam um maior número de bens no domicilio." (p.209-11).

Outra questão que se impõe, considerando os arranjos domiciliares numerosos e multigeracionais é que as relações de tensão são mais prováveis de ocorrerem neste tipo de conformação doméstica. É possível que, se as relações de tensão (conflitos e demandas excessivas), outra dimensão do apoio social, fossem avaliadas, estas poderiam evidenciar outros resultados.

Ao contrário da renda, a escolaridade mostrou pouca influência sobre as redes sociais. Para as mulheres, baixos niveis educacionais aumentaram as chances delas estarem não casadas. Para os homens, com quatro anos de estudo, as suas chances de estarem morando sós, e de não estarem casados, diminuiram significativamente.

Com o intuito de verificar o efeito da estrutura das redes sociais sobre o apoio funcional foram construidos dois modelos de regressão logistica múltipla, considerando os diferentes aspectos estruturais das redes, variáveis explicativas do apoio funcional. A análise para cada um dos gêneros separadamente foi mantida. A hipótese aqui subjacente é que aspectos estruturais das redes sociais são especialmente relevantes para populações idosas porque não só proporcionam oportunidades de contatos, mas também por fomecerem o contexto no qual os apoios instrumental e emocional são recebidos. 
A expectativa da influência do IFC e do IDC sobre o apoio funcional não foi confirmada totalmente. Os resultados indicaram que, entre os homens, existe associação entre número de contatos e freqüência de ajudas recebidas, mas, isso não ocorre entre as mulheres. Entre elas, a baixa frequêencia de contatos associou-se com freqüência baixa de ajudas prestadas. Somente entre os homens, a diversidade de contatos relacionou-se com a freqüência de ajudas prestadas.

Achados anteriores mostraram que o número de contatos afeta significativamente diversos tipos de apoio funcional, inclusive ajudas recebidas (LIN e col. 1999). A explicação para a discordância dos resultados deste estudo pode estar relacionada com o fato de que o indice de contatos, ora em estudo, levou em consideração pessoas que residiam fora do domicílio e, por outro lado, o índice de ajudas recebidas/prestadas considerou também as ajudas prestadas pelos co-residentes. Como o número de ajudas dos co-residentes é expressivo, a associação dos indices pode estar alterada.

O status de coabitação apresentou uma intensa influência sobre o índice de ajudas recebidas em ambos os gêneros. Os idosos que moram sozinhos têm muito maior probabilidade de experienciar níveis mais baixos de ajudas recebidas do que aqueles que moram com outra pessoa. Como as variáveis de apoio social aqui investigadas não consideraram possíveis diferenciações nas necessidades de apoio, não se pode concluir que idosos que moram sós não teriam apoio se necessitassem. É possivel que os idosos que residem sozinhos reúnam diversas condições financeiras e de saúde favoráveis que fazem com que não tenham necessidades de certos tipos de ajuda como dinheiro, comida, roupas, transporte, ajuda nas tarefas de casa, em suma, de apoio funcional instrumental. Portanto, esta medida de ajudas recebidas (IFAR) não foi capaz de avaliar o nível do apoio funcional nestes idosos. Por outro lado, pode-se supor que, se o apoio funcional enfocado fosse o emocional os resultados poderiam ser bastante distintos.

É interessante notar que as chances de ocorrência de baixa freqüência de ajudas recebidas são significativamente maiores entre os não casados, entretanto, quando essa 
variável foi ajustada pelo status de coabitação, a associação só se manteve para os homens. Isto significa que, para as mulheres, o status de coabitação teve maior peso em relação ao estado civil, o que quer dizer que, independentemente do estado conjugal, a situação de morar só aumenta muito a chance de não receber ajudas.

No que diz respeito à relação entre nível de contatos e nível de ajudas prestadas, menores níveis deste tipo de apoio foram observados entre as mulheres com baixa freqüência de contatos e entre os homens com pequena diversidade de contatos.

\section{CONCLUSÕES}

O efeito de algumas características socioeconômicas e demográficas sobre as redes sociais não se diferenciou entre os gêneros. Idosos acima de 70 anos e os solteiros foram os que apresentaram os piores níveis em todos os aspectos da rede social, ou seja, tiveram chances elevadas para número reduzido de contatos, para pequena diversidade de contatos, para baixas freqüências de ajudas prestadas, para estarem morando sós e para estarem não casados. Menor renda foi um fator que "protegeu" os idosos em relação a morar só e a não receber e prestar ajudas. Em relação à influência do aspecto estrutural da rede sobre o apoio funcional, notou-se que idosos que moravam sós tinham muito elevadas as chances de baixas freqüências de ajudas recebidas e prestadas.

Observou-se que a chance para a ocorrência de menores níveis de contatos e de sua diversidade era mais alta entre os solteiros, independente do gênero; entretanto os homens se destacaram por suas chances serem muito mais elevadas que as das mulheres. Os homens viúvos e os de rendas mais baixas apresentaram menores níveis e menor diversidade de contatos. Entre as mulheres com menores niveis educacionais as chances da condição não-casamento foram elevadas. 
Os dados aqui analisados separadamente por gênero sugerem que idade, estado civil, renda per capita e escolaridade estão associados com as redes sociais entre os idosos. Entretanto, essas relações manifestam-se de modos desiguais entre gêneros, nas diferentes características sóciodemográficas e nas diversas dimensões da rede social. Um achado deste estudo que vale ser ressaltado, entre outros, é a condição dos idosos que tinham rendas mais baixas. Estes apresentaram, por um lado, piores níveis de integração social (poucos contatos não diversificados) e por outro lado, eram os que não moravam sós e recebiam mais apoio funcional. A situação desses idosos, residindo em domićlios multigeracionais, aparentemente mais incapacitados funcionalmente e dependendo exclusivamente do apoio informal prestado pela família, poderia estar encobrindo uma deficiência das políticas públicas relacionadas com a proteção aos idosos, ou seja, tal situação pode estar contribuindo para não deixar explícito o quanto ainda são incipientes as ações de apoio formal voltadas para essa população. Ações com vistas à prevenção e promoção de saúde desta população, poderiam ser orientadas tendo o domicílio multigeracional como um indicador de saúde que poderia ser capaz de identificar idosos com alto risco de perda funcional. Uma intervenção específica de apoio aos idosos e seus familiares poderia ser planejada com o apoio das Unidades Básicas de Saúde sob a estratégia dos Programas de Saúde da Família.

Além disso, sugere-se outros estudos que incluam dimensões qualitativas das redes sociais, como avaliações subjetivas do apoio, e aspectos negativos como conflitos e tensões, fatores não abrangidos neste estudo, que se revelaram importantes para os idosos. 


\section{REFERÊNCIAS}

Due P, Holstein B, Lund R, Modvig J, Avlund K. Social relations: network, support and relational strain. Soc Sci Med 1999; 48: 661-73.

House SJ, Landis KR, Umberson D. Social relationships and health. Science 1988; 241:540-5.

Krause N. Borawski-Clark E. Social class differences in social support among older adults. Gerontologist 1995, 35:498-508.

Lin N, Ye X, Ensel WM. Social support and depressed mood: a structural analysis. J Health Soc Behavior 1999; 40:344-59.

Litwin H Social network type and health status in a national sample of elderly Israelis. Soc Sci Med. 1998. 46:599-609.

Litwin H. Social network type and morale in old age. Gerontol 2001; 41:516-24.

Lund R, Modvig J, Due P, Holstein BE. Stability and change in structural social relations as preditor of mortality among elderly women and men. Euro J Epidemiol 2000; 16: 1087-97.

Olsen O, Iversen L, Sabroe S. Age and the operationalization of social support. Soc Sci Med $1991 ; 32: 767-71$.

Rosa TEC, Benício MHD'A, Latorre MRDO, Ramos LR. Fatores determinantes da capacidade funcional entre idosos. Rev Saúde Pública. 2003; 37:40-8. 
Saad PM. Arranjos domiciliares e transferências de apoio informal. In: Lebrão ML, Duarte YAO. SABE - Saúde, Bem-estar e Envelhecimento - O projeto SABE no município de São Paulo: uma abordagem inicial. Brasília: Organização Pan-Americana de Saúde, 2003, p. 201-24.

Turner RJ, Marino F. Social support and social structure: a descriptive epidemiology. J Health Soc Behavior 1994, 35:193-212.

Umberson D. Gender, marital status and the social control of health behavior. Soc Sci Med 1992, 8:907-17.

Yazaki LM, Melo AV, Ramos LR. Perspectivas atuais do papel da familia frente ao envelhecimento populacional: um estudo de caso. In: Fundação SEADE. A população idosa e o apoio familiar. São Paulo: 1991. p. 11-86. (Informe Demográfico, 24) 
Tabela 1 - Associação entre o índice de freqüência de contatos (IFC) e índice de diversidade de contatos (IDC) dos idosos e os fatores demográficos e sócioeconômicos - modelo de regressão logística múltipla.

\begin{tabular}{|c|c|c|c|c|}
\hline \multirow[t]{3}{*}{ Variáveis $(\%)$} & \multicolumn{2}{|c|}{$\begin{array}{c}\text { IFC } \\
\text { (baixa frequência) }\end{array}$} & \multicolumn{2}{|c|}{$\begin{array}{c}\mathrm{IDC} \\
\text { (pequena diversidade) }\end{array}$} \\
\hline & $\begin{array}{r}\text { Razão } \\
{[1 C} \\
\text { aj }\end{array}$ & $\begin{array}{l}\text { chances } \\
5 \%] \\
\text { tada }\end{array}$ & Raz & $\begin{array}{l}\text { chances } \\
\% \%] \\
\text { da }\end{array}$ \\
\hline & Mulheres & Homens & Mulheres & Homens \\
\hline $\begin{array}{l}\text { Idade } \\
60-64 \\
65-69 \\
70-74 \\
75-79 \\
80+ \\
\text { p (tendência) }\end{array}$ & $\begin{array}{c}1,00 \\
0,86[0,55-1,36] \\
1,02[0,64-1,62] \\
0,95[0,61-1,48] \\
1,93[1,27-2,94] \\
0,001\end{array}$ & $\partial$ & $\begin{array}{c}1,00 \\
1,73[0,91-3,32] \\
1,64[0,83-3,25] \\
1,58[0,83-3,02] \\
3,50[1,90-6,43] \\
<0,001\end{array}$ & $\partial$ \\
\hline $\begin{array}{l}\text { Estado conjugal } \\
\text { Casado } \\
\text { Solteiro } \\
\text { Separado/divorciado } \\
\text { Viúvo }\end{array}$ & $\begin{array}{c}1,00 \\
3,74[2,17-6,44] \\
1,56[0,96-2,55] \\
1,18[0,86-1,64]\end{array}$ & $\begin{array}{c}1,00 \\
9,85[4,04-24,03] \\
1,74[0,92-3,32] \\
1,81[1,17-2,81]\end{array}$ & $\begin{array}{c}1,00 \\
5,38[2,93-9,89] \\
1,76[0,95-324] \\
0,80[0,51-125]\end{array}$ & $\begin{array}{c}1,00 \\
8,38[3,67-19,15] \\
1,24[0,50-3,11] \\
1,6.4[0,91-2,95]\end{array}$ \\
\hline $\begin{array}{l}\mathrm{p} \\
\text { Renda per capita } \\
\text { mensal (RS) }\end{array}$ & $<0,001$ & 0,008 & $<0,001$ & $<0,001$ \\
\hline $\begin{array}{l}3^{\circ} \text { e } 4^{\circ} \text { quartil } \\
2^{\circ} \text { quartil } \\
1^{\circ} \text { quartil } \\
\text { p (tendência) } \\
\text { Escolaridade (n' de } \\
\text { anos de estudo) }\end{array}$ & 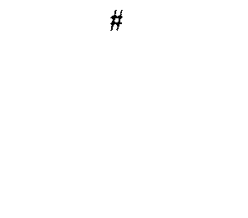 & $\begin{array}{c}1,00 \\
1,33[0,83-2,12] \\
2,21[1,35-3,60] \\
0,001\end{array}$ & $\#$ & $\begin{array}{c}1,00 \\
1,41[0,82-2,44] \\
3,46[1,95-6,15] \\
\infty 0,001\end{array}$ \\
\hline $\begin{array}{l}5+ \\
4 \\
1-3 \\
\text { Nunca foi à escola } \\
\mathrm{p}\end{array}$ & $\#$ & $\partial$ & $\#$ & $\partial$ \\
\hline
\end{tabular}


Tabela 2 - Associação entre status de coabitação/estado conjugal dos idosos e os fatores demográficos e sócioeconômicos - modelo de regressão logística múltipla

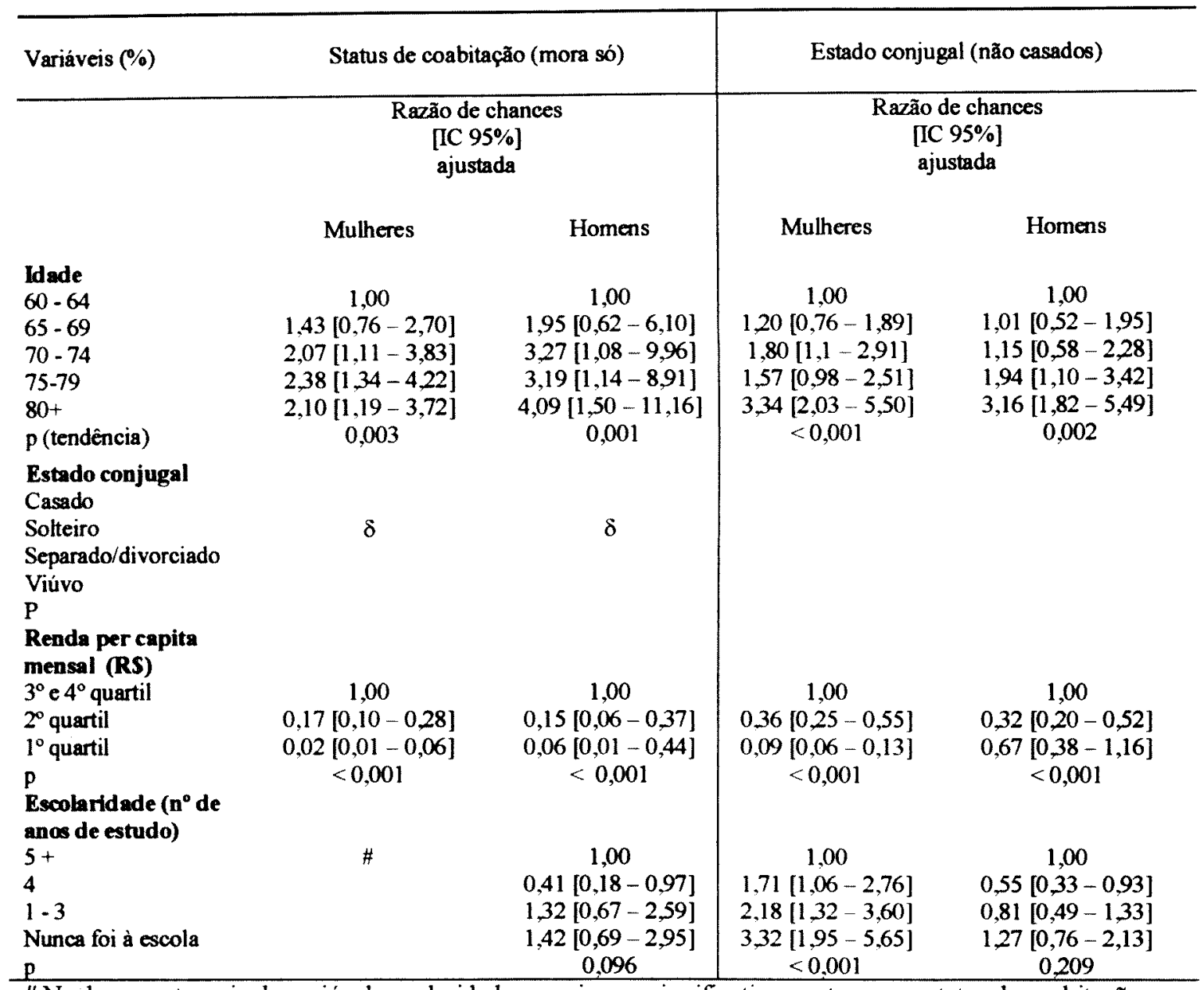

\# Nenhuma categoria da variável escolaridade associou-se significativamente com o status de coabitação e, portanto foi retirado do modelo ajustado.

$\delta$ Estado civil foi retirado dos modelos por apresentar alta colinearidade com a variável status de coabitação. 
Tabela 3 - Associação entre índice de ajudas recebidas/ índice de ajudas prestadas dos idosos e os fatores demográficos e sócioeconômicos - modelo de regressão logística múltipla

\begin{tabular}{|c|c|c|c|c|}
\hline \multirow[t]{3}{*}{ Variáveis (\%) } & \multicolumn{2}{|c|}{ IFAR (baixa frequência) } & \multicolumn{2}{|c|}{ IFAP (baixa frequência) } \\
\hline & $\begin{array}{r}\text { Razão } \\
\text { [IC } \\
\text { aj }\end{array}$ & $\begin{array}{l}\text { Shances } \\
\% \text { ] } \\
\text { da }\end{array}$ & $\begin{array}{r}\text { Razão } \\
\text { [I } \\
\text { a }\end{array}$ & $\begin{array}{l}\text { chances } \\
5 \%] \\
\text { ada }\end{array}$ \\
\hline & Mulheres & Homens & Mulheres & Homens \\
\hline $\begin{array}{l}\text { Idade } \\
60-64 \\
65-69 \\
70-74 \\
75-79 \\
80+ \\
p \text { (tendência) }\end{array}$ & $\begin{array}{c}1,00 \\
0,75[0,46-1,22] \\
0,74[0,44-1,22] \\
0,86[0,53-1,39] \\
0,31[0,18-0,53] \\
<0,001\end{array}$ & $\begin{array}{c}1,00 \\
0,73[0,35-1,57] \\
0,88[0,42-1,88] \\
0,40[0,19-0,84] \\
0,29[0,13-0,64] \\
0,002\end{array}$ & $\begin{array}{c}1,00 \\
0,98[0,52-1,84] \\
1,95[1,07-3,58] \\
1,82[1,02-3,24] \\
3,55[2,00-6,31] \\
<0,001\end{array}$ & $\begin{array}{c}1,00 \\
0,89[0,56-1,79] \\
0,97[0,48-1,96] \\
0,88[0,48-1,63] \\
1,32[0,72-2,41] \\
0,341\end{array}$ \\
\hline $\begin{array}{l}\text { Estado conjugal } \\
\text { Casado } \\
\text { Solteiro } \\
\text { Separado/divorciado } \\
\text { Viúvo } \\
\text { p }\end{array}$ & $\begin{array}{c}1,00 \\
2,43[1,24-4,77] \\
2,47[1,42-4,32] \\
2,03[1,34-3,07] \\
0,001\end{array}$ & $\begin{array}{c}1,00 \\
11,34[4,74-27,12] \\
4,95[2,32-10,59] \\
6,69[3,57-12,52] \\
<0,001\end{array}$ & $\begin{array}{c}1,00 \\
4,44[2,15-9,14] \\
3,37[1,72-6,59] \\
3,63[2,22-5,94] \\
\infty, 001\end{array}$ & $\begin{array}{c}1,00 \\
5,93[2,56-13,71] \\
4,92[2,54-9,53] \\
4,54[2,80-7,36] \\
40,001\end{array}$ \\
\hline $\begin{array}{l}\text { Renda per capita } \\
\text { mensal (RS) } \\
3^{\circ} \text { e } 4^{\circ} \text { quartil } \\
2^{\circ} \text { quartil } \\
1^{\circ} \text { quartil } \\
\text { p (tendência) } \\
\text { Escolaridade (n' de } \\
\text { anos de estudo) } \\
5+ \\
4 \\
1 \text {-3 } \\
\text { Nunca foi à escola } \\
\text { p(tendência) }\end{array}$ & $\begin{array}{c}1,00 \\
0,89[0,55-1,46] \\
0,75[0,45-1,24] \\
0,71[0,41-1,22] \\
0,106\end{array}$ & $\begin{array}{c}1,00 \\
0,44[0,21-0,88] \\
0,86[0,46-1,61] \\
0,52[0,25-1,06] \\
0,266 \\
\end{array}$ & $\begin{array}{c}1,00 \\
1,18[0,65-2,14] \\
1,23[0,69-2,19] \\
3,32[1,95-5,65] \\
0,291 \\
\end{array}$ & $\begin{array}{c}1,00 \\
0,85[0,46-1,56] \\
1,51[0,86-2,66] \\
1,68[0,94-3,02] \\
0,016 \\
\end{array}$ \\
\hline
\end{tabular}


Tabela 4 - Associação entre apoio funcional e apoio estrutural - modelo de regressão logística múltipla

\begin{tabular}{|c|c|c|c|c|}
\hline \multirow[t]{3}{*}{ Variáveis (\%) } & \multicolumn{2}{|c|}{$\begin{array}{c}\text { IFAR } \\
\text { (baixa frequência) }\end{array}$} & \multicolumn{2}{|c|}{$\begin{array}{c}\text { IFAP } \\
\text { (baixa frequiência) }\end{array}$} \\
\hline & $\begin{array}{c}\text { Razão de chances } \\
\text { [IC 95\%] } \\
\text { ajustada (a) }\end{array}$ & $\begin{array}{c}\text { Razão de chances } \\
\text { [IC 95\%] } \\
\text { ajustada (b) }\end{array}$ & $\begin{array}{c}\text { Razao de chances } \\
\text { [IC 95\%] } \\
\text { ajustada (c) }\end{array}$ & $\begin{array}{c}\text { Razão de chances } \\
\text { [IC 95\%] } \\
\text { ajustada (d) }\end{array}$ \\
\hline & Mulheres & Homens & Mulheres & Homens \\
\hline \multicolumn{5}{|l|}{ IFC } \\
\hline Alta frequêencia & $\#$ & 1,00 & 1,00 & $\partial$ \\
\hline $\begin{array}{l}\text { Baixa freqüência } \\
p\end{array}$ & & $\begin{array}{c}1,77[1,01-3,10] \\
0,04\end{array}$ & $\begin{array}{c}1,89[1,11-3,20] \\
0,02\end{array}$ & \\
\hline \multicolumn{5}{|l|}{ IDC } \\
\hline Grande diversidade & & & 1,00 & 1,00 \\
\hline $\begin{array}{l}\text { Pequena diversidade } \\
\text { p }\end{array}$ & $\#$ & $\partial$ & $\begin{array}{c}0,99[0,50-1,95] \\
0,97\end{array}$ & $\begin{array}{c}1,73[1,06-2,82] \\
0,03\end{array}$ \\
\hline \multicolumn{5}{|l|}{$\begin{array}{l}\text { Status de } \\
\text { coabitacăo }\end{array}$} \\
\hline $\begin{array}{l}\text { Não mora só } \\
\text { Mora só }\end{array}$ & $\begin{array}{c}1,00 \\
6,91[4,52-10,57]\end{array}$ & $\begin{array}{c}1,00 \\
10,82[4,78-24,52]\end{array}$ & $\begin{array}{c}1,00 \\
10,38[6,56-16,43]\end{array}$ & $\begin{array}{c}1,00 \\
5,07[2,71-9,50]\end{array}$ \\
\hline $\begin{array}{l}\text { p } \\
\text { Estado conjugal }\end{array}$ & $<0,001$ & $<0,001$ & $<0,001$ & $<0,001$ \\
\hline Casado & 1,00 & 1,00 & 1,00 & 1,00 \\
\hline Solteiro & $1,12[0,53-2,37]$ & $4,29[1,25-9,38]$ & $1,75[0,76-4,04]$ & $3,32[1,41-7,79]$ \\
\hline Separado/divorciado & $1,53[0,85-2,77]$ & $1,45[0,55-3,82]$ & $1,85[0,89-3,86]$ & $2,17[1,07-4,39]$ \\
\hline Viúvo & $1,12[0,72-1,75]$ & $2,47[1,13-5,38]$ & $1,87[1,11-3,16]$ & $2,77[1,71-4,46]$ \\
\hline $\mathrm{p}$ & 0,57 & 0,02 & 0,12 & $<0,001$ \\
\hline
\end{tabular}

\# As variáveis indice de contatos e índice de diversidade não se associaram significativamente com os indices em questão, em análise univariada prévia (aqui não apresentada) $e$, portanto foram retiradas dos modelos ajustados das mulheres. $\partial$ As variáveis índice de contatos (IFAP) e índice de diversidade (IFAR) não se associaram significativamente com os indices em questão, em análise univariada prévia (aqui não apresentada) e, portanto foram retiradas dos modelos ajustados dos homens.

(a) ajustada por idade e renda, (b) ajustada por idade, renda e escolaridade

(c) ajustada por idade e renda, (d) ajustada por escolaridade 


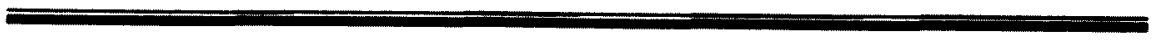

CAPÍTULO 3 (Artigo 3)

DETERMINANTES DO ESTADO NUTRICIONAL DE IDOSOS DO MUNICÍPIO DE SÃO PAULO: FATORES SÓCIOECONÔMICOS, REDES SOCIAIS DE APOIO E ESTILO DE VIDA 


\section{RESUMO}

Objetivos: O presente estudo teve como objetivo investigar as redes sociais, além de outros fatores, como determinantes do estado nutricional de idosos do Município de São Paulo. Métodos: Estudou-se amostra probabilística de 2.143 idosos (60+) da cidade de São Paulo (inquérito SABE - Saúde, bem-estar e envelhecimento), focalizando-se as dimensões estruturais (índice de freqüência de contatos - IFC, índice de diversidade de contatos - IDC, coabitação e situação conjugal) e funcionais (índice de frequêencia de ajudas recebidas - IFAR e indice de freqüência de ajudas prestadas - IFAP) das redes sociais. Adotou-se o indice de massa corporal $\left(\mathrm{IMC}-\mathrm{Kg} / \mathrm{m}^{2}\right)$ como indicador de estado nutricional. Utilizou-se análise de regressão logística múltipla em modelos hierarquizados. Resultados: Idade, raça, escolaridade e renda associaram-se com baixo peso e com obesidade, com algumas variações inter-gênero. Baixas freqüências de contatos aumentam as chances de baixo peso nas mulheres e o casamento mostrou-se protetor para baixo peso (mulheres solteiras) e prejudicial para a obesidade (mulheres casadas). $\mathrm{O}$ hábito do fumo associou-se positivamente com baixo peso (ambos os gêneros) e negativamente com obesidade (mulheres). Não realizar atividade física teve relação com obesidade (mulheres). Conclusões: A hipótese central deste estudo de que apoio social associa-se positivamente com estado nutricional adequado de idosos foi confirmada apenas parcialmente. Além das contribuições que podem ser sugeridas por ele, outros estudos incluindo outras dimensões do apoio social devem ser realizados, dadas as lacunas existentes sobre as redes sociais como determinantes do estado nutricional de idosos. 
Descritores: Idosos, redes sociais, apoio social, obesidade, baixo peso, fatores de risco de estado nutricional de idosos 


\begin{abstract}
Objectives: The purpose of this study was to research social networks and other factors, as determinants of the nutritional state of those elderly people. Methods: A probability sample of 2,143 elderly people (60+) from the city of São Paulo was studied (SABE Wealth, Welfare, and Aging query), focusing on structural dimensions [contact frequency index (IFC), contact diversity index (IDC), cohabitation, and conjugal status], and functional dimensions [aid received frequency index (IFAR) and aid granted frequency index (IFAP)] of the social networks. A body mass index was adopted (BMI $\mathrm{Kg} / \mathrm{m}^{2}$ ) as nutritional state indicator. A multiple logistic regression analysis based on hierarchical models was used. Results: age, race, education, and income are associated to low weight and obesity, with some intergender variations. Low contact frequency increases the chances of low weight among women and marriage shows to favor low weight among single women and cause obesity among married women. Smoking habits are positively associated to low weight (both genders) and negatively associated to obesity (women). The lack of physical activity is related to obesity (women). Conclusions: The core hypothesis of this study is that considering social support as positively associated to the appropriate nutritional state of elderly people is only partially confirmed. In addition to the contributions this study might suggest, other studies should be conducted to include other dimensions of social support in view of the existing gaps in the current social networks as determinants of the nutritional state of elderly people.
\end{abstract}


Descriptors: Elderly people, social networks, social support, nutritional state, body mass index, risk factors de nutritional state de elderly people. 


\section{INTRODUÇÃO}

A relação entre saúde e estado nutricional vem sendo continuamente reconhecida e intensamente atestada, tanto por estudos que apontam a obesidade como um importante problema de saúde pública, por sua associação positiva com as doenças crônicas e degenerativas (MANN 1974; VAN ITALLIE 1979; RISSANEN e col., 1989; RISSANEN e col., 1991; MONTEIRO e col., 2000), quanto por aqueles que encontram a magreza como fator de risco de morte precoce. (RISSANEN e col., 1989; SONG e SUNG, 2000). Pode-se salientar que os idosos constituem-se em um grupo específico que é especialmente vulnerável a inúmeras conseqüências de distúrbios nutricionais relacionadas aos agravos à saúde (McINTOSH e col.,1989). Diversas investigações, especialmente com população de idosos, têm apontado que distúrbios nutricionais relacionados com perda de peso estão associados à incapacidade funcional (GREENSPAR e col. 1994; LAUNER e col., 1994), ao aumento de internações hospitalares e com a duração da internação (MESSNER e col., 1991; EDINGTON e col., 2000).

Pode-se dizer que existe uma complexa rede de fatores envolvida no contexto dos estudos sobre a determinação do estado nutricional de idosos. As evidências de associação nem sempre são fáceis de serem obtidas; entretanto, são listados como potenciais influenciadores do estado nutricional em idosos, além dos fatores físicos (estado de saúde), dos fatores sócioeconomômicos (renda baixa, baixo nível de escolaridade), os fatores sociais (apoio/isolamento social e arranjo familiar) (CHEN 1986; GOODWIN 1989; MORLEY 1997).

Com base nos conhecimentos que vêm se acumulando sobre as relações entre redes sociais e saúde física e mental sugere-se que a rede social teria os mesmos efeitos positivos para o estado nutricional que têm para a saúde. Dentro dessa perspectiva, a 
hipótese do controle social é um dos possíveis modelos explicativos dos mecanismos através dos quais o apoio social influencia a saúde. Os relacionamentos interpessoais podem fornecer modelos de mudanças no estilo de vida, controle e pressão sobre comportamentos (os pares podem apoiar hábitos alimentares saudáveis) e dar acesso a informações (UMBERSON 1992; KELSEY e col., 1997). O apoio necessário (compras, preparo de alimentos e companhia às refeições) origina-se de relacionamentos mantidos com cônjuge, com amigos e com membros de organizações de trabalhos voluntários. Sendo que, no caso do idoso, a dependência de outros para alimentar-se é muito mais pronunciada (McINTOSH e col., 1989).

Nesse panorama, partindo-se da hipótese de que redes sociais estão positivamente relacionadas com estado nutricional adequado de idosos, o objetivo deste estudo foi investigar a associação de algumas dimensões das redes sociais sobre o baixo peso e sobre a obesidade da população idosa do Município de São Paulo. Como o desenvolvimento de programas efetivos para tratar ou prevenir distúrbios nutricionais numa população depende também de se ter uma clara configuração do estado nutricional desta população, este estudo incluiu também o objetivo de analisar a prevalência de baixo peso e obesidade dos idosos do Município de São Paulo, segundo variáveis sóciodemográficas e de estilo de vida.

\section{MÉTODOS}

Este estudo é parte do inquérito sobre Saúde, Bem-estar e Envelhecimento (Projeto SABE) realizado na cidade de São Paulo em pessoas de 60 anos ou mais, durante o período de janeiro de 2000 a março de 2001. Trata-se de uma pesquisa Multicêntrica (em sete paises da América Latina e Caribe) coordenada e financiada pela 
Organização Pan-Americana de Saúde/Organização Mundial de Saúde (OPAS/OMS) e, no Brasil, executada por equipe da Faculdade de Saúde Pública.

A amostra probabilística foi formada por 1.568 entrevistas realizadas entre os 1.852 idosos identificados nos domicílios sorteados. Em seguida, para compensar a mortalidade na população de maiores de 75 anos e completar o número desejado de entrevistas nesta faixa etária, foi feito um acréscimo de 575 entrevistas realizadas com residentes nos distritos sorteados anteriormente. A amostra final foi composta de 2.143 pessoas de 60 anos e mais. A taxa de resposta ao levantamento foi de $84,7 \%$, dentro do esperado estatisticamente. Entre os motivos principais pelos quais as entrevistas não foram realizadas incluíram-se a recusa em participar do estudo e a não possibilidade de localizar o entrevistado em pelo menos três visitas ao domicílio.

A variável dependente, indice de massa corporal (IMC), foi calculada como peso corporal $(\mathrm{Kg})$ dividido pelo quadrado da altura $\left(\mathrm{m}^{2}\right)$. Utilizou-se a recomendação da Organização Pan-Americana de Saúde (OPAS 2002) para a classificação: IMC menor que $23 \mathrm{Kg} / \mathrm{m}^{2}$ (baixo peso); $23 \mathrm{Kg} / \mathrm{m}^{2}<=\mathrm{IMC}<28 \mathrm{Kg} / \mathrm{m}^{2}$ (peso normal); IMC > $=30$ $\mathrm{Kg} / \mathrm{m}^{2}$ (obesidade). $\mathrm{Na}$ análise dos fatores associados, o estado nutricional foi investigado através de duas variáveis dicotômicas: baixo peso $=1$ e peso normal $=0$; obesidade $=1$ e peso normal $=0$. Para a decisão de investigar os determinantes dos pesos extremos (obesidade e baixo peso) dos idosos, foram considerados o indubitável efeito prejudicial do excesso de peso na saúde dos individuos, a elevada prevalência de baixo peso nos idosos e a tendência atual de considerar também a magreza como fator de risco para a saúde.

Os indicadores de redes sociais, variáveis independentes, estudados foram: 
- Índice de freqüência de $\operatorname{contatos}^{1}$ (IFC) com filhos, irmãos, outros familiares e com amigos (máximo de 301 contatos por mês e um mínimo de zero), dicotomizado em quartil inferior ( $<12$ contatos) e demais ( $>=12$ contatos).

- Índice de diversidade de contatos (IDC), calculado como número de diferentes tipos de contatos ocorridos duas ou mais vezes/mês (máximo de quatro tipos e um mínimo de zero), dicotomizado em quartil inferior ( $<1$ contato regular) e demais $(>=1$ contato regular).

- Status de coabitação, variável dicotômica indicando se o idoso vivia só ou não.

- Situação conjugal, categorizada em casado, solteiro, separado/divorciado e viúvo.

- Índice de ajudas efetivamente recebidas (IFAR), freqüência de ajudas efetivamente recebidas de pessoas que moram junto, filhos e irmãos que não moram junto, outros familiares e amigos (máximo de 280 e mínimo de zero), dicotomizado em quartil inferior e demais.

- Índice de apoio efetivamente prestado (IFAP) a pessoas que moram junto, filhos e irmãos que não moram junto, outros familiares e amigos (máximo de 336 e mínimo de zero), dicotomizado em quartil inferior e demais.

Ainda entre as variáveis independentes foram estudados os fatores socioeconômicos, os demográficos e os relacionados ao estilo da vida:

- Idade em anos: grupos etários de 60 a 64, 65 a 69, 70 a 74, 75 a 79 e 80 anos e mais.

- Raça: branca; negra/mulata; Indígena/mestiça; asiática e outras.

\footnotetext{
${ }^{1}$ Os índices de contato e de sua diversidade foram construídos segundo sugestão de LUND e col., 2000.
} 
- renda mensal do idoso per capita em reais - soma dos rendimentos declarados pelo entrevistado dividido pelo número de pessoas que dependia desta renda estratificada em quartis: $1 .^{\circ}(<\mathrm{R} \$ 75,50) ; 2 .^{\circ}(75,50<=$ renda per capita $<\mathrm{R} \$$ $151,00)$ e $3^{\circ} 4^{\circ}(>=R \$ 151,00)$.

- escolaridade em número de anos de estudo: nunca foi à escola, 1 a 3 anos, 4 anos e 5 anos ou mais.

- Tabagismo: nunca fumou; fumou, parou; fuma atualmente.

- Exercícios físicos ou atividades físicas vigorosas regulares nos últimos 12 meses: sim, não

- Consumo de bebida alcoólica: sim, não.

Devido ao fato de existirem grandes diferenças entre o perfil das mulheres e o dos homens, todas as análises foram realizadas considerando os gêneros separadamente.

As análises dos diferenciais na distribuição do baixo peso e da obesidade, segundo variáveis selecionadas e potencialmente associadas com estes distúrbios nutricionais, foram realizadas considerando-se a ponderação da amostragem para o cálculo das prevalências (SILVA 2003).

Para a identificação da associação individualizada entre cada variável de estudo e os estados nutricionais inadequados em questão, foi realizada análise múltipla de regressão logística (HOSMER e LEMESHOW, 1989), empregando-se a técnica de análise hierarquizada proposta por VICTORA e col., 1997. Como variações nas redes sociais e no estado nutricional podem ser influenciadas por fatores socioeconômicos e demográficos, estes foram considerados determinantes distais, que condicionam diretamente os demais grupos de fatores de risco. Considerou-se que a atuação das variáveis relacionadas às redes sociais sobre os distúrbios nutricionais do idoso teria 
precedência sobre as de estilo de vida, portanto, estas constituíram respectivamente o segundo e o terceiro bloco na análise hierarquizada - Figura 1. A seleção das variáveis de controle foi realizada adotando-se o nível crítico de significância igual a 0,20. Para a interpretação dos resultados, considerou-se o valor de $\mathrm{p}<0,05$ para a identificação de associação estatisticamente significativa.

\section{RESULTADOS}

A amostra final deste estudo compreendeu 1796 idosos, dos quais 1064 eram mulheres e 732 eram homens, que se submeteram às medidas antropométricas.

Na Tabela 1 estão apresentadas prevalências de baixo peso e os resultados da análise de regressão logística bruta, segundo fatores sóciodemográficos, para mulheres e homens. Para ambos os gêneros, o baixo peso manteve associação significativa positiva e negativa com grupo etário e com escolaridade, respectivamente, embora nem todas as categorias desses fatores tenham se mostrado estatisticamente associadas. A prevalência de baixo peso está significativamente associada aos grupos etários de 70 a 74 e de 80 anos e mais, sendo que nestes a chance de ocomência do baixo peso foi aproximadamente 2 vezes maior que a do grupo mais jovem. Note-se que para os homens com mais de 80 anos a chance se elevou para em torno de 3 vezes, em relação ao grupo mais jovem. A associação com tendência à significância foi observada somente na categoria "nunca freqüentou escola", que apresentou razão de chances de 1,64 (IC= $0,98 ; 2,77)$ e $1,54(\mathrm{IC}=0,94 ; 2,55)$ para mulheres e homens, respectivamente.

Entre as mulheres, raça associou-se significativamente com o baixo peso, entretanto somente a categoria asiática alcançou significância estatística, sendo a chance 
3,10 vezes maior $(\mathrm{IC}=1,48 ; 6,49)$ em relação à branca.

Somente entre os homens a renda apresentou associação com o baixo peso, inversa e altamente significativa, com razão de chances de $1,60(\mathrm{IC}=1,05 ; 2,43)$ e 2,42 $(\mathrm{IC}=1,36 ; 4,29)$ para rendas do $2^{\circ} \mathrm{e} 1^{\circ}$ quartis, respectivamente.

Foram apresentadas na Tabela 2 as prevalências de baixo peso segundo fatores relativos às redes sociais e os relacionados com o estilo de vida e respectivos resultados de análise logística bruta, para mulheres e homens.

Para ambos os gêneros, o fator estado conjugal não alcançou associação significativa, com exceção das categorias separado/divorciado para as mulheres (razão de chances $=2,01$ e IC $=1,15 ; 3,52$ ) e viúvo para os homens (razão de chances $=1,67 \mathrm{e}$ $\mathrm{IC}=1,08 ; 2,58$ ).

Para as mulheres, o IFC associou-se com o baixo peso, sendo que para a baixa freqüência de contatos a chance de ocorrência de tal estado nutricional se eleva em mais de $50 \%$, comparando-se com altas freqüências de contatos (razão de chances $=1,54 \mathrm{e}$ IC $=1,06 ; 2,25$ ).

O IDC associou-se com o baixo peso somente para os homens, onde se observa a chance de 1,68 vezes maior $(\mathrm{IC}=1,01 ; 2,78)$ do distúrbio nutricional ocorrer quando a diversidade de contatos é pequena, em relação à grande diversidade de contatos.

Os demais fatores, status de coabitação, IFAR e IFAP não se mostraram associadas com o baixo peso, em nenhum dos gêneros.

Para ambos os gêneros, a relação entre tabagismo e baixo peso foi altamente significativa, embora a categoria "fumou, parou", não tenha apresentado a mesma significância. As pessoas que fumavam apresentaram chances aproximadamente 2 vezes maior de ter baixo peso $(\mathrm{RC}=2,11 ; \mathrm{IC}=1,31 ; 3,41$ - mulheres e $\mathrm{RC}=1,77 ; \mathrm{IC}=1,10 ; 2,85$ - homens ), quando comparadas com aquelas que nunca fumaram. 
Somente para os homens, a não realização regular de atividade fisica manteve-se como risco para o baixo peso, apresentando uma chance $59 \%$ maior para o baixo peso em relação aos que praticavam atividade física regularmente.

O consumo de bebida alcoólica não se associou com o baixo peso em nenhum dos gêneros.

Os resultados relativos à associação entre obesidade e fatores sóciodemográficos, para homens e para mulheres, estão apresentados na Tabela 3.

Observou-se relação positiva entre baixo peso e grupo etário, para ambos os gêneros, ao contrário, a obesidade manteve associação significativa negativa com o grupo etário, somente para as mulheres ( $p$ tendência linear $=0,048$ ). Para este gênero, os grupos etários com chances significativamente maiores de ocorrência de obesidade foram os de 60 a 64 e de 70 a 74 anos, $\mathrm{RC}=1,79 ; \mathrm{IC}=1,13 ; 2,82$ e $\mathrm{RC}=1,73 ; \mathrm{IC}=1,05$; 2,85 , respectivamente. Relativamente às mulheres, as prevalências de obesidade entre os homens são menores, entretanto, nestes, as chances de ocorrência do distúrbio nutricional são superiores às do outro gênero. Os homens de 65 a 69 anos tiveram $R C=2,66(I C=1,02 ; 6,95)$ de apresentar obesidade enquanto entre os de $70 \mathrm{a} 74$ anos esta chance se eleva para $3,86(\mathrm{IC}=1,47 ; 10,11)$.

Em ambos os gêneros, raça, renda e escolaridade não mostraram nenhuma influência sobre a obesidade, exceto a categoria indígena/mestiça que apresentou associação estatisticamente significativa, por outro lado, entre os homens de origem indigena ou mestiça as chances foram significativamente aumentadas e iguais a 2,43 $(\mathrm{IC}=1,13 ; 5,21)$ de ocorrência de obesidade.

Na Tabela 4 estão apresentadas prevalências de obesidade e os resultados da análise de regressão logistica bruta, segundo fatores relativos aos indicadores de redes sociais e estilo de vida, para homens e para mulheres. 
Observou-se que entre as mulheres, em referência às casadas, os demais estados conjugais, mantiveram relação negativa com a obesidade, ou seja, entre as solteiras, as separadas ou divorciadas e as viúvas as chances de ocorrência de obesidade são menores do que entre as casadas. Entretanto, somente as solteiras apresentaram tais chances estatisticamente significativas $(\mathrm{RC}=0,36 \mathrm{e} \mathrm{IC}=0,17 ; 0,79)$.

Para os homens, não se evidenciou nenhuma associação significativa entre obesidade $\mathrm{e}$ as variáveis relacionadas às redes sociais.

No bloco de variáveis de estilo de vida, o hábito atual do fumo foi fator de diminuição das chances de se apresentar obesidade, e a não realização regular de atividade fisica manteve-se como risco para o mesmo tipo de estado nutricional, em ambos os casos. Entretanto, a relação fumo-obesidade e atividade física-obesidade apresentaram significancia estatística apenas para as mulheres $(R C=0,52$ e $I C=0,29$; 0,95 e $\mathrm{RC}=1,54 ; \mathrm{IC}=1,06$ e 2,23, para o primeiro e segundo caso, respectivamente).

A Tabela 5 apresenta cada um dos níveis correspondentes aos blocos com as respectivas variáveis que se associaram significativamente com o baixo peso e aquelas que foram mantidas para controle por apresentarem $p<0,20$.

Entre as mulheres, as variáveis sóciodemográficas (nivel 1), das redes sociais (nivel 2) e do estilo de vida (nível 3) não foram modificadas com os ajustes acrescentados, mantendo associações semelhantes às observadas na análise univariada.

Para os homens, a associação dos fatores sociodemográficos (nível 1) com o baixo peso não foi modificada quando controlados entre si. A exceção foi observada na escolaridade em que, com o ajuste, as categorias " 1 a 3 anos de escolaridade" e 4 anos de escolaridade" passaram a associar-se negativamente de modo significativo, com o baixo peso. No nível 2 , os fatores ligados à rede social perderam a significância estatística e nenhum deles foi mantido no nivel subseqüente. No nível 3, atividade física 
perdeu a significância estatística $(p=0,450)$ quando os blocos anteriores foram acrescentados e tabagismo manteve-se com forte associação, sendo "fuma atualmente" uma categoria de risco para o baixo peso.

$\mathrm{Na}$ Tabela 6 estão apresentados os níveis que correspondem aos blocos do modelo hierarquizado, com as respectivas variáveis que se associaram com a obesidade. O critério de seleção foi o mesmo adotado para o baixo peso.

Para as mulheres, a significância da associação da escolaridade com a obesidade (nível 1) foi elevada e inversa quando controlada pela idade, alcançando significância estatística. As variáveis de apoio social (nível 2) e as de estilo de vida (nível 3) não foram modificadas pelo ajuste acrescentado.

No que diz respeito à população masculina, as variáveis sociodemográficas (nível 1) mantiveram a associação semelhante à da análise univariada quando ajustadas entre si. Nenhuma variável de redes sociais (nivel 2) foi mantida na análise múltipla. A atividade física (nivel 3), mantida no modelo para controle, alcançou significância estatística quando ajustada pelas variáveis sociodemográficas, com razão de chances de 2,08 e IC $=1,01 ; 4,28$.

\section{DISCUSSÃO}

A população de estudo foi composta por uma amostra probabilística de individuos de 60 anos e mais residentes na área urbana do Município de São Paulo (SILVA 2003). A coleta de dados foi realizada por entrevistadores devidamente treinados para a realização de entrevistas domiciliares com a população estudada, empregando-se o questionário do Projeto SABE, padronizado pela OPS para o estudo multicêntrico. A mensuração antropométrica foi realizada por entrevistadores 
especialmente treinados para essa função, empregando instrumentos e técnicas devidamente padronizados. Esses são aspectos virtuosos do estudo que contribuíram para diminuir a chance da ocorrência de erros sistemáticos ou vieses durante a coleta dos dados, o que fortaleceu a validade interna do estudo.

A principal limitação deste estudo está relacionada com a impossibilidade de identificar a precedência temporal de parte dos fatores estudados e de realizar medidas diretas de risco, conseqüências do delineamento de corte seccional da pesquisa. Isso implica em que não seja possível afirmar com certeza, por exemplo, que baixas freqüências de contatos causaram o baixo peso nas mulheres, pois tanto essa afirmação, quanto a de que o estado nutricional influenciou a diminuição de contatos com outras pessoas; ou ainda, que um terceiro fator não estudado pode ser responsável por tal distúrbio nutricional, são plenamente aceitáveis.

Outra questão importante diz respeito ao contexto dos estudos sobre a determinação do estado nutricional de idosos, estamos num situação bastante controversa relacionada à dificuldade em se distinguir as mudanças que são inerentes ao processo de envelhecimento daquelas que lhe são secundárias, ou seja, tributáveis a qualquer outro fator relacionado com o avanço da idade.

Com as evidências acumuladas a respeito das variações no peso, altura e composição corporal, segundo a faixa etária e o sexo - aliadas aos achados de que peso corporal ideal para a sobrevivência aumenta com a idade - a adoção de pontos de corte mais elevados do IMC de acordo com o aumento da idade, tanto para a definição de baixo peso quanto para a obesidade, tem sido sugerida em algumas publicações (ANDRES e col., 1993; AAFP, ADA, NCAI 1994). A Organização Pan-Americana de Saúde (OPAS) recomenda a seguinte classificação para ser usada na Pesquisa Saúde, Bem-Estar e Envelhecimento na América Latina e Caribe (Projeto SABE): IMC menor 
que $23 \mathrm{Kg} / \mathrm{m}^{2}$, baixo peso; IMC igual ou maior que $23 \mathrm{Kg} / \mathrm{m}^{2}$ e menor que $28 \mathrm{Kg} / \mathrm{m}^{2}$, peso normal; IMC igual ou maior que $28 \mathrm{Kg} / \mathrm{m}^{2}$ e menor que $30 \mathrm{Kg} / \mathrm{m}^{2}$, sobrepeso; e IMC maior ou igual a $30 \mathrm{Kg} / \mathrm{m}^{2}$, obesidade (OPAS 2002), sendo, portanto, estes os niveis de corte adotados.

Entretanto, para possibilitar discussão e comparabilidade destes resultados com outros estudos, foram calculadas as prevalências de baixo peso empregando-se o $\mathrm{MMC}<$ $18,5 \mathrm{Kg} / \mathrm{m}^{2}$. Observaram-se prevalências de $2,8 \%$ e $3,3 \%$, para mulheres e homens e as seguintes proporções nos grupos etários; $2,2 \%$ e $3,3 \%$ para $60-64$ anos; $1,8 \%$ e $0,9 \%$ para $65-69$ anos; $3,4 \%$ e $4,0 \%$ para $70-74 ; 2,7 \%$ e $4,4 \%$ para $75-79 ; 5,7 \%$ e $8,3 \%$ para $80+$. Estas prevalências apresentaram-se bastante reduzidas quando comparadas com outros países em desenvolvimento que mostram elevadas prevalências de baixo peso na população de 60 anos e mais, tais como 29,8\% (Mali), 52,6\% e 56,4\%, para homens e mulheres, respectivamente (Índia) e $51 \%$ e $65,2 \%$, para homens e mulheres, respectivamente (Vietnan) (CHILIMA e ISMAIL, 1998; NAIDU e RAO; 1994, GIAY e KHOI, 1994).

De modo geral, a diferença nas prevalências de baixo peso e de obesidade intergêneros e a relação entre estado nutricional e idade concordam com a tendência do perfil nutricional da população idosa brasileira, com base nos dados da Pesquisa Nacional sobre Saúde e Nutrição (TAVARES e ANJOS, 1999). Tomando-se as proporções de baixo peso observadas nessa pesquisa, entre os maiores de 60 anos, no sudeste urbano como parâmetro, nota-se que em nosso estudo houve redução nas proporções deste tipo de distúrbio nutricional, sendo de 0,50 e 0,41 pontos percentuais a redução observada entre mulheres e homens, respectivamente. Entretanto, em relação à obesidade, verificaram-se crescimentos da ordem de 0,24 (mulheres) e 0,40 (homens) pontos percentuais. 
Portanto, embora se observe notável redução na prevalência de idosos com baixo peso, por outro lado, chamou a atenção o crescimento da prevalência de obesos, aumentando conseqüentemente os riscos, principalmente nos homens, para diversas doenças crônicas e degenerativas.

\section{Fatores sóciodemográficos}

A magnitude da associação entre grupo etário e baixo peso foi mantida quando ajustada para os demais fatores socioeconômicos, para ambos os gêneros. Maiores chances de ocorrência de baixo peso foram observadas nos grupos etários 70 a 74 e 80 .

Observou-se que o nível educacional da população estudada no seu conjunto é baixo, resultado das políticas de educação prevalecentes nas décadas de 30 e 40 , quando o acesso à escola era ainda bastante restrito. Entretanto, é interessante notar que, para as mulheres, a escolaridade manteve relação inversa significativa com a obesidade, estatisticamente controlada pelos efeitos da idade e raça. Pode-se dizer que o nível educacional, mesmo com pequeno número de anos de estudo, diferencia os individuos em relação ao seu acesso a informações, confirmando a suposição de que esse é importante determinante do estado nutricional (MONTEIRO 1998). Ao contrário, entre os homens, a escolaridade não se associou com a obesidade. Em relação à renda, a obesidade ocorreu com maior freqüência nos niveis mais altos, embora a renda inferior não tenha alcançado significância estatística, provavelmente pelo pequeno número de idosos nessa categoria.

Pobreza é, talvez, o mais importante fator de risco para a desnutrição na população em geral e principalmente em crianças/jovens e idosos (TAVARES e ANJOS, 1999; MONTEIRO 1998). Não é coincidência que nestes resultados as chances significativamente maiores de baixo peso sejam encontradas entre os menos 
escolarizados (em ambos os gêneros) e entre os mais pobres (nos homens). Chamou a atenção que os homens de renda inferior, estatisticamente controlados para os efeitos da idade, raça e escolaridade, mantiveram significativamente a chance 2,5 vezes maior de apresentarem baixo peso.

Em geral, as associações entre raça e estado nutricional são explicadas a partir de padrões de consumo adquiridos por experiências étnicas-culturais anteriores. Sustenta-se que a etnia realmente tem um importante papel na dieta dos idosos (WINKLEBY e col., 1996; CHEN 1986). Sabe-se, também, que na Ásia, especialmente no Japão, a prevalência de baixo peso é maior do que na maioria dos paises ocidentais desenvolvidos (WHO 1995), isso parece concordar com um dos resultados deste estudo onde as mulheres de origem asiática, presume-se imigrantes japonesas, apresentaram chances elevadas de baixo peso (3,5 vezes maior). É sabido que os imigrantes japoneses retiveram padrões alimentares de sua cultura original e que estes são de baixo teor de gordura, isso poderia estar relacionado aos baixos pesos observados. Entretanto, o mesmo não ocorreu entre os homens asiáticos, o que sugere a existência de outros fatores, aqui não estudados, além daqueles observados em relação às mulheres.

Entre os homens, encontrou-se chance significativamente maior de ocorrência de obesidade na raça indígena/mestiça, mesmo sendo esta ajustada por idade e renda. A explicação para esse resultado poderia estar relacionada com a assimilação, por esse grupo étnico, de hábitos associados à urbanidade, muito distintos dos hábitos e costumes alimentares próprios da sua cultura.

\section{Fatores de apoio social}

A associação entre a presença de amplas redes de amigos e a adequada ingestão de nutrientes, portanto, estado nutricional adequado (McINTOSH e col., 1989); e a 
relação entre idosos socialmente ativos e dietas alimentares mais diversificadas e adequadas (KRONDL e col., 1982) sugeriram a hipótese de que distúrbios relacionados com inadequação alimentar, poderiam ser influenciados pelo tipo de integração social dos idosos nas suas redes sociais. Entretanto, os resultados desta pesquisa confirmaram só parcialmente tal suposição. Observou-se que o índice de contatos (quantidade) e o índice de diversidade (amplitude) mostraram efeito sobre o baixo peso, mas não sobre a obesidade. Mulheres que relataram baixa freqüência de contatos com parentes e amigos (menos integradas socialmente), independentemente do estado civil, idade e raça, apresentaram chances aumentadas de baixo peso em aproximadamente 50\%. Homens que responderam não ter contatos regulares (pelo menos duas vezes por mês) com ninguém, excluindo os co-residentes, foram associados com o baixo peso, todavia, a significância não foi mantida quando este foi estatisticamente controlado pela idade, escolaridade e renda. Daí, conclui-se que quantidade de contatos que a mulher tem na sua rede social tem influência sobre o baixo peso, mas isso não vale para os homens; por outro lado, para ambos os gêneros, a amplitude da rede social não influencia o baixo peso, nem a obesidade.

Pesquisa anteriormente realizada, considerando a hipótese do controle social, sugere que o casamento pode beneficiar a saúde das pessoas por ser é mais provável que o agente do controle social seja exercido pelos cônjuges do que por outras pessoas. Observou-se também que é mais freqüente que a mulher exerça esse papel do que o homem (UMBERSON 1992). No presente estudo, o efeito protetor do casamento foi observado na população feminina, onde mulheres separadas/divorciadas apresentaram significativamente maior chance para o baixo peso. Contudo, contrariando as expectativas, o casamento não mostrou efeito entre os homens com relação à ocorrência de baixo peso ou obesidade. Para esse tipo de estado nutricional, nas as mulheres, o 
casamento mostrou-se como fator de risco. Aqui, as condições indicativas de nãocasamento (solteira, separada/divorciada e viúva) apresentaram-se como fator protetor para a obesidade, embora somente a categoria solteira tenha alcançado e mantido significância estatística quando a variável estado civil foi controlada por idade e escolaridade.

Diversos autores relatam achados relacionando baixos pesos com pessoas vivendo sós (MORLEY 1997; SARLIO-LÄHTEEKORVA e LAHELMA, 1999). Levando em conta na população de idosos desta pesquisa a situação de morar só é mais freqüente entre aqueles que reúnem mais condições de dependência (os mais velhos e portanto com mais incapacidades funcionais), presumiu-se a possibilidade encontrar resultados consistentes com a literatura. Não obstante, status de coabitação não se associou com nenhum tipo de estado nutricional, em nenhum dos gêneros.

No que diz respeito à dimensão das funções das redes sociais (IFAR - ajudas recebidas e IFAP - ajudas prestadas), estas não se associaram com nenhum dos distúrbios nutricionais estudados. Se entre os idosos a dependência de outros para alimentar-se é muito mais pronunciada, imaginou-se que seriam maiores as chances de distúrbio alimentar, com conseqüente distúrbio nutricional entre aqueles que apresentaram baixa freqüência em ajudas recebidas. Contudo, tais suposições não foram confirmadas.

Dos diversos aspectos das redes sociais estudados, somente índice de contatos e estado civil mostraram influência sobre o estado nutricional. Portanto, a hipótese de que apoio social associa-se positivamente com estado nutricional adequado em idosos, à semelhança dos efeitos positivos das redes sociais sobre a saúde, foi confirmada apenas parcialmente. Não existem ainda bases teóricas nem empíricas para continuar a sustentar ou abandonar tal hipótese, entretanto para a discussão das possíveis explicações para os 
resultados negativos encontrados pode-se levantar alguns aspectos metodológicos de fragilidade deste estudo.

O primeiro aspecto de problema metodológico está relacionado com a mensuração das dimensões das redes sociais. Dado que os indicadores de tais dimensões aqui empregados (IFC, IDC, IFAR e IFAP) foram desenvolvidos ad hoc para analisar dados secundários de uma pesquisa não delineada originalmente para investigar as redes sociais, existe a possibilidade de que estas não tenham sido mensuradas adequadamente.

Por outro lado, têm-se considerado que a influência das redes sociais sobre a saúde das pessoas depende mais de variáveis demográficas do que se pensava. Ou seja, certas medidas de redes sociais podem ser menos válidas em ambientes rurais e em pequenas cidades e para mulheres (DEAN e col., 1994). Isto tem impelido os investigadores a desenvolver medidas de redes sociais específicas para grupos específicos. Portanto, uma das explicações que se pode aventar para os resultados desta pesquisa é que as dimensões das redes sociais que são relevantes para estes idosos podem não ter sido mensuradas.

Finalmente, neste estudo considerou-se o efeito direto como modelo explicativo dos mecanismos através dos quais a rede social influencia a saúde (apoio social é protetor à saúde independentemente do estresse), portanto a influência de variáveis da personalidade, depressão ou tensão psicológica, na relação entre as medidas de rede social e estado nutricional não foi investigada. Por um lado, numerosos estudos evidenciam que redes sociais por si, sem considerar o estresse, têm efeito protetor para a saúde e, por outro lado, inúmeros outros formecem evidências de que as redes sociais reduzem o impacto do estresse. Vale ressaltar que esta questão metodológica é um dos pontos de maior discordância entre os autores da área. Na verdade, não obstante existirem poucas dúvidas de que rede social prediz desfechos de saúde, de quê forma 
componentes do ambiente social provêem efeitos protetores ou prejudiciais à saúde,é algo que ainda permanece não esclarecido. (DEAN e col., 1992).

\section{Fatores de estilo de vida}

O efeito negativo do tabagismo sobre o peso tem sido documentado em diversas investigações com populações adulta e idosa (ECK e col., 1992; CORNONI-HUNTLEY e col., 1991). Consistente com os achados anteriores, nesta pesquisa, homens e mulheres que fumavam, apresentaram o dobro de chance de terem baixo peso, e as mulheres fumantes apresentaram metade da chance de serem obesas, quando comparados com os que nunca tinham fumado, estes resultados foram estatisticamente controlados por fatores socioeconômicos, demográficos e de redes sociais.

Embora a avaliação da atividade física dos idosos tenha sido bastante simplificada neste estudo, a expectativa de que atividade fisica se associasse negativamente com a obesidade (ECK e col., 1992, SUNDQUIST e JOHANSSON, 1998) foi confirmada. Nesse aspecto, é importante lembrar que a prevalência da não prática de atividade fisica é da ordem de 78,7\% (mulheres) e de 75,1\% (homens) e que, portanto, a contribuição relativa desse fator para a ocorrência da obesidade (RAP\%) entre estes idosos pode ser estimada em $36,8 \%$ e $41,6 \%$ entre mulheres e homens, respectivamente. Isso significa dizer que uma intervenção que estimulasse todos os idosos à prática da atividade física poderia prevenir o aparecimento de mais de um terço dos casos de obesidade.

O consumo de álcool não apresentou associação com estado nutricional, o que é consistente com achados que não encontraram nenhuma variação no estado nutricional com a ingestão de bebida alcoólica (GOODWIN 1989), entretanto, esse dado é contraditório com os achados de outros estudos (MORLEY 1997). 


\section{CONCLUSÕES}

Em relação aos fatores sócioeconômicos e demográficos, para ambos os gêneros, idade manteve relação direta com o baixo peso e inversa com a obesidade, mulheres asiáticas associaram-se com o baixo peso, enquanto homens indígenas com a obesidade, mulheres menos escolarizadas relacionaram-se com ambos os distúrbios nutricionais, e homens mais pobres mantiveram relação tanto com baixo peso quanto com obesidade.

A hipótese central deste estudo de que apoio social associa-se positivamente foi confirmada apenas parcialmente. Em relação às redes sociais, concluiu-se que baixas freqüências de contatos aumentam as chances de ocorrência de baixo peso nas mulheres, mas não para os homens, e que, para ambos os gêneros, ter uma rede social menos diversificada não têm influência sobre o baixo peso, nem sobre a obesidade. $O$ casamento mostrou efeitos diversificados: protetor para baixo peso (mulheres separadas/divorciadas), prejudicial para a obesidade (mulheres casadas) e nenhum efeito (homens)

No que diz respeito às variáveis de estilo de vida, homens e mulheres que fumavam foram associados com o baixo peso e no caso das mulheres, também com obesidade (relação inversa); as mulheres, que responderam não praticar atividade fisica, tinham aumentadas as chances de obesidade.

Indicar com precisão as características de idosos sob risco de distúrbios nutricionais pode facilitar o desenvolvimento de programas para tratar ou prevenir tais distúrbios. Ainda existem poucos estudos, específicos para idosos, sobre determinantes do estado nutricional e, portanto, além das contribuições que podem ser sugeridas por 
este estudo, outros estudos que incluam outras dimensões devem ser realizados. Aspectos como trocas sociais, avaliação subjetiva de apoio emocional e/ou instrumental e as interações negativas devem ser acrescentados em pesquisas futuras para verificar e explicar outros efeitos de fatores relacionados às redes sociais que podem modificar 0 estado nutricional dessa população.

\section{REFERÊNCIAS}

American Academy of Family Physicians, The American Dietetic Association, National Council On The Aging Inc. (AAFP, ADA, NCAI). Incoporating nutrition screening and interventions into medical practice. 1994. (A Monograph for physicians).

Andres R, Muller DC, Sorkin JD. Long-term effects of change in body weight on allcause mortality. Ann Intern Med 1993 119:737-43.

Chen LH. Nutritional aspects of aging. Boca Raton: CRC Press, 1986. Part II, p.76115.

Chilima DM, Ismail SJ. Anthropometric characteristics of older people in rural Malawi. Euro J Clin Nutr 1998; 52:643-49. 
Cornoni-Huntley JC, Harris TB, Everett DF, Albanes D, Micozzi MS, Miles TP, et al. An overview of body weight of older persons, including the impact on mortality. $\mathbf{J}$ Clin Epidemiol, 1991, 743-53.

Dean K, Holst E, Kreiner S, Schoenborn C, Wilson R. Measurement issues in research on social support and health. J Epidemiol Community Health.1994. 48:201-6.

Eck LH, Hackett-Renner C, Klesges LM. Impact of diabetic status, dietary intake, physical activity, and smoking status on body mass index in NHANES II. Am J Clin Nutr 1992;56:329-33.

Edington j, Boorman j, Durrant ER, Perkins A, Giffin CV James R, et al. Prevalence of malnutrition on admission to four hospitals in England. The malnutrition prevalence group. Clin Nutr 2000;19: 191-5.

Giay T, Khoi HH. Use of body mass index in the assessment of adult nutritional status in Vietnam. Euro J Clin Nutr 1994; 48, Suppl. 3:S124-S30.

Goodwin JS. Social, psychological and physical factors affecting the nutritional status of elderly subjects: separating cause and effect. Am J Clin Nutr 1989;50:1201-9.

Greenspar SL, Myers ER, Maitland LA, Resnick NM, Hayes WC. Fall severity and bone mineral density as risk factors for hip fracture in anbulatory elderly. JAMA 1994;271:128-33. 
Hosmer DM, Lemeshow S. Applied logistic regression. New York: John Wiley \& Sons; 1989.

Kelsey K, Earp JA, Kirkley BG. Is social support beneficial for dietary chage? A review of the literature. Fam Community Health 1997; 20(3): 70-82.

Krondl M, Lau D, Yurkiw MA, Coleman PH. Food use and perceived food meanings of the elderly. J Am Diet Assoc 1982; 80:523-9.

Launer LJ, Harris T, Rumpel C, Madans J. Body mass index, Weight change, and risk of mobility disability in middle-aged and older women. JAMA 1994; 271:1093-98.

Lund R, Modvig J, Due P, Holstein BE. Stability and change in structural social relations as preditor of mortality among elderly women and men. Euro $\mathbf{J}$ Epidemiol 2000; 16: 1087-97.

Mann GV. The influence of obesity on health. N Eng J Med 1974; 178-85.

McIntosh WA, Shifflett PA, Picou J. Social support, stressful events, strain, dietary intake, and the elderly. Med Care 1989; 27:140-53.

Messner RL, Stephens N, Wheeler WE, Hawes MC. Effect of admission nutritional status on length of hospital stay. Gastroenterol Nurs 1991, 202-205. (referido no nutrition screening) 
Monteiro CA, Mondini L, Souza ALM, Popkin BM. Da desnutrição para a obesidade: a transição nutricional no Brasil. In Monteiro CA (org). Velhos e novos males da saúde no Brasil. 2000; p. 247-55.

Monteiro CA. Epidemiologia da obesidade. In: Halpern A, Matos AFG, Suplicy HL, Mancini MC, Zanella MT. Obesidade.São Paulo:Lemos Editorial; 1998. p.15-30.

Morley JE. Anorexia of aging: physiologic and pathologic. Am J Clin Nutr 1997; 66:760-73.

Naidu AN, Rao NP. Body mass index: a measure of the nutritional status in Indian populations. Euro J Clin Nutr 1994; 48, Suppl. 3:S131-S40.

Organização Pan-Americana (OPAS). XXXVI Reunión del Comitê Asesor de Investigaciones en Salud - Encuesta Multicêntrica - Salud Bienestar y Envejecimiento (SABE) en América Latina e el Caribe - Informa preliminar. Disponível em <URL: http://www.opas.org/program/sabe.htm.> (mar.2002).

Rissanen A, Heliövaara M, Knekt P, Aromaa A, Reunanen A, Maatela J. Weigth and mortality in Finnish men. J Clin Epidemiol 1989; 781 -89.

Rissanen A, Knekt P, Heliövaara M, Aromaa A, Reunanen A, Maatela J. Weigth and mortality in Finnish women. J Clin Epidemiol 1991; 787-95. 
Sarlio-Lähteekorva S, Lahelma E. The association of body mass index with social and economic disadvantage in women and men. Int J Epidemiol. 1999; 28:445-9.

Silva NN. Aspectos metodológicos - Processo de amostragem. In: Lebrão ML, Duarte YAO. SABE - Saúde, Bem-estar e Envelhecimento - O projeto SABE no município de São Paulo: uma abordagem inicial. Brasília: Organização Pan-Americana de Saúde, 2003, p.47-57.

Song Y, Sung J. Body mass index and mortality: a twelve-year prospective study in Korea. Epidemiol 2001; 12:173-79

Sundquist J, Johansson S. The influence of socio economic status, ethnicity and lifestyle on body mass index in a longitudinal study. Int J Epidemiol 1998; 57-63.

Tavares EL Anjos LA. Perfil antropométrico da população idosa brasileira. Resultados da Pesquisa Nacional sobre Saúde e Nutrição. Cad Saúde Pública 1999; 15: 759-68.

Umberson D. Gender, marital status and the social control of health behavior. Soc Sci Med 1992; 8:907-17.

Van Itallie TB. Obesity: adverse effects on health and logevity. Am J Clin Nutr 1979; 2732-3

Victora CG, Hutly SR, Fuchs SC, Olinto MTA. The role of conceptual frameworks in epidemiological anlysis: a hierarquical approach. Int J Epideiol 1997; 26:224-7. 
Winkleby MA, Gardner CD, Taylor CB. The influence of gender and socioeconomic factors on Hispanic/white differences in body mass index. Prev Med. 1996;25:203-11.

World Health Organizacion. Physical status: the use and interpretation of anthropometry. Geneva: WHO; 1995. (Technical Report Series, 854). 
Figura 1 - Referencial teórico para a investigação dos fatores determinantes do estado nutricional do idoso, estruturados em níveis hierarquizados.

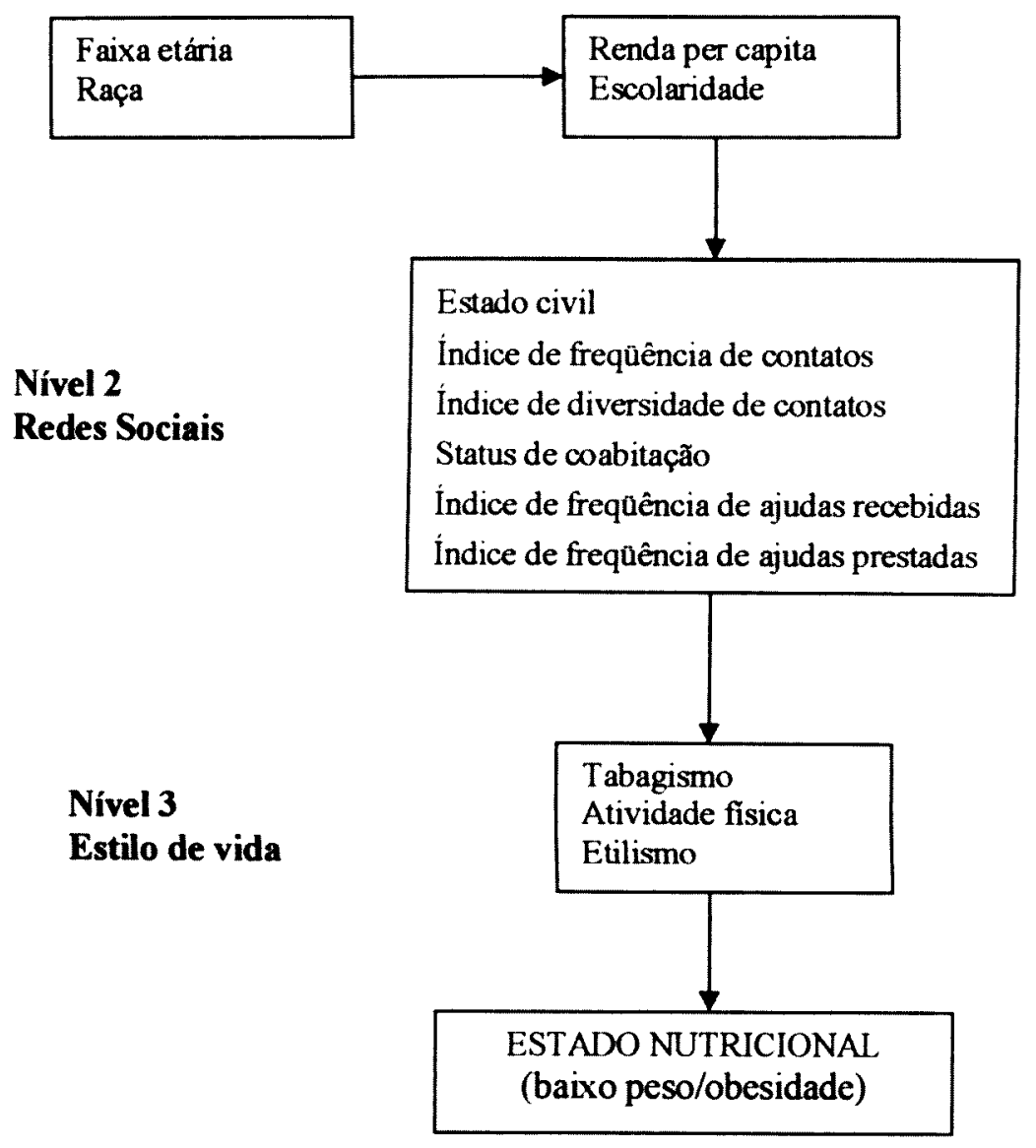

Nível 1

Demográfico e Sócioeconômico 
Tabela 1 - Prevalência de baixo peso e sua associação com os fatores sócioeconômicos - razão de chances (RC) bruta, intervalo de confiança (IC 95\%) e significância.

\begin{tabular}{|c|c|c|c|c|c|c|}
\hline \multirow[b]{2}{*}{ Variáveis (\%) } & \multicolumn{3}{|c|}{ Mulheres } & \multicolumn{3}{|c|}{ Homens } \\
\hline & $\mathrm{N}$ & $\%$ & $\mathrm{RC}$ [IC 95\%] & $\mathbf{N}$ & $\%$ & $\mathrm{RC}$ [IC 95\%] \\
\hline \multicolumn{7}{|l|}{ Faira etária } \\
\hline $60-64$ & 220 & 14,8 & 1 & 155 & 19,8 & 1 \\
\hline $65-69$ & 204 & 17,8 & $1,17[0,67-2,06]$ & 104 & 16,4 & $0,74[0,37-1,46]$ \\
\hline $70-74$ & 180 & 20,7 & $1,83[1,03-3,25]$ & 108 & 29,6 & $1,93[1,05-3,56]$ \\
\hline $75-79$ & 232 & 22,6 & $1,63[0,95-2,80]$ & 180 & 27,6 & $1,64[0,96-2,79]$ \\
\hline $80+$ & 227 & 29,5 & $2,01[1,19-3,38]$ & 185 & 45,4 & $2,84[1,71-4,73]$ \\
\hline$p^{1}$ & & & 0,049 & & & $<0,0001$ \\
\hline$p^{2}$ & & & 0,004 & & & $<0,0001$ \\
\hline \multicolumn{7}{|l|}{ Rapa } \\
\hline Branca & 737 & 16,5 & 1 & 520 & 21,9 & 1 \\
\hline Negra/mulata & 178 & 25,0 & $1,39[0,89-2,17]$ & 11 & 26,3 & $1,37[0,85-2,19]$ \\
\hline Indigena/mestiça & 94 & 19,5 & $1,20[0,69-2,09]$ & 55 & 31,8 & $0,96[0,49-1,89]$ \\
\hline Asiática & 39 & 40,2 & $3,10[1,48-6,49]$ & 37 & 27,8 & $1,37[0,67-2,81]$ \\
\hline Outra & 9 & (a) & $3,30[0,56-20,16]$ & 2 & (a) & $?$ \\
\hline$p$ & & & 0,022 & & & 0,621 \\
\hline \multicolumn{7}{|l|}{ Escolaridade } \\
\hline $5+$ & 161 & 17,7 & 1 & 158 & 19,4 & 1 \\
\hline 4 & 317 & 16,1 & $0,91[0,54-1,54]$ & 196 & 24,0 & $0,85[0,52-1,39]$ \\
\hline $1-3$ & 245 & 19,9 & $1,51[0,89-2,56]$ & 207 & 19,8 & $0,72[0,44-1,18]$ \\
\hline Nunca foi à escola & 282 & 24,4 & $1,64[0,98-2,77]$ & 164 & 34,3 & $1,54[0,94-2,55]$ \\
\hline$p^{\prime}$ & & & 0,023 & & & 0,013 \\
\hline $\mathrm{p}^{2}$ & & & 0,006 & & & 0,147 \\
\hline \multicolumn{7}{|l|}{ Renda } \\
\hline $3^{\circ}$ e $4^{\circ}$ quartil & 407 & 20,5 & 1 & 383 & 19,1 & 1 \\
\hline $2^{\circ}$ quartil & 184 & 19,1 & $0,89[0,55-1,43]$ & 163 & 30,5 & $1,60[1,05-2,43]$ \\
\hline $1^{\circ}$ quartil & 251 & 19,4 & $0,83[0,54-1,27]$ & 66 & 42,8 & $2,42[1,36-4,29]$ \\
\hline $\mathbf{p}^{1}$ & & & 0,687 & & & 0,004 \\
\hline $\mathrm{p}^{2}$ & & & 0,392 & & & $<0,001$ \\
\hline Total & 1063 & 19,3 & & 732 & 23,7 & \\
\hline
\end{tabular}

(a) Percentuais não apresentados devido ao pequeno número de casos nessa categoria. 
Tabela 2 - Prevalência de baixo peso e sua associação com os fatores de redes sociais (indice de freqüência de contatos - IFC, índice de diversidade de contatos - IDC, status de coabitação, índice de freqüência de ajudas recebidas - IFAR e índice de ajudas prestadas - IFAP) e de estilo de vida - razão de chances (RC) bruta, intervalo de confiança (IC 95\%) e significância.

\begin{tabular}{|c|c|c|c|c|c|c|}
\hline \multirow[b]{2}{*}{ Variáveis (\%) } & \multicolumn{3}{|c|}{ Mulheres } & \multicolumn{3}{|c|}{ Homens } \\
\hline & $\mathrm{N}$ & $\%$ & RC [IC 95\%] & $\mathrm{N}$ & $\%$ & RC [IC 95\%] \\
\hline \multicolumn{7}{|l|}{ Estado civil } \\
\hline Casado & 394 & 16,4 & 1 & 543 & 23,0 & 1 \\
\hline Solteiro & 59 & 18,8 & $1,01[0,50-2,06]$ & 26 & 18,5 & $0,94[0,37-2,37]$ \\
\hline Separado/divorc. & 95 & 263 & $2,01[1,15-3,52]$ & 46 & 17,8 & $0,98[0,46-2,09]$ \\
\hline Viúvo & 514 & 20,5 & $1,24[0,86-1,80]$ & 117 & 36,1 & $1,67[1,08-2,58]$ \\
\hline $\mathrm{p}$ & & & 0,097 & & & 0,140 \\
\hline \multicolumn{7}{|l|}{ IFC } \\
\hline Alta freqüência & 824 & 182 & 1 & 529 & 23,9 & 1 \\
\hline Baixa frequeência & 232 & 23,7 & $1,54[1,06-225]$ & 196 & 23,7 & $0,88[0,60-1,30]$ \\
\hline p & & & 0,026 & & & 0,534 \\
\hline Grande diversidade & 951 & 18,9 & 1 & 637 & 22,3 & 1 \\
\hline Pequena diversidade & 105 & 23,5 & $1,43[0,85-2,40]$ & 88 & 35,6 & $1,68[1,01-2,78]$ \\
\hline \multicolumn{7}{|l|}{$\begin{array}{l}\text { Status de } \\
\text { combitapalo }\end{array}$} \\
\hline Não mora só & 852 & 20,3 & 1 & 662 & 23,8 & 1 \\
\hline Mora só & 211 & 14,4 & $0,77[0,50-1,19]$ & 70 & 22,3 & $1,23[0,71-2,14]$ \\
\hline \multicolumn{7}{|l|}{ IFAR } \\
\hline Alta frequência & 711 & 21,1 & 1 & 572 & 23,6 & 1 \\
\hline Baixa frequência & 261 & 152 & $0,76[0,50-1,13]$ & 97 & 23,6 & $1,25[0,76-2,05]$ \\
\hline IFAP & & & 0,178 & & & 0,385 \\
\hline Alta frequêencia & 758 & 18,9 & 1 & 533 & 23,8 & 1 \\
\hline Baixa frequeencia & 201 & 20,8 & $\begin{array}{c}1,25[0,85-1,86] \\
0,260\end{array}$ & 140 & 23,1 & $\begin{array}{c}1,35[0,88-2,06] \\
0,171\end{array}$ \\
\hline \multicolumn{7}{|l|}{ Tabagismo } \\
\hline Nunca fumou & 782 & 17,1 & 1 & 200 & 20,2 & 1 \\
\hline Fumou, parou & 177 & 17,5 & $1,19[0,76-1,88]$ & 390 & 18,7 & $0,82[0,55-1,24]$ \\
\hline Fuma atualmente & 104 & 36,0 & $2,11[1,31-3,41]$ & 282 & 39,3 & $1,77[1,10-2,85]$ \\
\hline $\begin{array}{l}\text { p } \\
\text { Atividade fisica }\end{array}$ & & & 0,009 & & & 0,002 \\
\hline Sim & 231 & 18,0 & 1 & 92 & 21,2 & 1 \\
\hline Nåo & 832 & 19,7 & $1,31[0,88-1,95]$ & 54 & 24,9 & $1,59[1,07-2,36]$ \\
\hline $\begin{array}{l}\mathrm{p} \\
\text { Consumo de } \\
\text { bebida alcólica }\end{array}$ & & & 0,185 & & & 0,022 \\
\hline Não & 859 & 19,8 & 1 & 129 & 27,1 & 1 \\
\hline Sim & 204 & 17,3 & $0,81[0,52-124]$ & 83 & 20,0 & $0,78 \underset{0,55-1,10]}{[0,59}$ \\
\hline
\end{tabular}


Tabela 3 - Prevalência de obesidade e sua associação com os fatores sócioeconômicos - razão de chances (RC) bruta, intervalo de confiança (IC 95\%) e significância.

\begin{tabular}{|c|c|c|c|c|c|c|}
\hline \multirow[b]{2}{*}{ Variáveis (\%) } & \multicolumn{3}{|c|}{ Mulheres } & \multicolumn{3}{|c|}{ Homens } \\
\hline & $\mathrm{N}$ & $\%$ & $\mathrm{RC}$ [IC 95\%] & $N$ & $\%$ & $\mathrm{RC}$ [IC 95\%] \\
\hline \multicolumn{7}{|l|}{ Faixa etária } \\
\hline $80+$ & 227 & 22,3 & 1 & 185 & 03,9 & 1 \\
\hline $75-79$ & 232 & 25,9 & $1,31[0,81-2,10]$ & 180 & 09,9 & $2,47[0,99-6,15]$ \\
\hline $70-74$ & 180 & 30,2 & $1,73[1,05-2,85]$ & 108 & 13,8 & $3,86[1,47-10,11]$ \\
\hline $65-69$ & 204 & 25,3 & $1,13[0,70-1,83]$ & 104 & 13,0 & $2,66[1,02-6,95]$ \\
\hline $60-64$ & 220 & 34,7 & $1,79[1,13-2,82]$ & 155 & 10,0 & $1,99[0,78-5,12]$ \\
\hline$p^{1}$ & & & 0,061 & & & 0,091 \\
\hline$p^{2}$ & & & 0,048 & & & 0,297 \\
\hline \multicolumn{7}{|l|}{ Raca } \\
\hline Branca & 737 & 30,4 & 1 & 520 & 09,1 & 1 \\
\hline Negra/mulata & 178 & 27,6 & $1,14[0,76-1,72]$ & 11 & 13,1 & $1,34[0,65-2,75]$ \\
\hline Indígena/mestiça & 94 & 24,6 & $0,74[0,50-1,11]$ & 55 & 20,7 & $2,43[1,13-5,21]$ \\
\hline Asiática & 39 & 13,7 & $0,53[0,19-1,51]$ & 37 & 2,9 & $0,31[0,04-2,38]$ \\
\hline Outra & 9 & (a) & $2,08[0,35-12,43]$ & 2 & (a) & $?$ \\
\hline $\begin{array}{l}\text { p } \\
\text { Escolaridade }\end{array}$ & & & 0.431 & & & 0,127 \\
\hline $5+$ & 161 & 28,1 & 1 & 158 & 08,8 & 1 \\
\hline 4 & 317 & 28,9 & $1,23[0,77-1,96]$ & 196 & 11,5 & $1,15[0,56-2,40]$ \\
\hline $1 \cdot 3$ & 245 & 30,4 & $1,61[0,99-2,60]$ & 207 & 09,8 & $0,80[0,37-1,71]$ \\
\hline Nunca foi à escola & 282 & 28,2 & $1,41[0,87-2,30]$ & 164 & 15,1 & $1,34[0,34-1,62]$ \\
\hline$p^{1}$ & & & 0,237 & & & 0,551 \\
\hline$p^{2}$ & & & 0,106 & & & 0,760 \\
\hline \multicolumn{7}{|l|}{ Renda } \\
\hline $3^{\circ}$ e $4^{\circ}$ quartil & 407 & 29,6 & 1 & 383 & 13,0 & 1 \\
\hline $2^{\circ}$ quartil & 184 & 27,5 & $0,94[0,61-1,46]$ & 163 & 05,9 & $0,46[0,21-1,01]$ \\
\hline $1^{\circ}$ quartil & 251 & 27,2 & $0,94[0,64-1,38]$ & 66 & 10,7 & $?$ \\
\hline$p^{1}$ & & & 0,939 & & & 0,149 \\
\hline $\mathrm{p}^{2}$ & & & 0740 & & & 0,324 \\
\hline Total & 1063 & 29,0 & & 732 & 10,9 & \\
\hline
\end{tabular}

(a) Percentuais não apresentados devido ao pequeno número de casos nessa categoria. 
Tabela 4 - Prevalência de obesidade e sua associação com os fatores de redes sociais (índice de freqüência de contatos - IFC, índice de diversidade de contatos - IDC, status de coabitação, índice de freqüência de ajudas recebidas - IFAR e índice de ajudas prestadas - IFAP) e estilo de vida - razão de chances (RC) bruta, intervalo de confiança (IC 95\%) e significância.

Homens

\begin{tabular}{|c|c|c|c|c|c|c|}
\hline Variáveis (\%) & $\mathrm{N}$ & $\%$ & $\mathrm{RC}$ [IC 95\%] & $\mathrm{N}$ & $\%$ & $\mathrm{RC}[\mathrm{IC} 95 \%]$ \\
\hline \multicolumn{7}{|l|}{ Estado civil } \\
\hline Casado & 394 & 32,2 & 1 & 543 & 10,5 & 1 \\
\hline Solteiro & 59 & 20,8 & $0,36[0,17-0,79]$ & 26 & 09,4 & $0,72[0,16-3,26]$ \\
\hline Separado/divorc. & 95 & 19,7 & $0,64[0,35-1,16]$ & 46 & 16,5 & $1,69[0,69-4,16]$ \\
\hline Viúvo & 514 & 28,9 & $0,86[0,62-1,18]$ & 117 & 10,6 & $0,66[0,29-1,52]$ \\
\hline $\mathbf{p}$ & & & 0,049 & & & 0,437 \\
\hline \multicolumn{7}{|l|}{ IFC } \\
\hline Alta freqüencia & 824 & 29,8 & 1 & 529 & 12,1 & 1 \\
\hline Baixa freqüência & 232 & 25,8 & $0,95[0,66-1,38]$ & 196 & 08,4 & $0,80[0,44-1,44]$ \\
\hline & & & 0,800 & & & 0,461 \\
\hline \multicolumn{7}{|l|}{ IDC } \\
\hline Grande diversidade & 951 & 29,2 & 1 & 637 & 11,0 & 1 \\
\hline Pequena diversidade & 105 & 27,1 & $1,04[0,63-1,74]$ & 88 & 11,5 & $1,50[0,71-3,17]$ \\
\hline & & & 0,872 & & & 0,291 \\
\hline \multicolumn{7}{|l|}{$\begin{array}{l}\text { Status de } \\
\text { coabitaciao }\end{array}$} \\
\hline Não mora só & 852 & 28,4 & 1 & 662 & 10,9 & 1 \\
\hline Mora só & 211 & 31,8 & $0,98[0,68-1,41]$ & 70 & 112 & $0,74[0,28-1,96]$ \\
\hline & & & 0,898 & & & 0,553 \\
\hline \multicolumn{7}{|l|}{ IFAR } \\
\hline Alta freqüência & 711 & 28,4 & 1 & 572 & 11,1 & 1 \\
\hline Baixa frequêencia & 261 & 33,8 & $1,16[0,82-1,63]$ & 97 & 12,6 & $1,00[0,47-2,16]$ \\
\hline \multicolumn{7}{|l|}{ IFAP } \\
\hline Alta freqüência & 758 & 30,0 & 1 & 533 & 11,2 & 1 \\
\hline \multirow[t]{2}{*}{ Baixa freqüência } & 201 & 25,3 & $0,78[0,53-1,15]$ & 140 & 11,9 & $0,95[0,48-1,88]$ \\
\hline & & & 0,210 & & & 0,890 \\
\hline \multicolumn{7}{|l|}{ Tabagismo } \\
\hline Nunca fumou & 782 & 30,8 & 1 & 200 & 14,4 & 1 \\
\hline Fumou, parou & 177 & 31,4 & $0,97[0,65-1,46]$ & 390 & 11,8 & $1,01[0,57-1,79]$ \\
\hline Fuma atualmente & 104 & 13,5 & $0,52[0,29-0,95]$ & 282 & 05,0 & $0,54[0,22-1,53]$ \\
\hline & & & 0,105 & & & 0,343 \\
\hline \multicolumn{7}{|l|}{ Atividade fisica } \\
\hline Sim & 231 & 23,1 & 1 & 92 & 08,1 & 1 \\
\hline Não & 832 & 30,9 & $1,54[1,06-2,23]$ & 54 & 12,2 & $1,61[0,88-2,97]$ \\
\hline & & & 0,023 & & & 0,125 \\
\hline \multicolumn{7}{|l|}{$\begin{array}{l}\text { Consumo de } \\
\text { bebida alcoblica }\end{array}$} \\
\hline Não & 859 & 27,5 & 1 & 129 & 10,3 & 1 \\
\hline $\operatorname{Sim}$ & 204 & 34,7 & $1,19[0,83-1,71]$ & 83 & 11,7 & $1,44[0,86-2,40]$ \\
\hline $\mathrm{p}$ & & & 0,358 & & & 0,163 \\
\hline
\end{tabular}


Tabela 5. Fatores associados com o baixo peso dos idosos - regressão logística múltipla hierarquizada - razão de chances (RC), intervalo de confiança (IC 95\%) e significância.

\begin{tabular}{|c|c|c|c|c|c|}
\hline \multirow[b]{2}{*}{ Modelos } & \multicolumn{2}{|c|}{ Mulheres } & \multicolumn{3}{|c|}{ Homens } \\
\hline & Variáveis & $\mathrm{RC}$ [IC 95\%] & $\begin{array}{c}\text { Valor de } \\
\mathrm{p}\end{array}$ & RC [IC 95\%] & $\begin{array}{c}\text { Valor de } \\
\mathrm{p}\end{array}$ \\
\hline \multirow[t]{19}{*}{ Nivel 1} & $\begin{array}{l}\text { Faira etária } \\
60-64\end{array}$ & 1 & & 1 & \\
\hline & $65-69$ & $1,22[0,68-2,18]$ & $0,011^{(1)}$ & $0,78[0,37-1,65]$ & $<0,001^{(1)}$ \\
\hline & $70-74$ & $1,88[1,03-3,42]$ & & $2,04[1,00-4,16]$ & \\
\hline & $75-79$ & $1,71[0,97-2,99]$ & & $1,56[0,85-2,88]$ & \\
\hline & $80+$ & $1,92[1,10-3,34]$ & & $2,74[1,51-4,97]$ & \\
\hline & Raça & & & & \\
\hline & Branca & 1 & & & \\
\hline & Negra/mulata & $1,31[0,82-2,08]$ & 0,014 & $\partial$ & \\
\hline & Indigena/mestiça & $1,14[0,64-2,04]$ & & & \\
\hline & Asiatica & $3,56[1,65-7,67]$ & & & \\
\hline & Outra & $3,51[0,55-22,26]$ & & & \\
\hline & Escolaridade & & & & \\
\hline & $5+$ & 1 & & 1 & \\
\hline & 4 & $0,92[0,53-1,06]$ & $0,029^{(1)}$ & $0,72[0,40-0,91]$ & 0,037 \\
\hline & $1-3$ & $1,55[0,89-2,70]$ & & $0,51[0,29-0,91]$ & \\
\hline & Nunca foi à escola & $1,51[0,86-2,65]$ & & $1,03[0,57-1,86]$ & \\
\hline & Renda & & & 1 & \\
\hline & $\begin{array}{l}3^{\circ} \text { e } 4^{\circ} \text { quartil } \\
2^{\circ} \text { quartil }\end{array}$ & $\partial$ & & $\frac{1}{1}$ & $\operatorname{lng}^{(1)}$ \\
\hline & $1^{\circ}$ quartil & & & $\begin{array}{l}1,4][0,44-2,30] \\
2,55[1,38-4,70]\end{array}$ & 0,002 \\
\hline \multirow[t]{10}{*}{ Nivel 2} & Estado civil & & & & \\
\hline & Casado & 1 & & & \\
\hline & Solteiro & $0,89[0,42-1,90]$ & 0,037 & \# & \\
\hline & Separado/divorc. & $2,28[1,25-4,16]$ & & & \\
\hline & Viúvo & $1,05[0,69-1,60]$ & & & \\
\hline & IFC & & & & \\
\hline & Alta freqüĉncia & 1 & 0.058 & $\partial$ & \\
\hline & $\begin{array}{l}\text { Baixa frequência } \\
\text { IDC }\end{array}$ & $1,48[0,99-2,21]$ & & & \\
\hline & Grande diversidade & $\partial$ & & 1 & 0,137 \\
\hline & & & & $1,56[0,87-2,81]$ & \\
\hline \multirow[t]{9}{*}{ Nivel 3} & Tabagismo & & & & \\
\hline & Nunca fumou & 1 & & 1 & \\
\hline & Fumou, parou & $1,10[0,67-1,82]$ & 0,029 & $0,80[0,49-1,30]$ & $<0,001$ \\
\hline & $\begin{array}{l}\text { Fuma atualmente } \\
\text { A tividade fisica }\end{array}$ & $2,05[1,20-3,49]$ & & $2,41[1,34-4,34]$ & \\
\hline & Sim & $\partial$ & & \# & \\
\hline & Năo & & & & \\
\hline & $\begin{array}{l}\text { Consumo de bebida } \\
\text { alcoolica }\end{array}$ & $\partial$ & & & \\
\hline & Não & & & 1 & 0,068 \\
\hline & Sim & & & $0.67[0,44-1,03]$ & \\
\hline
\end{tabular}

(1) $p$ tendência linear $\partial$ Variável retirada na análise univariada por apresentar $p>0,20$

\# Variável retirada na análise múltipla por apresentar $p>020$.

Nivel 1: mulheres - ajustado para faixa etária e escolaridade; homens - ajustado para faixa etária, raça, escolaridade e renda.

Nivel 2: mulheres - nivel 1 + estado civil e IFC; homens nível 1 + IDC

Nivel 3: mulheres - nivel 2 + tabagismo; homens - nivel 2 + tabagismo e consumo de bebida alcoólica 
Tabela 6 - Fatores associados com a obesidade dos idosos - regressão logística múltipla hierarquizada - razão de chances (RC), intervalo de confiança (IC 95\%) e significância.

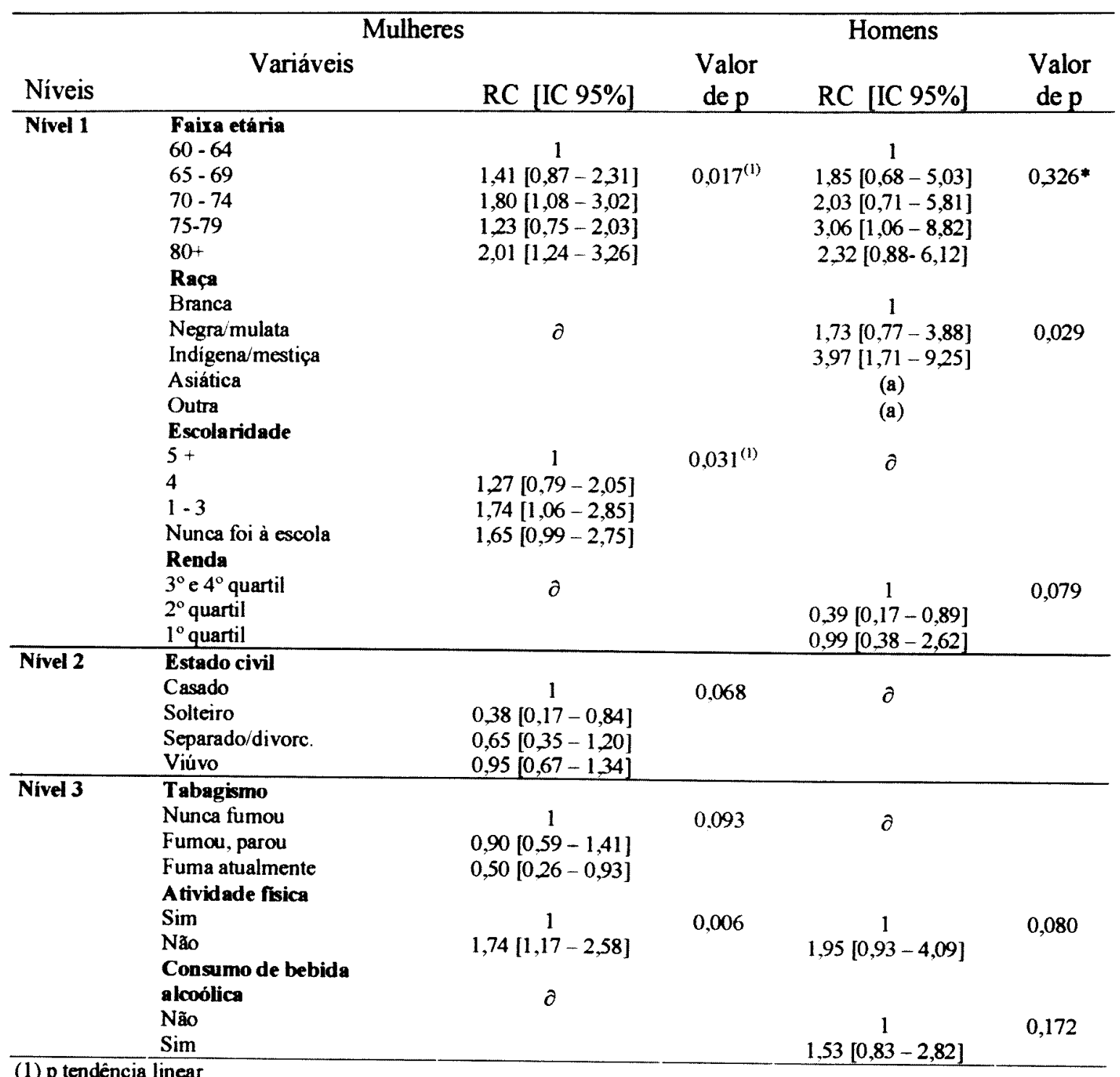

$\partial$ Variável retirada na análise univariada por apresentar $p>0,20$.

(a) RC não foi calculado devido ao pequeno número de casos nessa categoria

* Faixa etária foi mantida nos modelos subseqüentes como variável de controle por apresentar significância menor que 0,05 na faixa 65-69 anos.

Nivel 1: mulheres - ajustado por faixa etária e escolaridade; homens - ajustado por faixa etária, raça e renda.

Nivel 2: mulheres - nivel 1 + estado civil; homens - nenhuma variável do bloco de apoio social foi mantido.

Nivel 3: mulheres - nivel 2 + tabagismo e atividade fisica; homens - nivel 1 + atividade física e consumo de bebida alcoólica. 


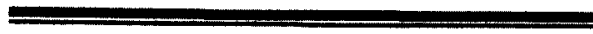

CONCLUSÕES GERAIS 
1. Existem poucas dúvidas de que variáveis relacionadas às redes sociais de apoio são preditoras de saúde. A despeito dessas evidências e do enorme interesse na consideração das relações sociais como determinantes da saúde, ainda falta consenso acerca da sua conceituação e operacionalização. A maioria dos investigadores da área tem concluído que rede social de apoio é um constructo multidimensional e têm descrito diferentes tipos ou categorias de redes de apoio social que devem ser consideradas e que podem ter diferentes conseqüências para a saúde física e mental dos indivíduos.

2. Tendo como objetivo investigar os diferenciais nas redes sociais de apoio em idosos do Município de São Paulo, este estudo analisou parte do banco de dados do Projeto SABE, homens e mulheres de mais de 60 anos de idade, separadamente. Os resultados sugerem que idade, estado civil, renda per capita e escolaridade estão associados com as redes sociais de apoio entre os idosos. Entretanto, essas relações manifestam-se de modos desiguais entre gêneros, nas diferentes características sóciodemográficas e nas diversas dimensões da rede. Um desses resultados que vale ser ressaltado, entre outros, é a condição dos idosos residindo em domicílios multigeracionais, aparentemente mais incapacitados funcionalmente e dependendo exclusivamente do apoio informal prestado pela família. Ações com vistas à prevenção e promoção de saúde desta população, poderiam ser orientadas tendo o domicílio multigeracional como um indicador de saúde, que poderia ser capaz de identificar idosos com alto risco de perda funcional. Uma intervenção específica de apoio a esses idosos e seus familiares poderia ser planejada com participação das Unidades Básicas de Saúde sob a estratégia dos Programas de Saúde da Família.

Finalmente, sugere-se outros estudos desta população que incluam dimensões qualitativas das redes sociais de apoio, como avaliações subjetivas do apoio, e aspectos 
negativos como conflitos e tensões, fatores não abrangidos neste estudo, que se revelaram importantes para os idosos.

3. Com base nos conhecimentos que vêm se acumulando sobre as relações entre redes sociais de apoio e saúde física e mental, sugere-se que a rede social teria os mesmos efeitos positivos para o estado nutricional que tem para a saúde geral. Entretanto na pesquisa realizada com idosos (60 anos e mais) no Município de São Paulo (Projeto SABE), a hipótese central de que rede social de apoio associa-se positivamente com estado nutricional foi confirmada apenas parcialmente. Concluiu-se que baixas freqüências de contatos aumentam as chances de ocorrência de baixo peso nas mulheres, mas não nos homens. Conclui-se também que, para ambos os gêneros, ter uma rede social menos diversificada não têm influência sobre o baixo peso nem sobre a obesidade. $\mathrm{O}$ casamento mostrou efeitos variados: protetor para baixo peso (mulheres separadas/divorciadas), prejudicial para a obesidade (mulheres casadas) e nenhum efeito (homens).

Uma questão pode ser colocada no que diz respeito ao delineamento da pesquisa. Estudos seccionais onde fatores e efeitos são observados no mesmo momento histórico impede a demarcação da seqüência temporal. Esta limitação metodológica compromete as evidências de relação causal entre os fatores aqui estudados e o estado nutricional. Isso implica em que não seja possível afirmar com certeza, por exemplo, que baixas freqũências de contatos causaram o baixo peso nas mulheres, pois tanto essa afirmação, quanto a de que o estado nutricional influenciou a diminuição de contatos com outras pessoas podem ser verdadeiras. Pode-se afirmar, ainda, que um terceiro fator não estudado pode ser responsável por tal distúrbio nutricional. 


\section{BIBLIOGRAFIA}

American Academy Of Family Physicians, The American Dietetic Association, National Council On The Aging Inc. (AAFP, ADA, NCAI). Incoporating nutrition screening and interventions into medical practice. 1994. (A Monograph for physicians).

Andres R, Muller DC, Sorkin JD. Long-term effects of change in body weight on allcause mortality. Ann Intern Med 1993 119:737-43.

Barrera M Jr. Distinctions between social support: concepts, measures, and models. Am J Community Psychol. 1986; 14:117-28.

Bazo MT, Oñate CM. Sociologia de la vejez. In: Bazo MT (coord.). Envejecimiento y sociedad: una perspectiva internacional. Madri: Editorial Medica Panamericana; 1999. p. 47-102.

Benzeval M. The self-reported health status of alone parents. Soc Sci Med. 1998; 46:1337-53.

Berkman LF, Glass T, Brissette I, Seeman TE. From Social integration to health: Durkheim in the new millennium. Soc Sci Med. 2000; 51:843-57.

Berkman LF, Syme SL. Social networks, host resistance, and mortality: a nine-year follow-up study of Alameda County residents. Am J Epidemiol. 1979; 186-204. 
Borkan GA, Hults DE, Stephen GG, Robbins AH, Silbert CK. Age changes in body composition revealed by computed tomography. J Gerontol 1983; 38:673-7.

Burr ML, Phillips KM. Anthropometric norms in the elderly. Brit J Nutr 1984, 51:1659.

Cassel J. The contribution of the social enviroment to host resistance. Am J Epidemiol. $1976,107-23$.

Castro R, Campero L, Hernández B. La investigación sobre apoyo social en salud: situación actual y nuevos desafios. Rev Saúde Pública. 1997; 4: 425-35.

Cattell V. Poor people, poor places, and poor health: the mediating role of social networks and social capital. Soc Sci Med. 2001, 52:1 501-16.

Ceria CD, Masaki KH, Rodriguez BL, Chen R, Yano K, Curb JD. The relationship of psychosocial factors to total mortality among older Japanese-American men: the Honolulu heart program. Am J Geriatr Soc. 2001; 49:725-31.

Chen LH. Nutritional aspects of aging. Boca Raton: CRC Press, 1986. Part II, p.76115.

Chilima DM, Ismail SJ. Anthropometric characteristics of older people in rural Malawi. Euro J Clin Nutr 1998; 52:643-49. 
Chor D, Griep RH, Lopes CS, Faerstein E. Medidas de rede e apoio social no Estudo Pró-Saúde: pré-teste e estudo piloto. Cad Saúde Pública. 2001;17:887-96.

Chumlea WC, Baumgartner RN. Status of anthropometry and body composition data in elderly subjects. Am J Clin Nutr 1989; 50:1158-66.

Cohen AD, Farley TA, Mason K. Why is poverty unhealthy? Social end physical mediators. Soc Sci Med. 2003; 57: $631-41$.

Cornoni-Huntley JC, Harris TB, Everett DF, Albanes D, Micozzi MS, Miles TP, et al. An overview of body weight of older persons, including the impact on mortality. $\mathbf{J}$ Clin Epidemiol, 1991, 743-53.

Davis MA, Moritz DJ, Neuhaus JM, Barclay JD, Gee L. Living arrangements, changes in living arrangements, and survival among community dwelling older aldults. Am $\mathbf{J}$ Public Health. 1997; 87:371-7.

Due P, Holstein B, Lund R, Modvig J, Avlund K. Social relations: network, support and relational strain. Soc Sci Med. 1999; 48: 661-73.

Due P, Holstein B, Lund R, Modvig J, Avlund K. Social relations: network, support and relational strain. Soc Sci Med 1999; 48: 661-73.

Eck LH, Hackett-Renner C, Klesges LM. Impact of diabetic status, dietary intake, physical activity, and smoking status on body mass index in NHANES II. Am J Clin Nutr 1992;56:329-33 
Edington j, Boorman j, Durrant ER, Perkins A, Giffin CV James R, et al. Prevalence of malnutrition on admission to four hospitals in England. The malnutrition prevalence group. Clin Nutr 2000;19: 191-5.

Giay T, Khoi HH. Use of body mass index in the assessment of adult nutritional status in Vietnam. Euro J Clin Nutr 1994; 48, Suppl. 3:S124-S30.

Goldman N, Korenman S, Weinstein, R. Marital Status and Health Among the Elderly. Soc Sci Med. 1995; 40: 1717-30.

Goodwin JS. Social, psychological and physical factors affecting the nutritional status of elderly subjects: separating cause and effect. Am J Clin Nutr 1989;50:1201-9.

Greenspar SL, Myers ER, Maitland LA, Resnick NM, Hayes WC. Fall severity and bone mineral density as risk factors for hip fracture in anbulatory elderly. JAMA 1994;271:128-33.

Guo SS, Zeller C, Chumlea WC, Siervogel RM. Aging, body composition, and lifestyle: the Fels longitudinal study. Am J Clin Nutr 1999, 405-11.

Harris NG. Nutrição no envelhecimento. In: Mahan LK, Escott-Stumps. Krause: alimentos, nutrição e dietoterapia. São Paulo: Roca, 2002. p.276-93.

Hosmer DM, Lemeshow S. Applied logistic regression. New York: John Wiley \& Sons; 1989. 
House JS, Robbins C, Metzner HL. The association of social relationships and activities with mortality: prospective evidence from the Tecumseh community health study. Am J Epidemiol. 1982; 123-40.

House SJ, Landis KR, Umberson D. Social relationships and health. Science 1988; 241:5405.

Hu Y, Goldman N. Mortality differentials by marital status: an international comparison. Demography. 1990; 27: 233-50.

Hughes ME, Waite LJ. Health in household context: living arrangements and health in late middle age. J Health Soc Behavior. 2002; 43:1-21.

Kawachi I, Colditz GA, Ascherio A, Rimn EB, Giovannucci E, Stampfer MJ, Willett WC. A prospective study of social networks in relation to total mortality and cardiovascular disease in men in the USA. J Epidemiol Community Health. 1996; $50: 245-51$

Kawachi I, Kennedy BP, Glass R. Social capital and self-rated health: a contextual analysis. Am J Public Health. 1999; 8:1187-93.

Kelsey K, Earp JA, Kirkley BG. Is social support beneficial for dietary chage? A review of the literature. Fam Community Health 1997; 20(3): 70-82. 
Krause N, Markides K. Measuring Social Support Among Older Adults. Int J Aging and Human Development. 1990; 30: 37-53.

Krause N. Borawski-Clark E. Social class differences in social support among older adults. Gerontologist. 1995; 35:498-508.

Krondl M, Lau D, Yurkiw MA, Col.eman PH. Food use and perceived food meanings of the elderly. J Am Diet Assoc. 1982; 80:523-9.

Labra ME. Capital social y consejos de salud en Brasil. Un círculo virtuoso? Cad Saúde Pública. 2002; 18 (suplemento): 47-55

Launer LJ, Harris T, Rumpel C, Madans J. Body mass index, Weight change, and risk of mobility disability in middle-aged and older women. JAMA 1994; 271:1093-98.

Learner RM, Kivett VR. Discriminators of perceived dietary adequacy among the rural elderly. J Am Diet Assoc. 1981; 78:330-7.

Liang J, Krause NM, Bennett JM. Social exchange and well-being: is giving better than receiving? Psychology Aging. 2001, 3:511-23.

Lin N, Ye X, Ensel WM. Social support and depressed mood: a structural analysis. J Health Soc Behavior 1999; 40:344-59.

Litwin H. Social network type and morale in old age. Gerontol 2001; 41:516-24. 
Lund R, Modvig J, Due P, Holstein BE. Stability and change in structural social relations as preditor of mortality among elderly women and men. Euro J Epidemiol 2000; 16: 1087-97.

Mann GV. The influence of obesity on health. N Eng J Med 1974; 178-85.

McCulloch A. Social environments and health: cross sectional national survey. Br Med J. $2001 ; 323: 208-9$.

McIntosh WA, Shifflett PA, Picou J. Social support, stressful events, strain, dietary intake, and the elderly. Med Care 1989; 27:140-53.

McCamish-Svensson C, Samuelsson G, Hagberg B, Svensson T, Dehlin O. Social relationships and health as predictors of life satisfation in advanced old age: results from a swedish longitudinal study. Int J Aging and Human Development. 1999; 301-24.

Messner RL, Stephens N, Wheeler WE, Hawes MC. Effect of admission nutritional status on length of hospital stay. Gastroenterol Nurs 1991, 202-205. (referido no nutrition screening)

Monteiro CA, Mondini L, Souza ALM, Popkin BM. Da desnutrição para a obesidade: a transição nutricional no Brasil. In Monteiro CA (org). Velhos e novos males da saúde no Brasil. 2000; p. 247-55. 
Monteiro CA. Epidemiologia da obesidade. In: Halpern A, Matos AFG, Suplicy HL, Mancini MC, Zanella MT. Obesidade.São Paulo:Lemos Editorial; 1998. p.15-30.

Morley JE. Anorexia of aging: physiologic and pathologic. Am J Clin Nutr 1997; 66:760-73.

Murray E J. Marital protection and marital selection: evidence from a historicalprospective sample of American men. Demography. 2000; 37: 511-21.

Naidu AN, Rao NP. Body mass index: a measure of the nutritional status in Indian populations. Euro J Clin Nutr 1994; 48, Suppl. 3:S131-S40.

Nazário CL. Trabalho de campo para coleta de dados. In: Lebrão ML, Duarte YAO. SABE - Saúde, Bem-estar e Envelhecimento - O projeto SABE no município de São Paulo: uma abordagem inicial. Brasília: Organização Pan-Americana de Saúde, 2003, p. 59-67.

Olsen O, Iversen L, Sabroe S. Age and the operationalization of social support. Soc Sci Med $1991 ; 32: 767-71$.

Organização Pan-Americana (OPAS). XXXVI Reunión del Comitê Asesor de Investigaciones en Salud - Encuesta Multicêntrica - Salud Bienestar y Envejecimiento (SABE) en América Latina e el Caribe - Informa preliminar. Disponível em <URL: .$>$ (mar.2002). 
Orth-Gomér C, Udén AL. The measurement of social support in population surveys. Soc Sci Med 1987; $24: 83-94$.

Palinkas AL, Wingard D L, Barrett-Connor, E. The biocultural context of social networks and depression among the elderly. Soc Sci Med. 1990; 30: 442-447.

Palloni A, Peláez M. Histórico e natureza do estudo. In: Lebrão ML, Duarte YAO. SABE - Saúde, Bem-estar e Envelhecimento - O projeto SABE no município de São Paulo: uma abordagem inicial. Brasília: Organização Pan-Americana de Saúde, 2003, p. 15-32.

Pei X, Pillai V. Old Age support in China: The role of state and the family. Int $\mathbf{J}$ Aging and Human Development. 1999; 49: 197- 212.

Penninx BWJH, Tilburg T van, Kriegsman DMW, Deeg DJH, Boeke AJP, Eijk JThM van. Effects of social support and personal coping resources on mortality in older age: the longitudinal aging study Amsterdam. Am J Epidemiol. 1997; 146:510-9.

Pinquart M, Sörensen S. Influences of socioeconomic status, social network, and competence on subjective well-being in later life: a meta-analysis. Psychology and Aging. 2000; 15:187-224.

Pinquart M, Sörensen S. Older adults' preferences for informal, formal, and mixed support for future care needs: a comparison of Germany and the United States. Int $\mathbf{J}$ Aging Human Development. 2002; 54:291-314. 
Rahman MO. Age and gender variation in the impact of household structure on elderly mortality. Int J Epidemiol. 1999; 28:485-91.

Ramos LR, Rosa TEC, Oliveira ZMC, Medina MCG, Santos FRG. Perfil do idoso em área metropolitana na região sudeste do Brasil. Rev Saúde Pública. 1993; 27: 87-94.

Rissanen A, Heliövaara M, Knekt P, Aromaa A, Reunanen A, Maatela J. Weigth and mortality in Finnish men. J Clin Epidemiol 1989; 781-89.

Rissanen A, Knekt P, Heliövaara M, Aromaa A, Reunanen A, Maatela J. Weigth and mortality in Finnish women. J Clin Epidemiol 1991; 787-95.

Roberts SB. Regulation of energy intake in relation to metabolic state and nutrional status. Euro J Clin Nutr 2000; 54 (suppl 3) s64-9.

Rosa TEC, Benício MHD'A, Latorre MRDO, Ramos LR. Fatores determinantes da capacidade funcional entre idosos. Rev Saúde Pública. 2003; 37:40-8.

Saad PM. Arranjos domiciliares e transferências de apoio informal. In: Lebrão ML, Duarte YAO. SABE - Saúde, Bem-estar e Envelhecimento - O projeto SABE no município de São Paulo: uma abordagem inicial. Brasília: Organização PanAmericana de Saúde, 2003, p. 201-24. 
ANEXOS 

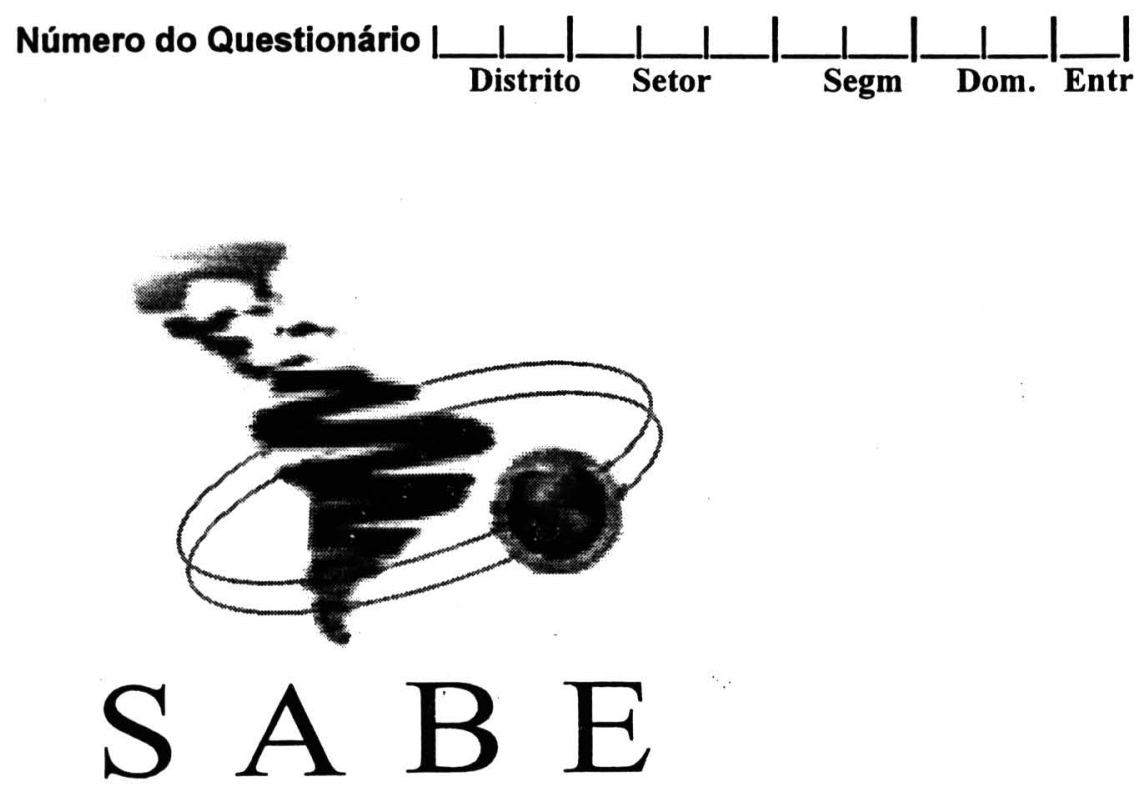

\section{SAÚDE, BEM-ESTAR E ENVELHECIMENTO NA AMÉRICA LATINA E CARIBE}

\section{Projeto SABE}

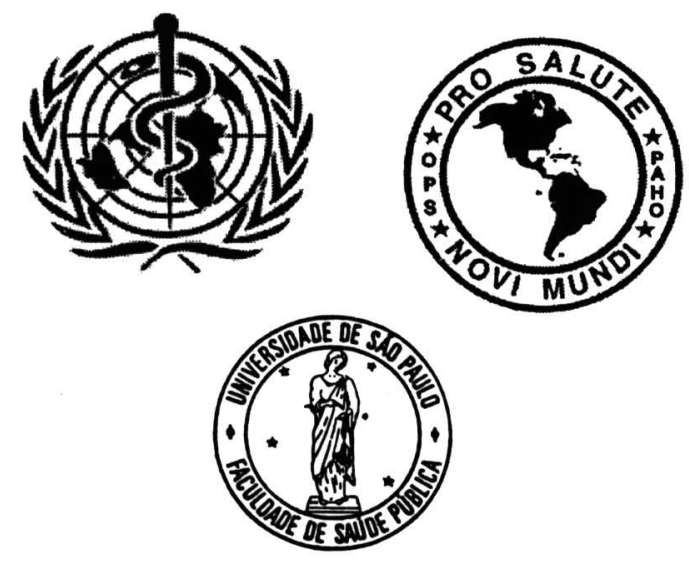

Organização Pan-Americana da Saúde

Faculdade de Saúde Pública/ Universidade de São Paulo 
PESQUISA SOBRE SAÚDE, BEM ESTAR E ENVELHECIMENTO, 1999

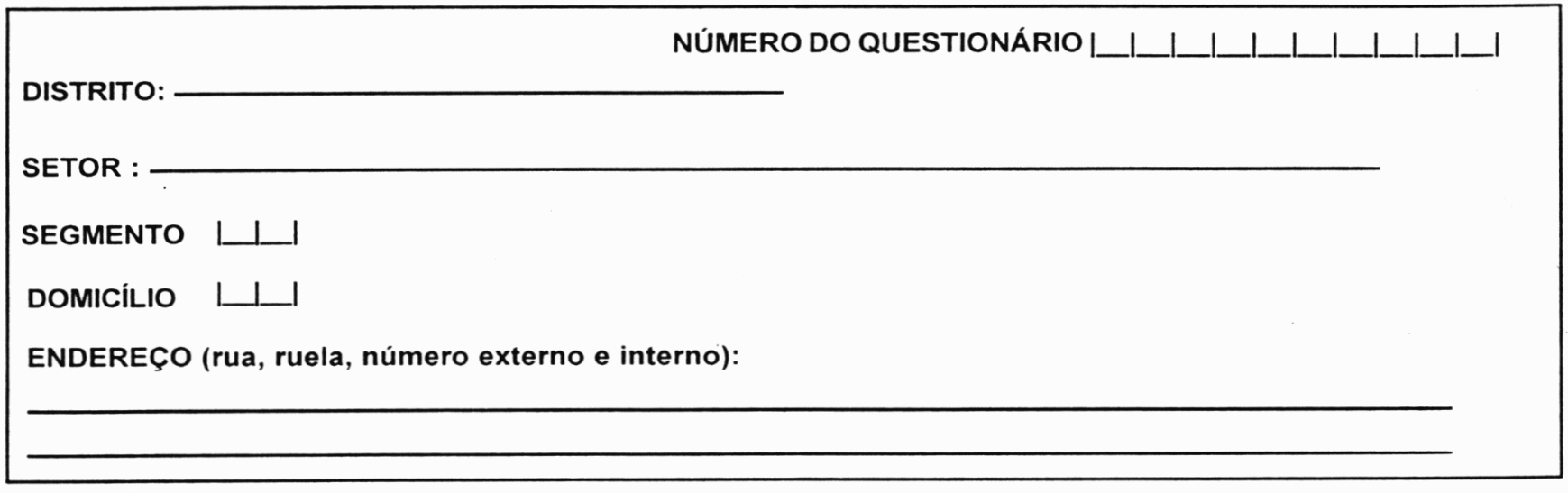

\begin{tabular}{|c|c|c|c|c|c|}
\hline $\begin{array}{l}\text { NOME DO } \\
\text { ENTREVISTADO }\end{array}$ & & & & SEXO: H M & \\
\hline VISITAS & 1 & 2 & 3 & 4 & \\
\hline DATA & $\begin{array}{l}\text { I_I_IDIA } \\
\text { I_I_IMÊS }\end{array}$ & $\begin{array}{l}\text { L_I_IDIA } \\
\text { I_I_IMÊs }\end{array}$ & $\begin{array}{l}\text { L___LIA } \\
\text { I_I_IMÊs }\end{array}$ & $\begin{array}{l}\text { I___ DIA } \\
\text { I_L_ MÊs }\end{array}$ & 2000 \\
\hline \multicolumn{5}{|l|}{\begin{tabular}{|l} 
NOME DO \\
ENTREVISTADOR
\end{tabular}} & \\
\hline \begin{tabular}{|l|} 
CÓDIGO DO \\
ENTREVISTADOR \\
\end{tabular} & 1 L_ا_L & 1_L_ا_L & L_L_ & 1 L_L & \\
\hline HORA DE INÍCIO & L1_l_Ll & I_l_l_l & L I_l_l_l & L_L_L1 & \\
\hline HORA DE TÉRMINO & 1 L_L_L & $1+1$ & 1 & $1-1$ & \\
\hline DURAÇÃO & I_I_I_ & L_1_ا I & I_L_L & 1 L1_l & MIN \\
\hline RESULTADO** & $\mathrm{L}$ & L L I & 1 & L I I & \\
\hline
\end{tabular}

*Códigos de Resultados:

01 Entrevista completa

02 Entrevista completa com informante substituto

03 Entrevista completa com informante auxiliar

04 Entrevista incompleta (anote em observaçöes)

05 Entrevista adiada
06 Ausente temporário

07 Nunca encontrou a pessoa

08 Recusou-se

09 Incapacitado e sem informante

10 Outros (anote em observaçōes)

\section{OBSERVAÇÕES}

\begin{tabular}{|c|c|c|c|c|c|}
\hline \multicolumn{2}{|c|}{$\begin{array}{l}\text { NOME DO INFORMANTE } \\
\text { SUBSTITUTO OU AUXILIAR: }\end{array}$} & \multicolumn{2}{|c|}{$\begin{array}{l}\text { PARENTESCO COM O } \\
\text { ENTREVISTADO: }\end{array}$} & \multicolumn{2}{|c|}{$\begin{array}{l}\text { TEMPO DE CONHECIMENTO (NO } \\
\text { CASO DE NÃO SER FAMILIAR) }\end{array}$} \\
\hline & SUPERVISĀO & CRITICA & CODIFICACÃOO & DIGITACÃO & 2000 \\
\hline \multicolumn{6}{|l|}{ NOME } \\
\hline DATA & $L_{D I A}^{L} \mid L_{M E S S}$ & 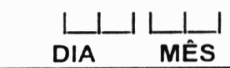 & $L_{D I A} \mid L_{\text {MÊS }}$ & $\underset{D I A}{L} L_{\text {MÊS }}^{\mid}$ & \\
\hline
\end{tabular}


Declaração de Consentimento

Estudo Saúde, Bem-estar e Envelhecimento

\section{SABE}

Por este meio aceito colaborar com o estudo "Saúde, Bem-estar e Envelhecimento" SABE. Os objetivos principais deste estudo são:

1. Descrever as condições de saúde das pessoas com 60 anos e mais no país.

2. Avaliar o acesso e utilização dos serviços disponiveis para o cuidado da saúde das pessoas com 60 anos e mais, incluindo os não tradicionais.

3. Definir a contribuição da família, dos programas de assistência pública e dos recursos privados para satisfazer as necessidades de saúde das pessoas com 60 anos e mais.

Meu consentimento em participar é voluntário, sem coerção ou força. Também entendo que tenho o direito de terminar a entrevista no momento em que desejar.

Aceito responder um questionário sobre meu estado de saúde e que sejam tomadas minhas medidas como o peso, estatura e gordura corporal. Serão realizados, além disso, um exame de força muscular manual e umas provas de eficiência física (caminhar, agachar, dobrar, levantar e sentar em uma cadeira).

Entendo que serão tomadas as medidas necessárias para assegurar a confidencialidade de toda informação que eu dê e que não será revelada minha identidade. Foi-me informado que se eu tiver alguma dúvida ou pergunta adicional sobre este estudo, posso telefonar à Dra. Maria Lúcia Lebrão, Coordenadora do Estudo em São Paulo nos telefones 3066-7724/3066-7744.

Entendo que não terei beneficio direto como participante neste estudo nem há perigo algum por participar do mesmo.

Nome: Data: 
SEÇÃO A - INFORMAÇÕES PESSOAIS

HORA DEINICIO: I_____ I I____ I

\section{DECLARAÇĀO VOLUNTÁRIA}

Antes de começar, gostaria de assegurar-lhe que esta entrevista é completamente voluntária e confidencial. Se houver alguma pergunta que o Sr não deseje responder, simplesmente me avise e seguiremos para a próxima pergunta.

\section{A.1a \\ Em que mês e ano o(a) Sr(a) nasceu? \\ A. $1 \mathrm{~b}$ \\ Quantos anos completos o(a) Sr.(a) tem? \\ A.1C ATENÇĀO \\ SOME A IDADE COM O ANO DE NASCIMENTO E ANOTEOTOTAL. \\ SE O(A) ENTREVISTADO(A) JÁ FEZ ANIVERSÁRIOEM \\ 2000, A SOMA DEVE SER 2000. SE NĀO FEZ \\ ANIVERSÁRIO AINDA, A SOMA DEVE SER 1999. \\ NO CASO DE INCONSISTÉNCIA, ESCLARECA COM \\ O(A)ENTREVISTADO(A).PEÇA ALGUMDOCUMENTO \\ DE IDENTIFICAÇÃO QUE MOSTRE A DATA DE \\ NASCIMENTO OU AIDADE. \\ SE A PESSOA TIVER MENOS DE 60 ANOS, AGRADEÇA \\ E ENCERRE A ENTREVISTA.}

A. 2

O(a) Sr(a) nasceu no Brasil?

A. 3

Em que pais o(a) $\mathrm{Sr}(a)$ nasceu?

A. $4 a$

No total, quantos anos o(a) $\mathrm{Sr}(\mathrm{a})$ viveu no Brasil?

A.4b

Desde que o Sr.(a) nasceu até os 15 anos, viveu no campo por 5 anos ou mais?

A.5a

O(a) Sr.(a) sabe ler e escrever um recado?

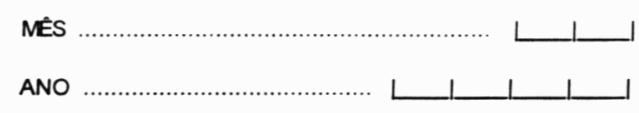

IDADE

L 1 - 1

SOMA

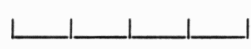

Pais
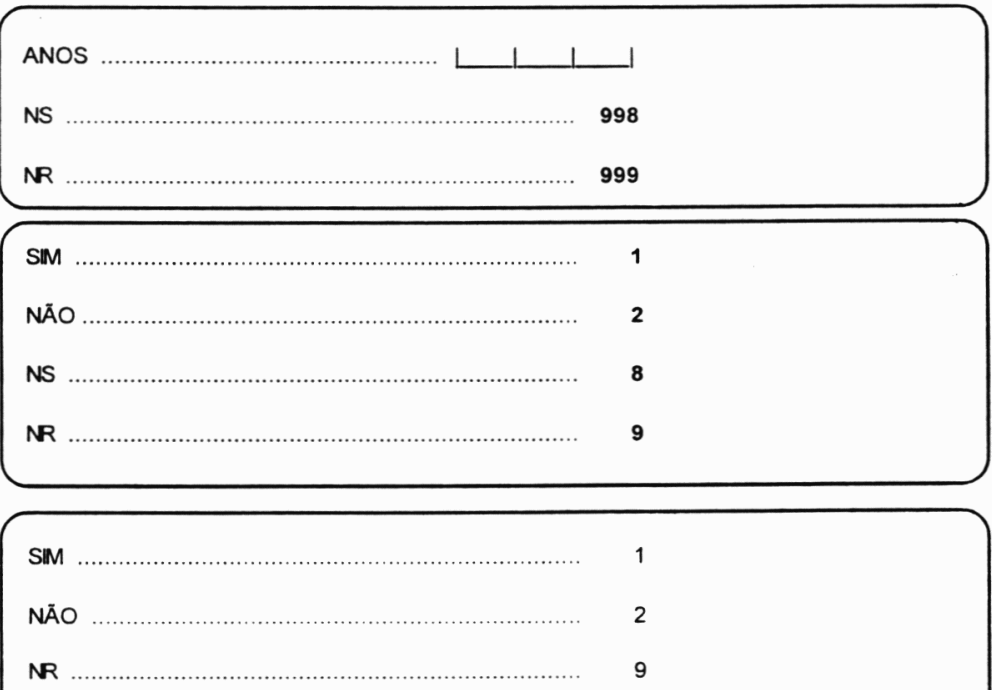
SEÇÃO A - INFORMAÇŌES PESSOAIS

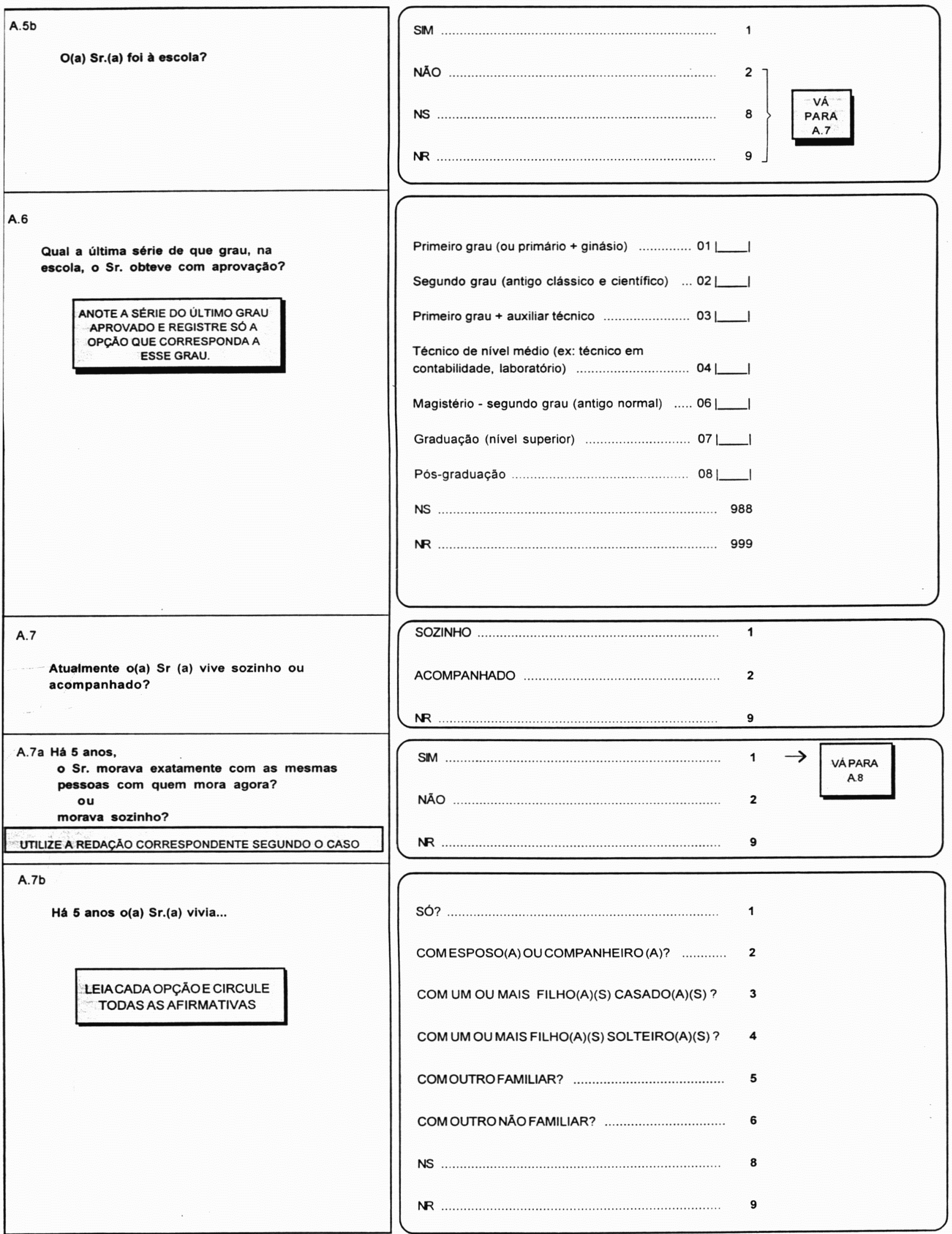


SEÇĀO A - INFORMAÇŌES PESSOAIS

A.11b

Qual a importância da religiāo em sua vida?

Qual destas opçōes o descreve melhor?

\section{HISTÓRIA DE UNIÕES}

A.13a

Com relação ao seu estado marital, alguma vez o(a) Sr.(a) foi casado(a) ou teve uma união livre?

A. $13 b$

No total, quantas vezes, o(a) Sr.(a) esteve casado(a) ou em uniăo?

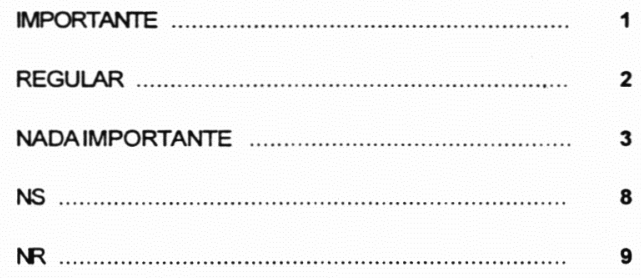

BRANCO (de origem européia) ……...................... 1

MESTIÇO (combinação de branco e índio) .............. 2

MULATO (combinação de branco e negro) …......... 3

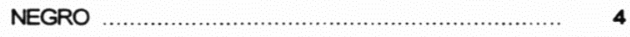

INDIGENA ….................................................. 5

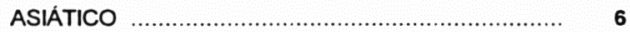

OUTRA

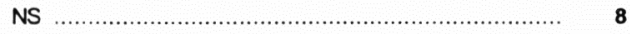

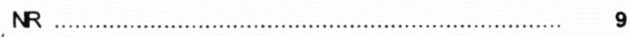

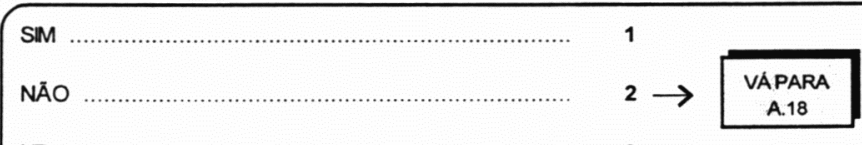

NR …....................................................

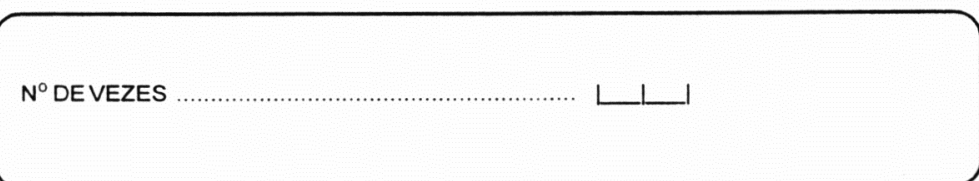


SEÇÃO A - INFORMAÇÕES PESSOAIS

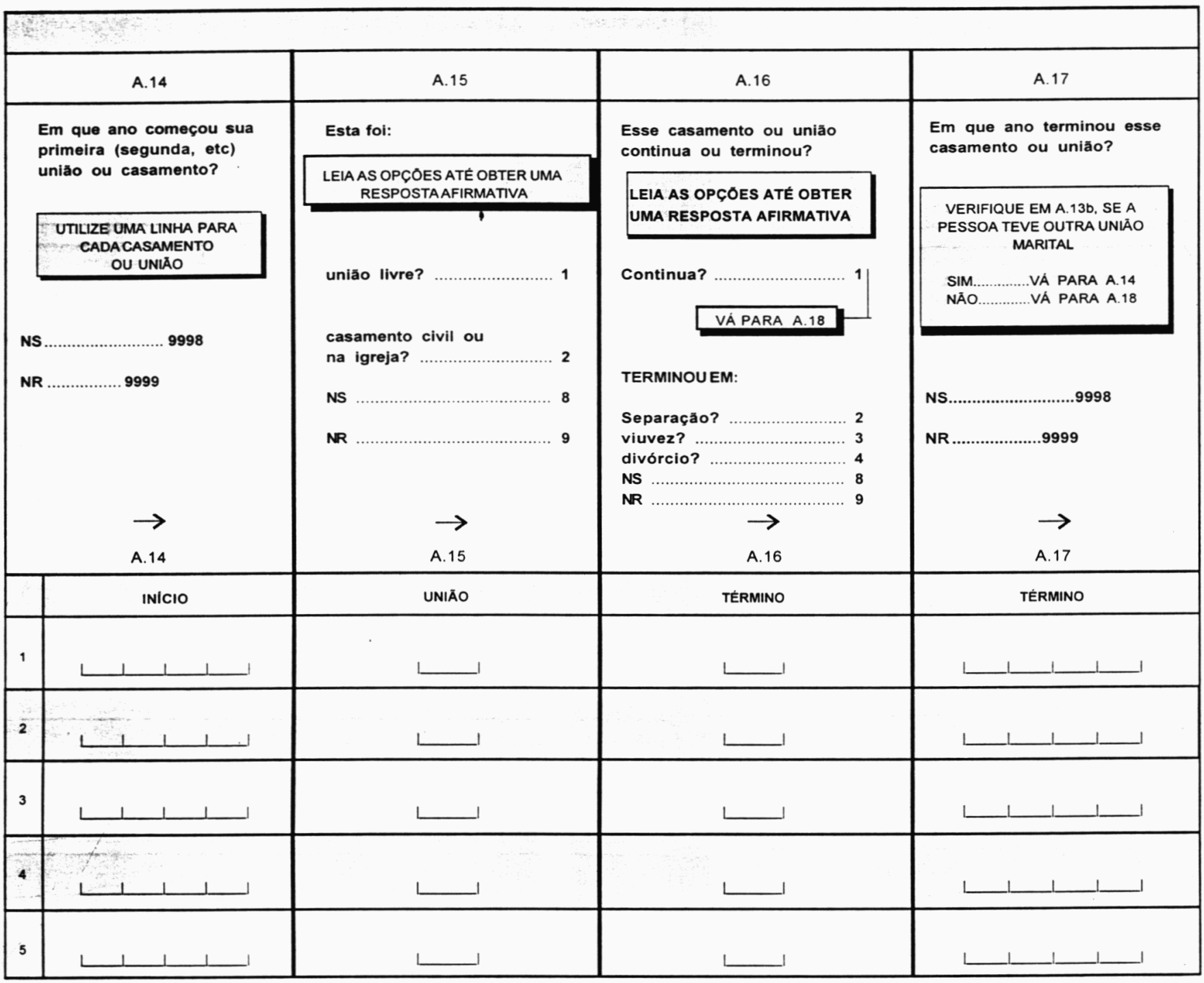

\section{AGORA QUERO FAZER-LHEALGUMAS PERGUNTAS SOBRE SUA HISTÓRIA FAMILIAR:}

\begin{tabular}{|c|c|}
\hline \multirow[t]{2}{*}{ A. 18} & $\begin{array}{l}\text { Quantos filhos e filhas nascidos vivos o(a) } \\
\text { Sr.(a) teve? }\end{array}$ \\
\hline & $\begin{array}{l}\text { NAO INCLUA ENTEADOS, FILHOS ADOTIVOS, } \\
\text { ABORTOS OU FILHOS NASCIDOS MORTOS. }\end{array}$ \\
\hline \multicolumn{2}{|l|}{ A. 19} \\
\hline \multicolumn{2}{|r|}{ Tem ou teve enteados? } \\
\hline & . \\
\hline \multicolumn{2}{|l|}{ A. 20} \\
\hline & Quantos enteados(as) teve? \\
\hline
\end{tabular}
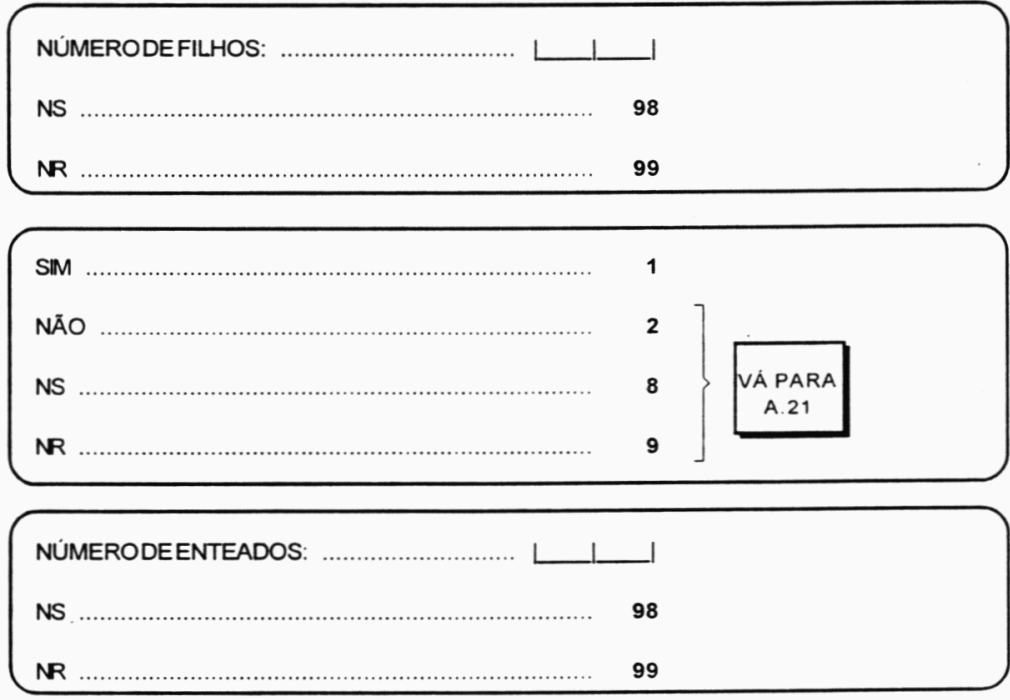
SEÇÃO C - ESTADO DE SAÚDE

\section{C.23}

Nos últimos três meses, em média, quantos dias por semana tomou bebidas alcoólicas? (Por exemplo: cerveja, vinho, aguardente ou outras bebidas que contenham álcool).

\section{C.23a}

Nos últimos três meses, nos dias em que tomou bebida alcoólica, quantos copos de vinho, cervejas, aguardente ou outra bebida tomou, em média, por dia?

C.24

O Sr. tem ou teve o hábito de fumar?

LEIA CADA OPÇÃO ATÉ OBTER UMA RESPOSTAAFIRMATIVA

C.24a

Quantos cigarros, charutos ou cachimbos fuma habitualmente por dia?

DEFINIÇÃO: UMMAÇO=20 CIGARROS

\section{C.24b}

Há quantos anos deixou de fumar?

SE DEIXOUDE FUMAR HÁ MENOS DE UM ANO, ANOTE "OO"
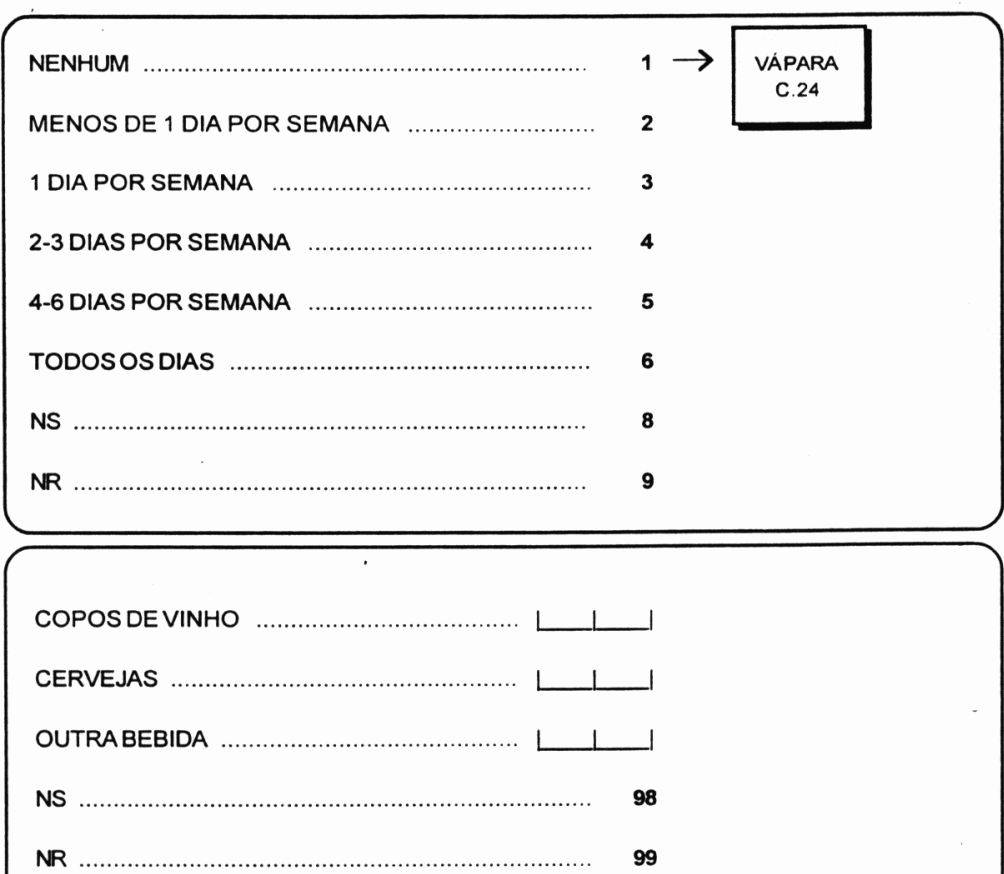

FUMAATUALMENTE

JÁ FUMOU, MAS NÃO FUMA MAIS

1

NUNCAFUMOU

NS

NR

CIGARROSPORDIA

CACHIMBOS

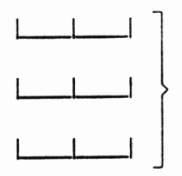

VÁ PARA

C. $24 \mathrm{C}$

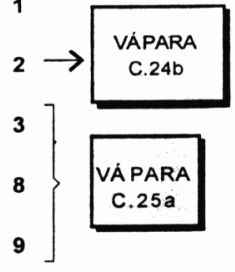

CHARUTOS

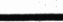


SEÇÃO C - ESTADO DE SAÚdE

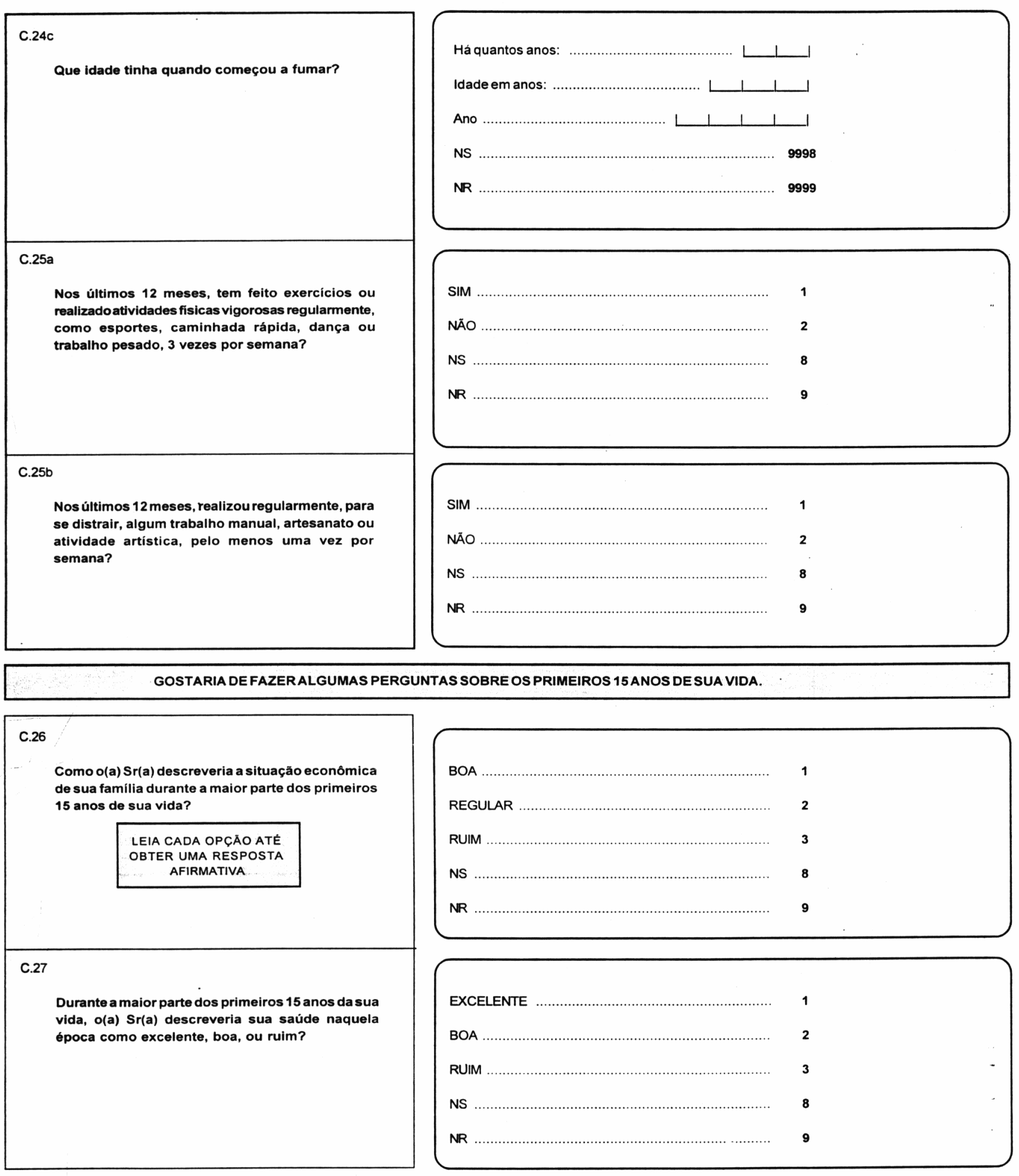


SEÇÃO G - REDE DE APOIO FAMILIAR E SOCIAL

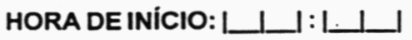

AGORA TEMOS ALGUMAS PERGUNTAS SOBRE SUA CASA. AS FAMILIAS E OS AMIGOS AJUDAM-SE MUTUAMENTE DE VÁRIAS MANEIRAS. PARTE DA NOSSA PESQUISA TEM POROBJETIVO DESCOBRIR COMOISTO ACONTECE. PARA TERMOS UM PANORAMA COMPLETO DA SITUAÇĀO DAS PESSOAS IDOSAS, PRECISAMOS CONHECER ALGUNS DETALHES SOBRE AS PESSOAS QUE MORAM HABITUALMENTE NESTA CASA.

DADOS GERAIS DOS MEMBROS DO DOMICILIO

Anote onome de todos os componentes da familia e inclua o ENTREVISTADO. Pergunte G.3 a G.16 para cada componente da familia E SOMENTE G.3 PARA O ENTREVISTADO.

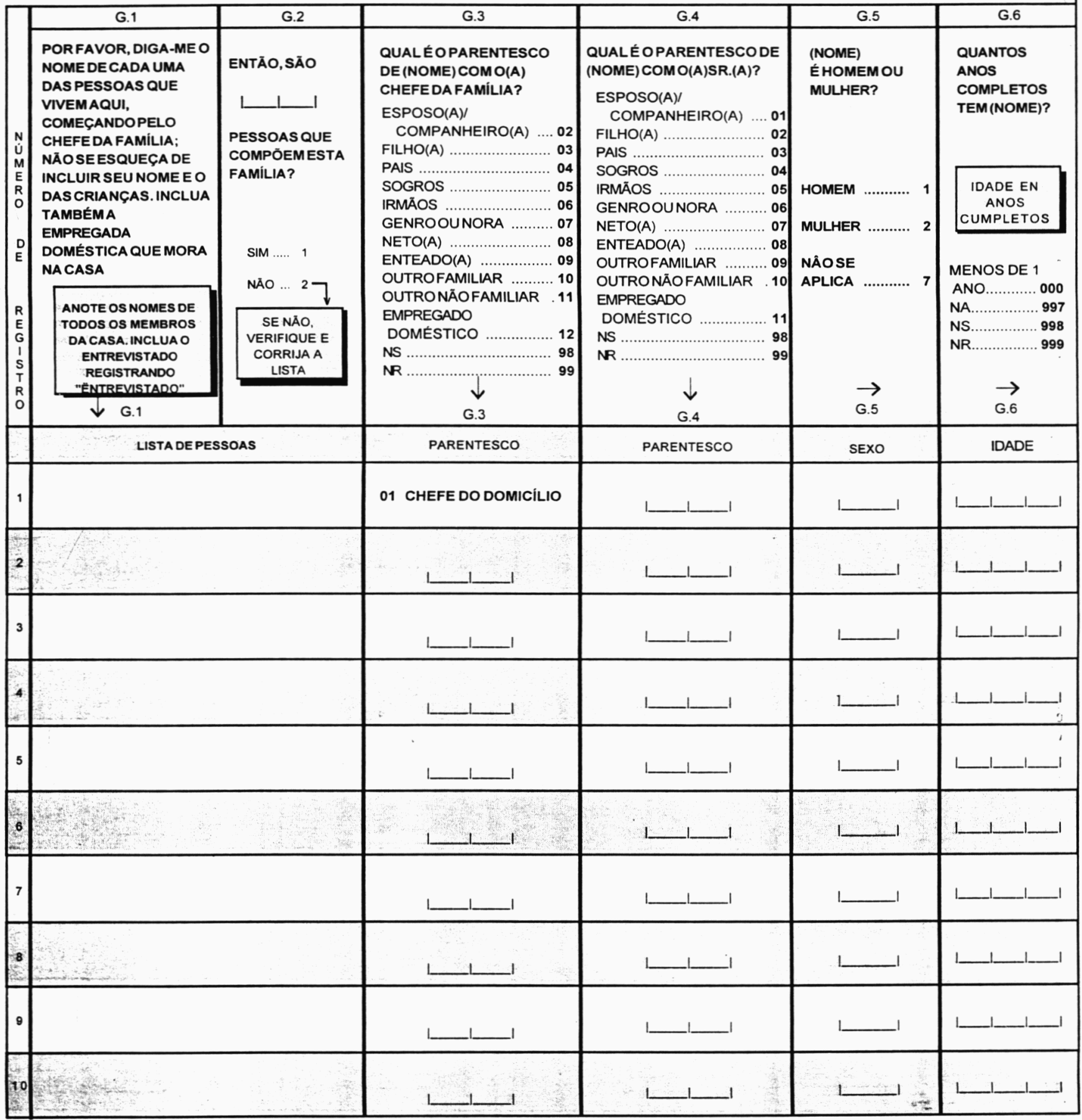


DADOS GERAIS E EDUCAÇĀO

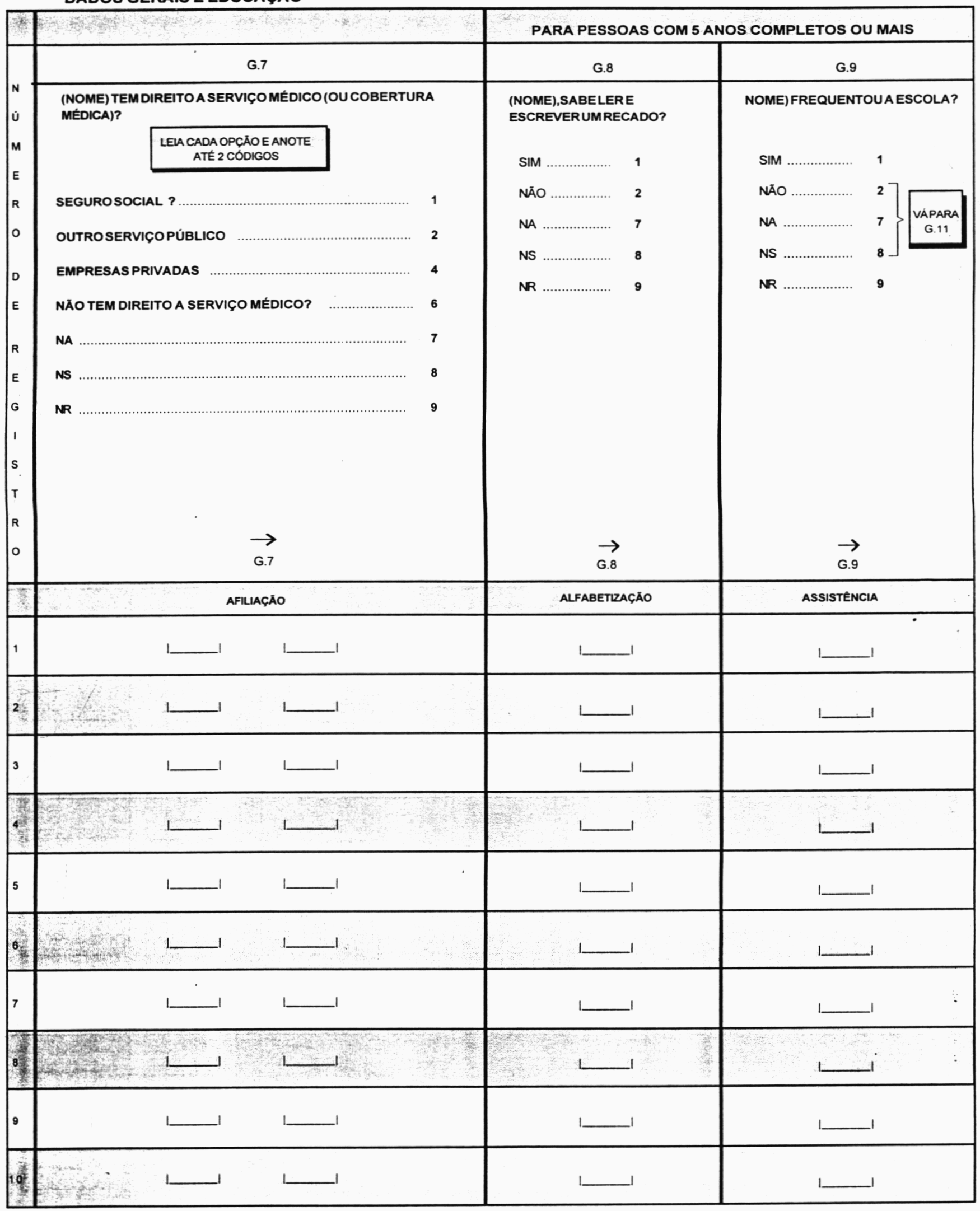


CARACTERISTICAS ECONÔMICAS E SERVIÇOS DE SAÚDE

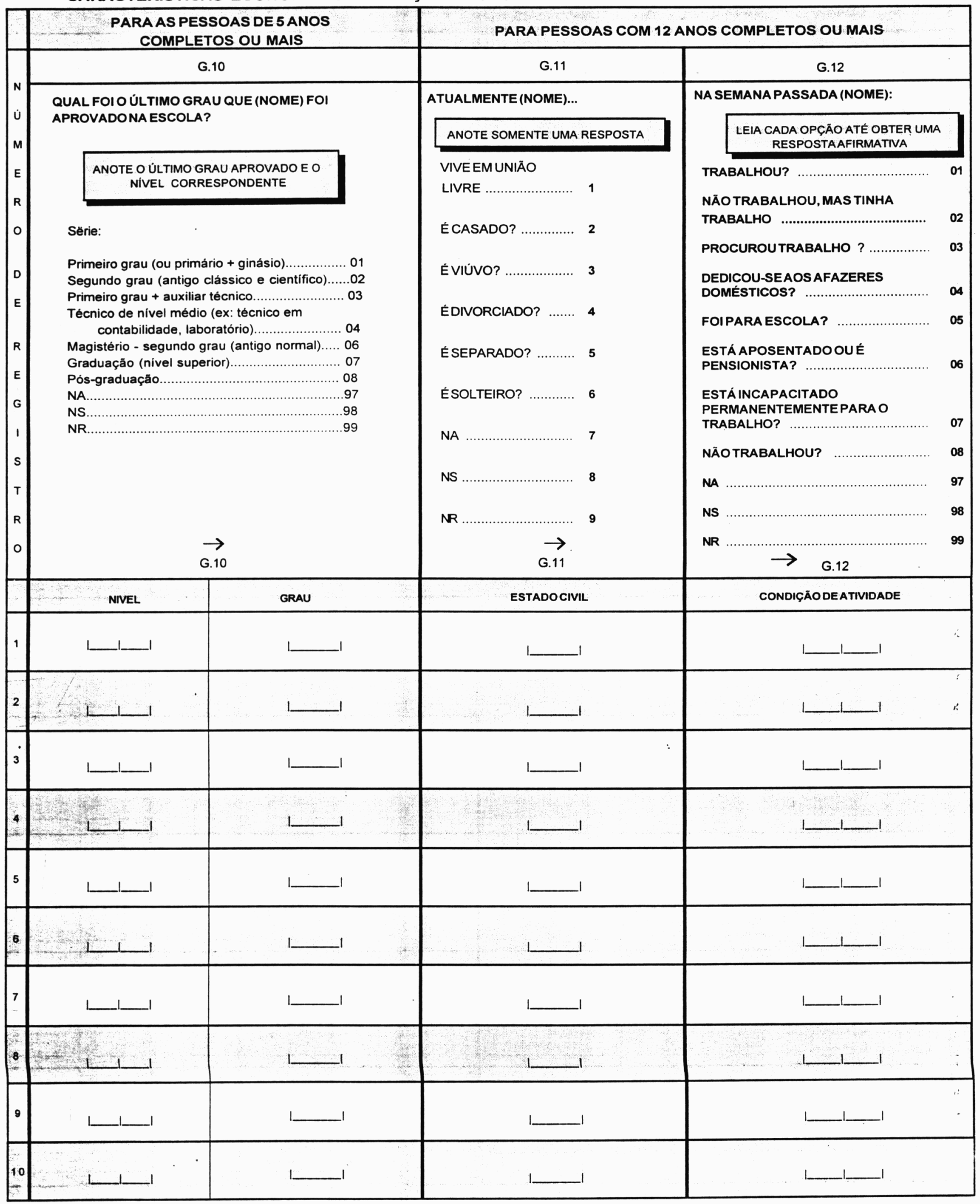


TRANSFERÊNCIAS

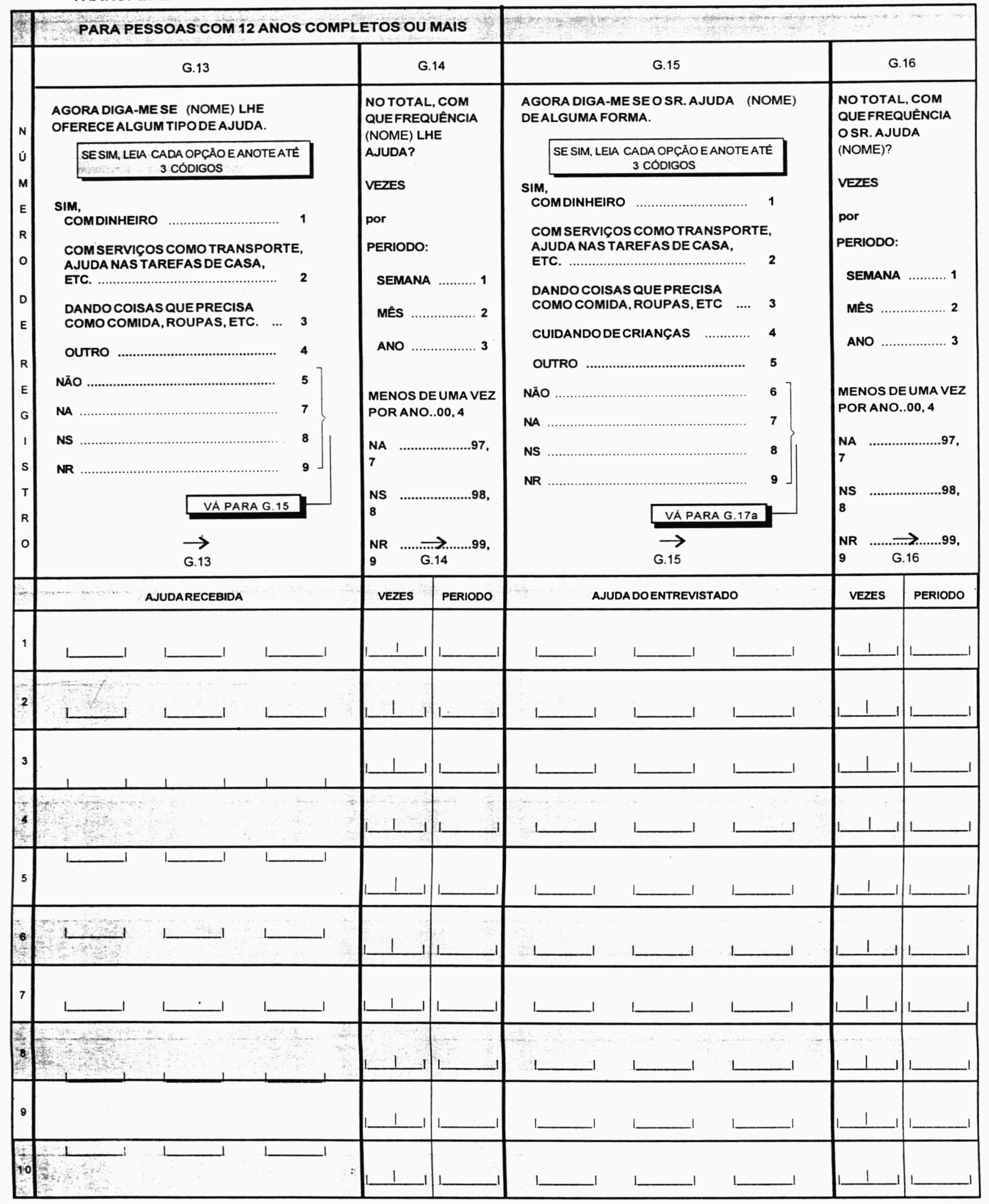


TRANSFERÊNCIAS

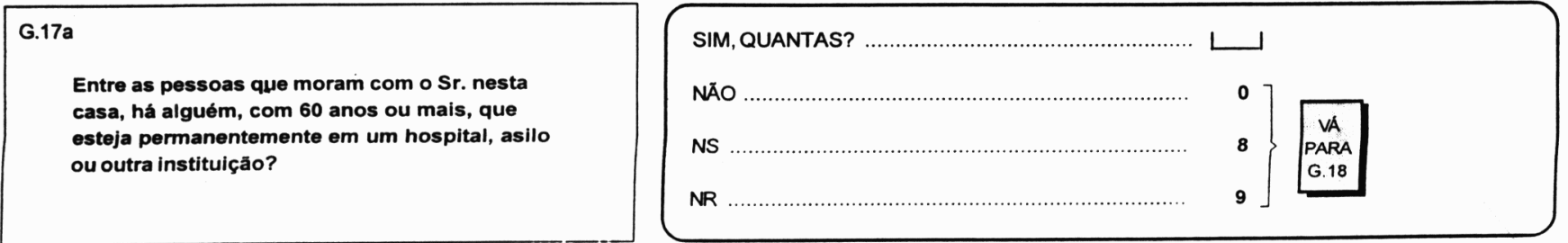

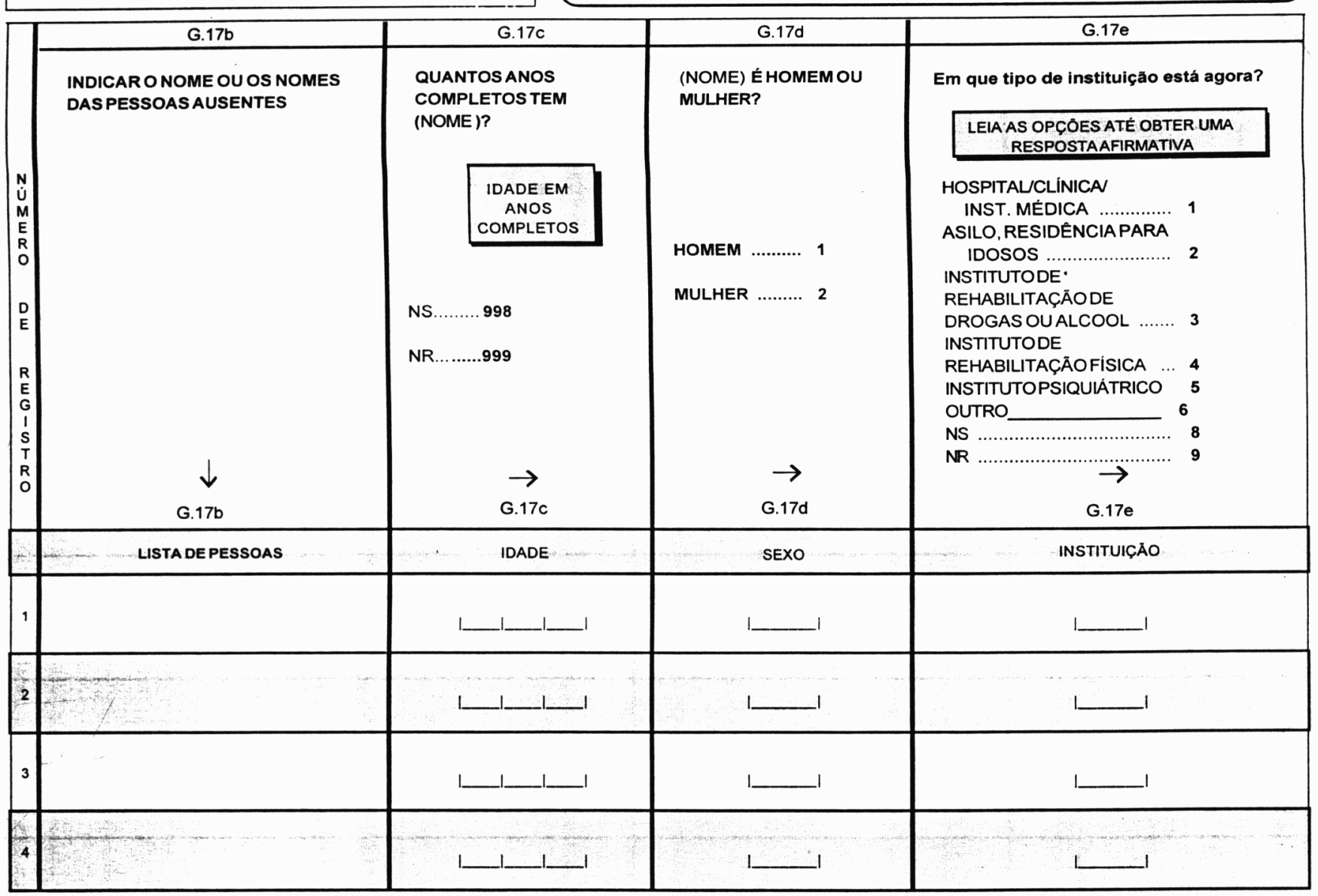

G.18 FILTRO

O entrevistado tem pelo menos um filho, enteado ou filho adotivo, atualmente vivo que não reside nessa casa. (ver pergunta A.23 e G.3)

$2 \rightarrow$ VAPARAG.32 
DADOS GERAIS DE FILHOS QUE NĀO MORAM NA CASA

\begin{tabular}{|c|c|c|c|c|}
\hline & G.18a & G.19 & G.20 & G.21 \\
\hline $\begin{array}{l}N \\
\dot{U} \\
\mathrm{M} \\
E \\
R \\
O \\
D \\
E \\
R \\
E \\
G \\
I \\
S \\
T \\
R \\
O\end{array}$ & 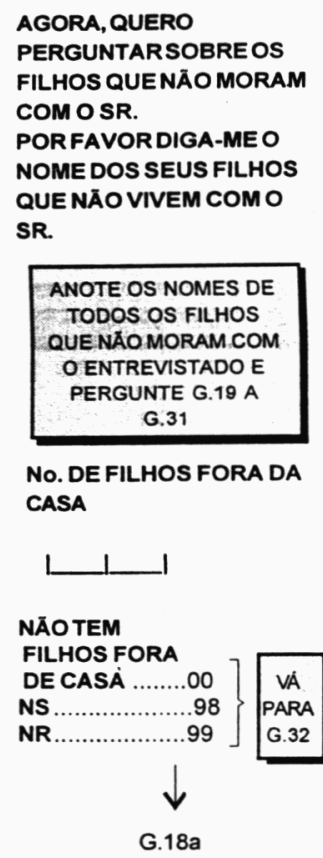 & $\begin{array}{l}\text { (NOME ) É SEU .... } \\
\begin{array}{|c|c|}\begin{array}{c}\text { LEIA AS OPCOOES ATE OBTER UMA } \\
\text { RESPOSTAAFIRMATIVA }\end{array} \\
\end{array} \\
\\
\end{array}$ & $\begin{array}{l}\text { (NOME) É HOMEMOU } \\
\text { MULHER? }\end{array}$ & $\begin{array}{l}\text { QUANTOS ANOS COMPLETOS TEM } \\
\text { (NOME )? } \\
\qquad \begin{array}{c}\text { IDADE EM } \\
\text { ANOS } \\
\text { COMPLETOS }\end{array} \\
\text { MENOS DE } 1 \text { ANO } \\
\text { NS }\end{array}$ \\
\hline 7 & NOME & PARENTESCO & SEXO & IDADE \\
\hline 1 & & ا & I & 1 L_ــ1_ \\
\hline 2 & & 1 & I & 1 \\
\hline 3 & & I & I & 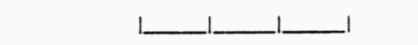 \\
\hline 4 & & ا & 1 & 1 \\
\hline 5 & & I & I I & | 1 \\
\hline 6 & & 1 & 1 & $1-1-1$ \\
\hline 7 & & I & Iـــ & 1 \\
\hline 8 & & I & I_ـ & 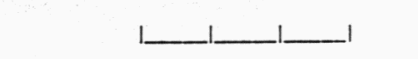 \\
\hline 9 & & 1 & 1 & 1 \\
\hline 10 & $4+5=$ & 1 & 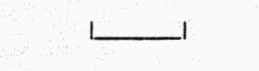 & 1 \\
\hline
\end{tabular}


DADOS GERAIS DOS FILHOS QUE NÃO VIVEM NA CASA

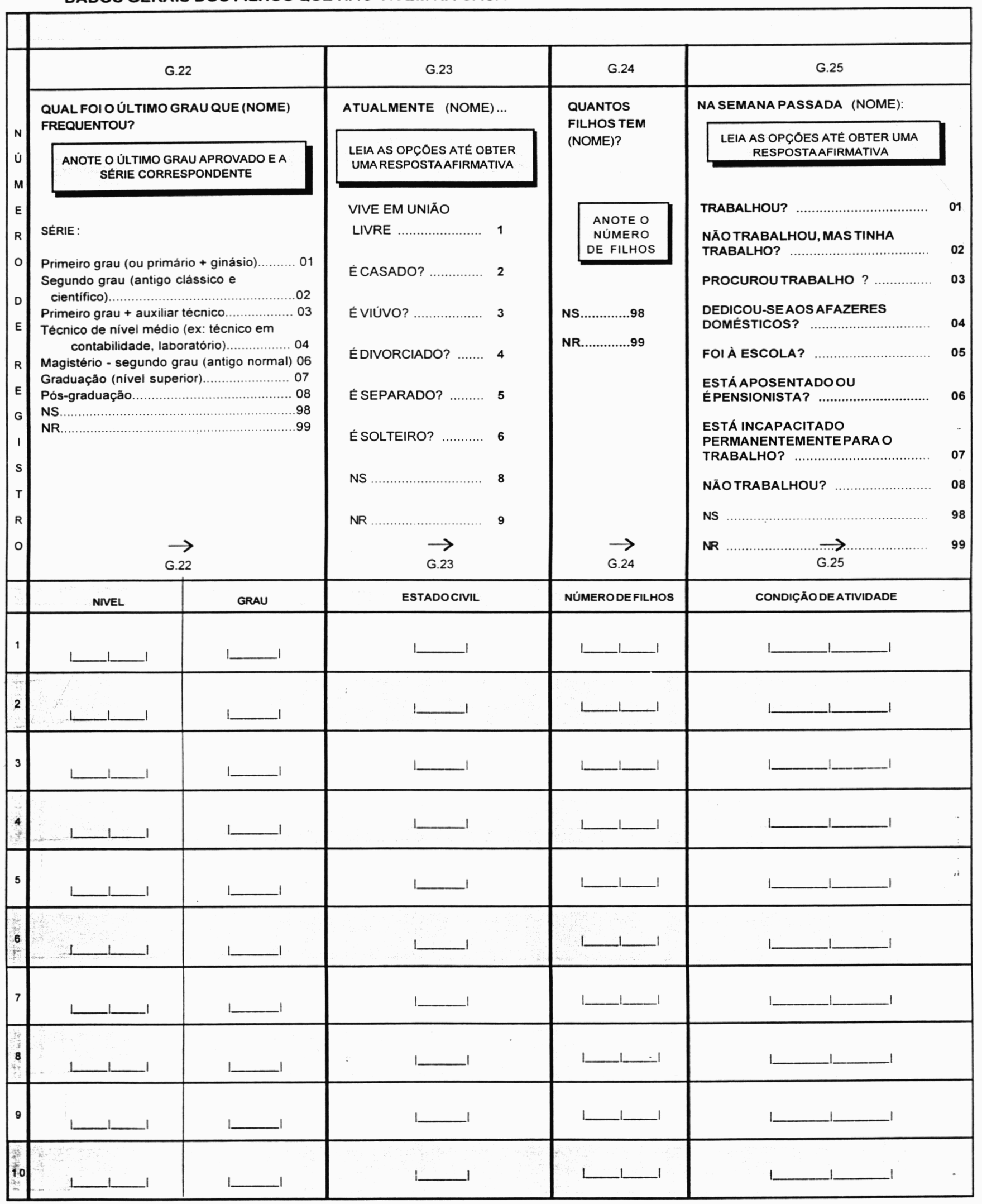


DADOS GERAIS DE FILHOS QUE NĀO MORAM NA CASA

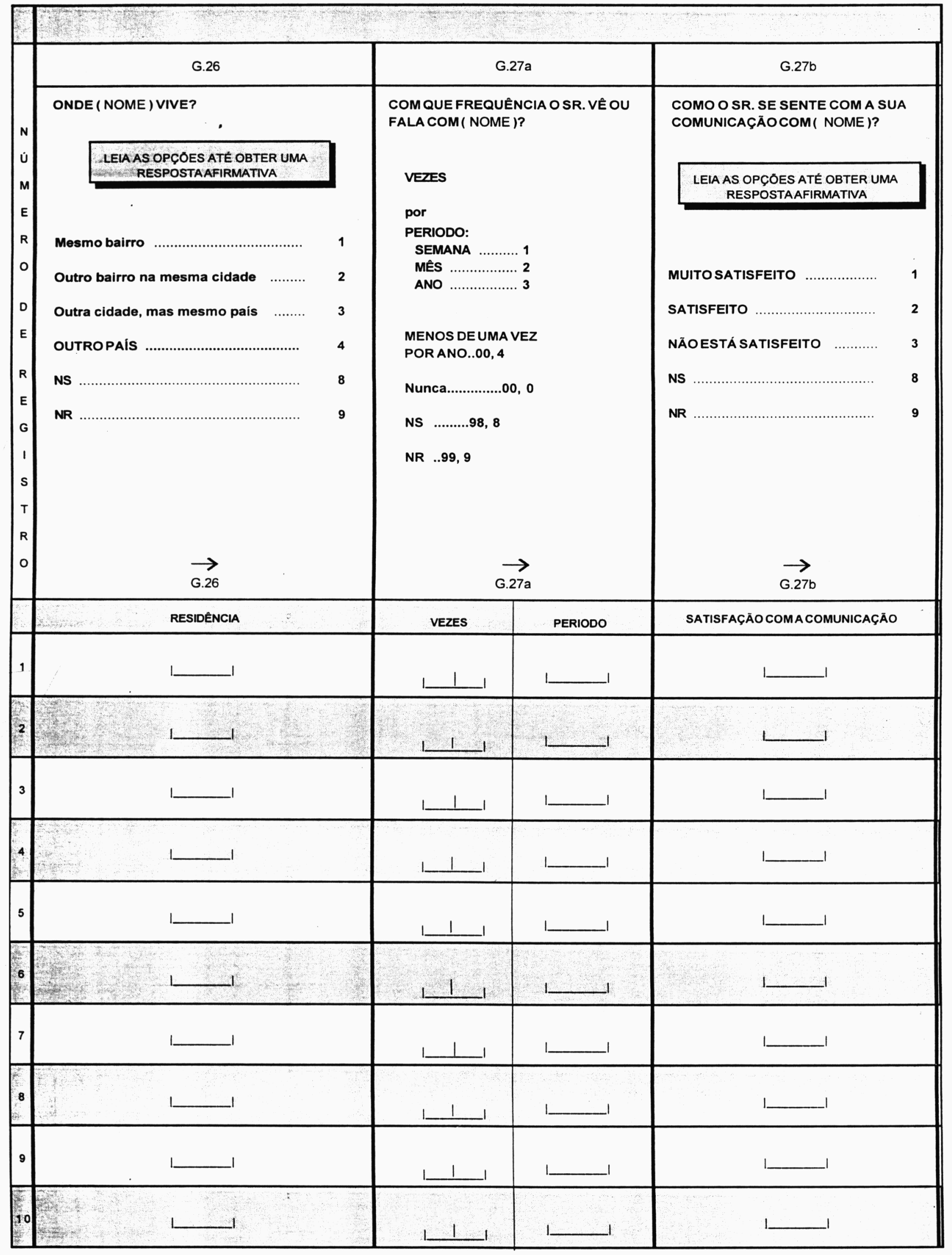


DADOS GERAIS DE FILHOS QUE NÃO MORAM NA CASA

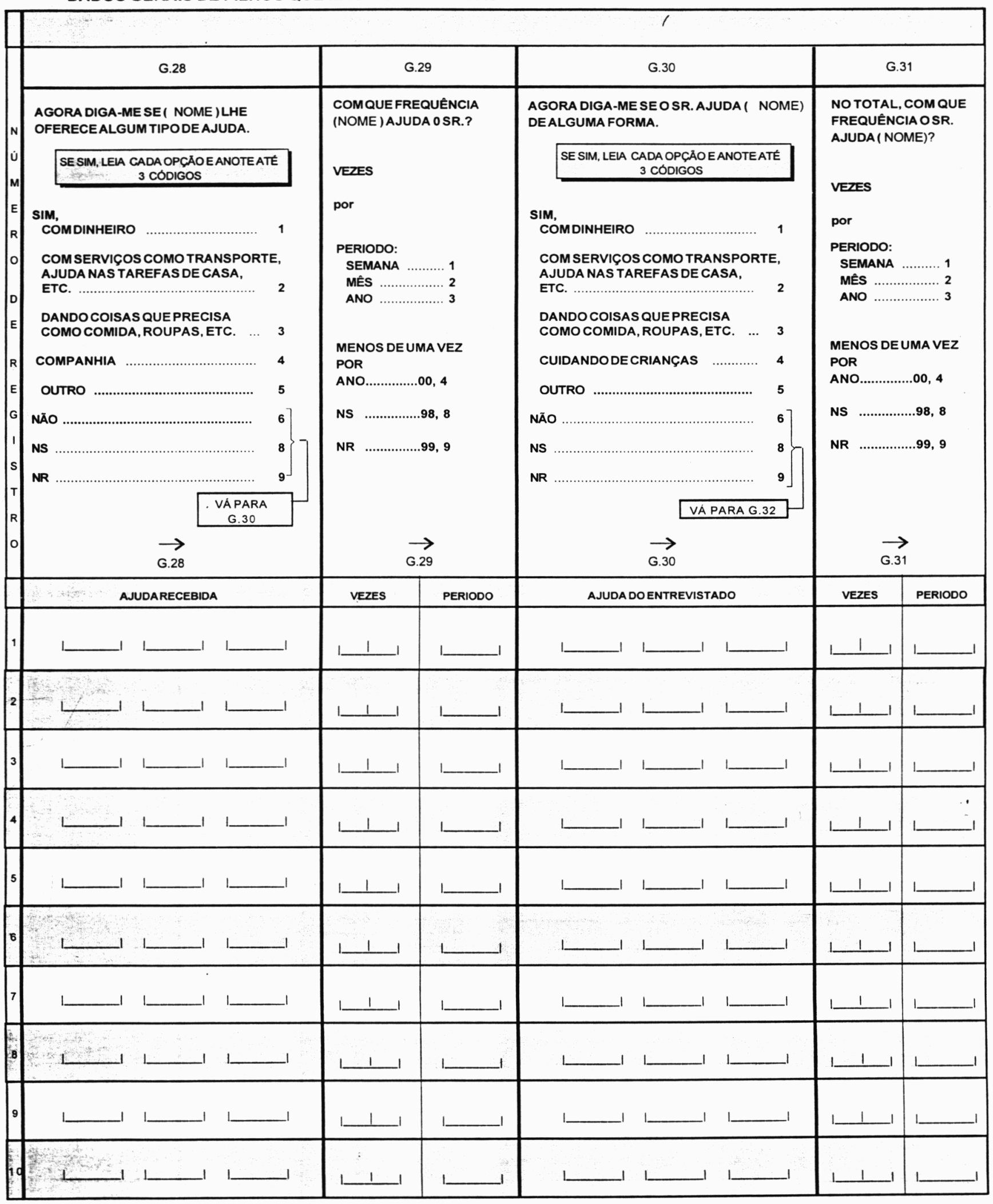


DADOS GERAIS DE IRMĀOS E IRMĀS

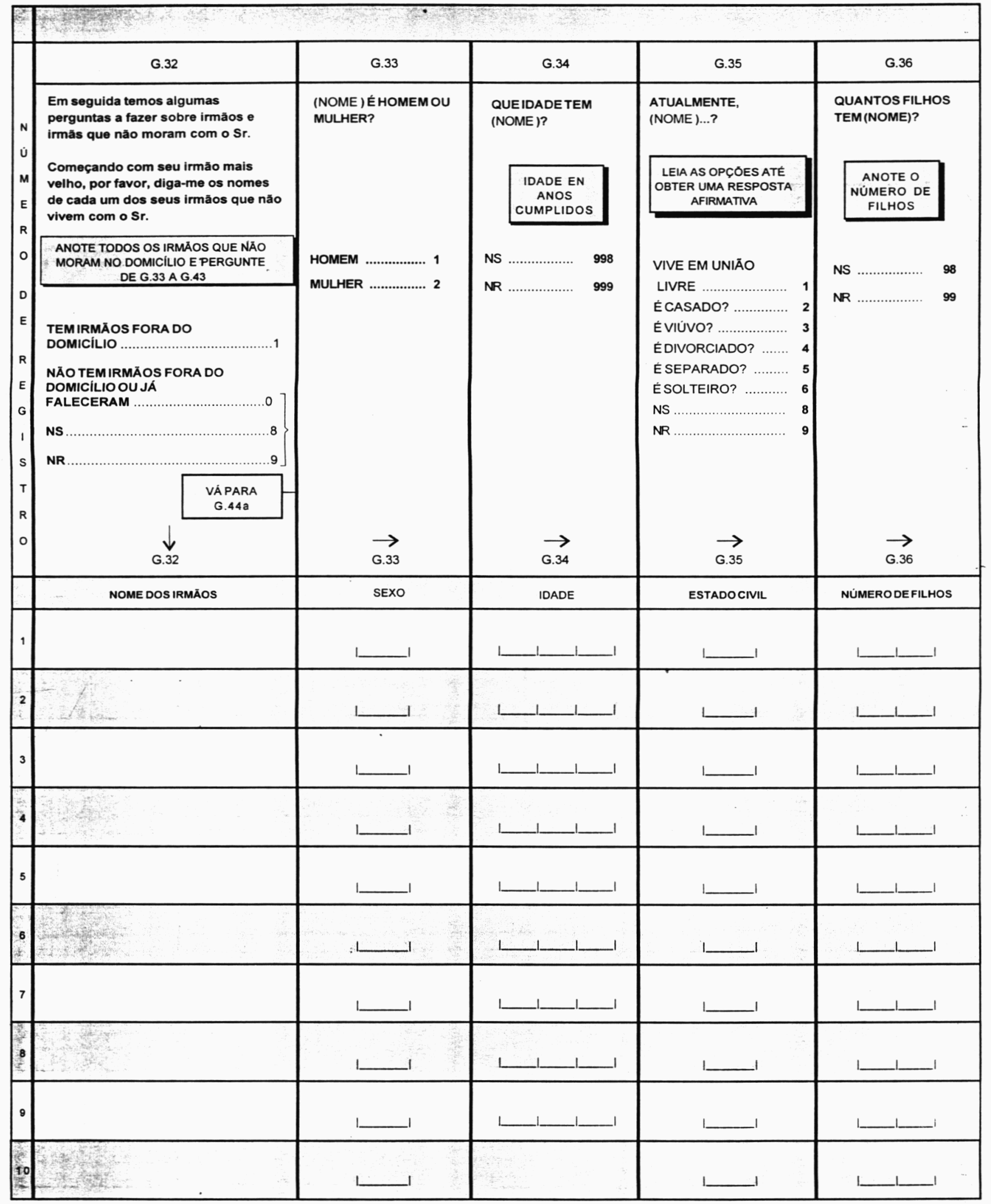


DADOS GERAIS DE IRMĀOS E IRMĀS

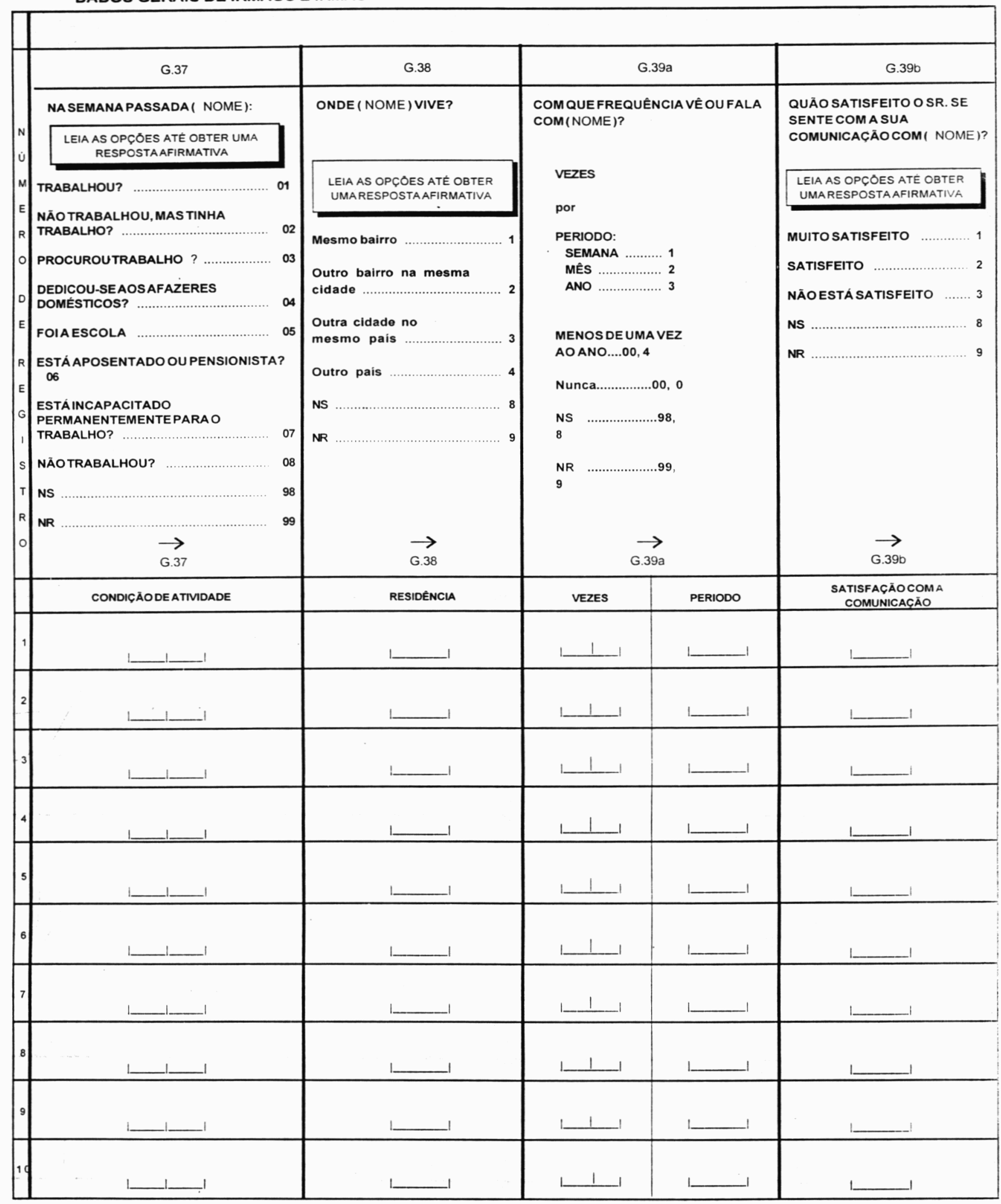


DADOS GERAIS DE IRMÃOS E IRMÃS

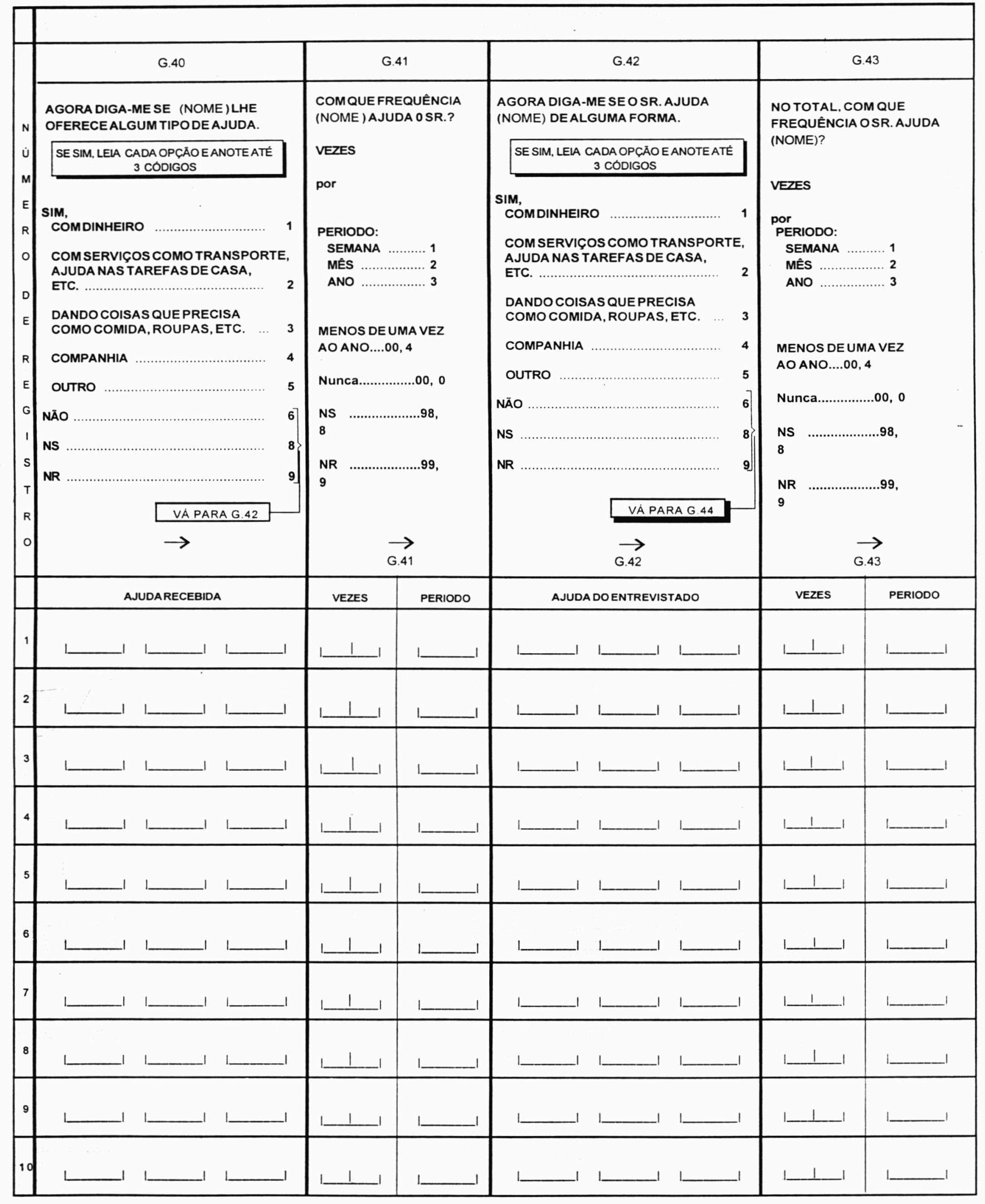


DADOS GERAIS DE OUTROS FAMILIARES E AMIGOS

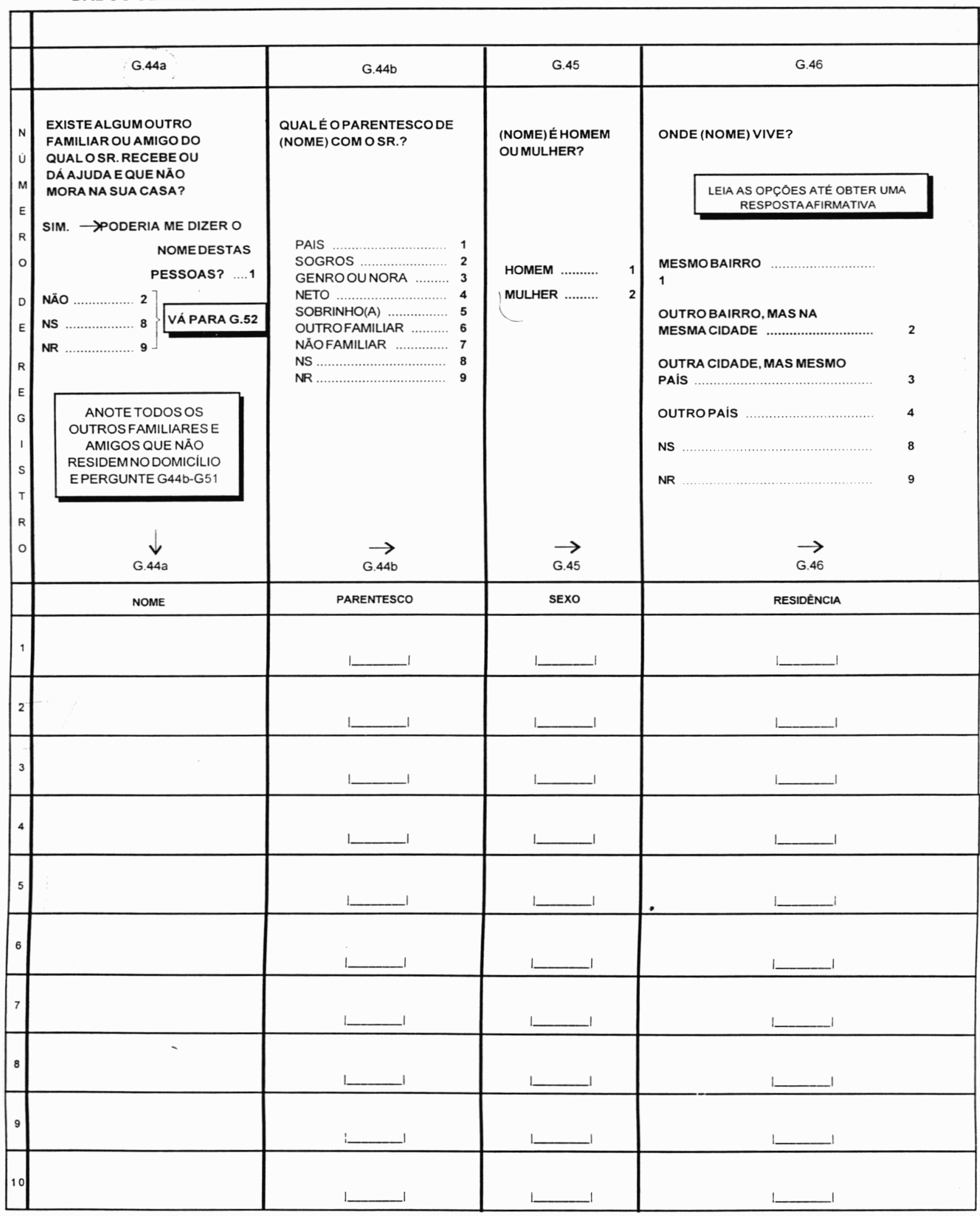


DADOS GERAIS DE OUTROS FAMILIARES E AMIGOS

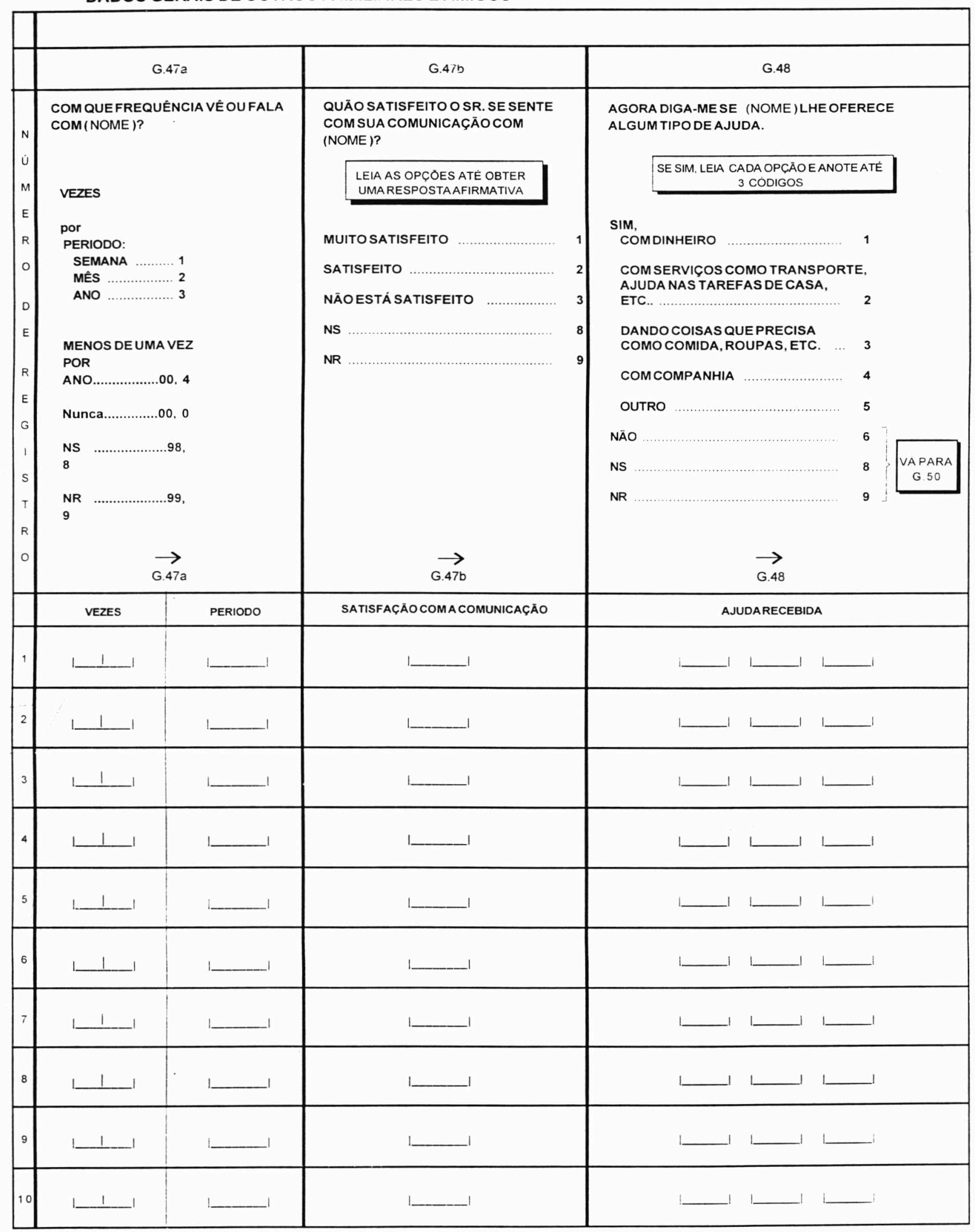


DADOS GERAIS DE OUTROS FAMILIARES E AMIGOS

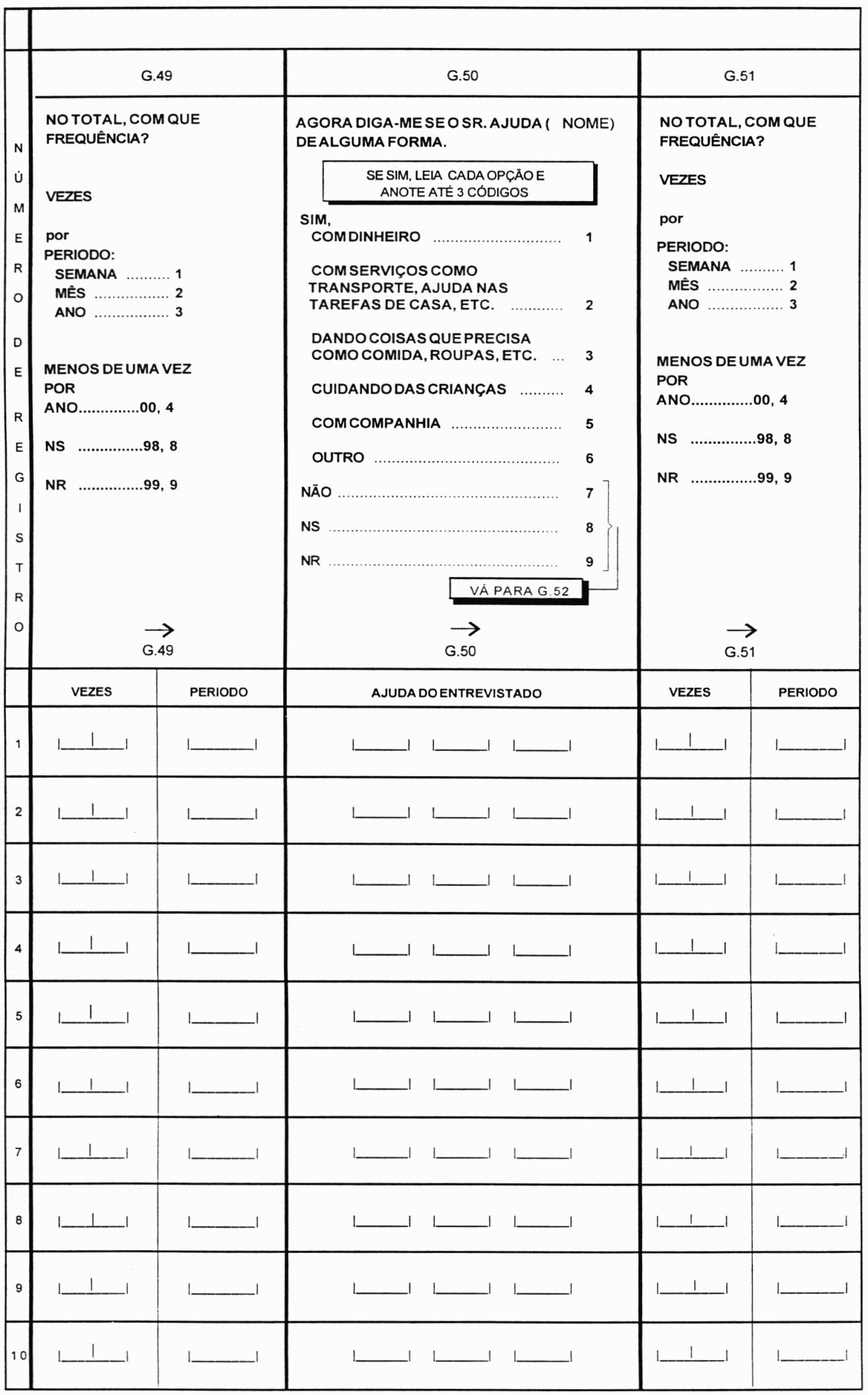


SEÇÃO H - HISTÓRIA DE TRABALHO E FONTES DE RECEITA

HORA DE INICIO: I___ I I___ |

H.1

Alguma vez, na sua vida, o(a) Sr.(a) teve algum trabalho, pelo qual recebeu um pagamento em dinheiro ou em espécie?

H.2

Alguma vez, na sua vida, trabalhou ou ajudou em um estabelecimento familiar, sem receber qualquer tipo de pagamento?

H.3

Qual a principal razão pela qual o(a) sr.(a) nunca trabalhou?

ANOTE SOMENTE UMA RESPOSTA

H.4

Que idade o(a) Sr.(a) tinha quando começou a trabalhar, na primeira vez?

H. 5

Na semana passada, o(a) Sr.(a)...(LEIA TODAS AS OPÇÕES ATÉ OBTER UMA RESPOSTA AFIRMATIVA)

LEIA AS OPÇŌES ATÉ OBTER UMA RESPOSTAAFIRMATIVA
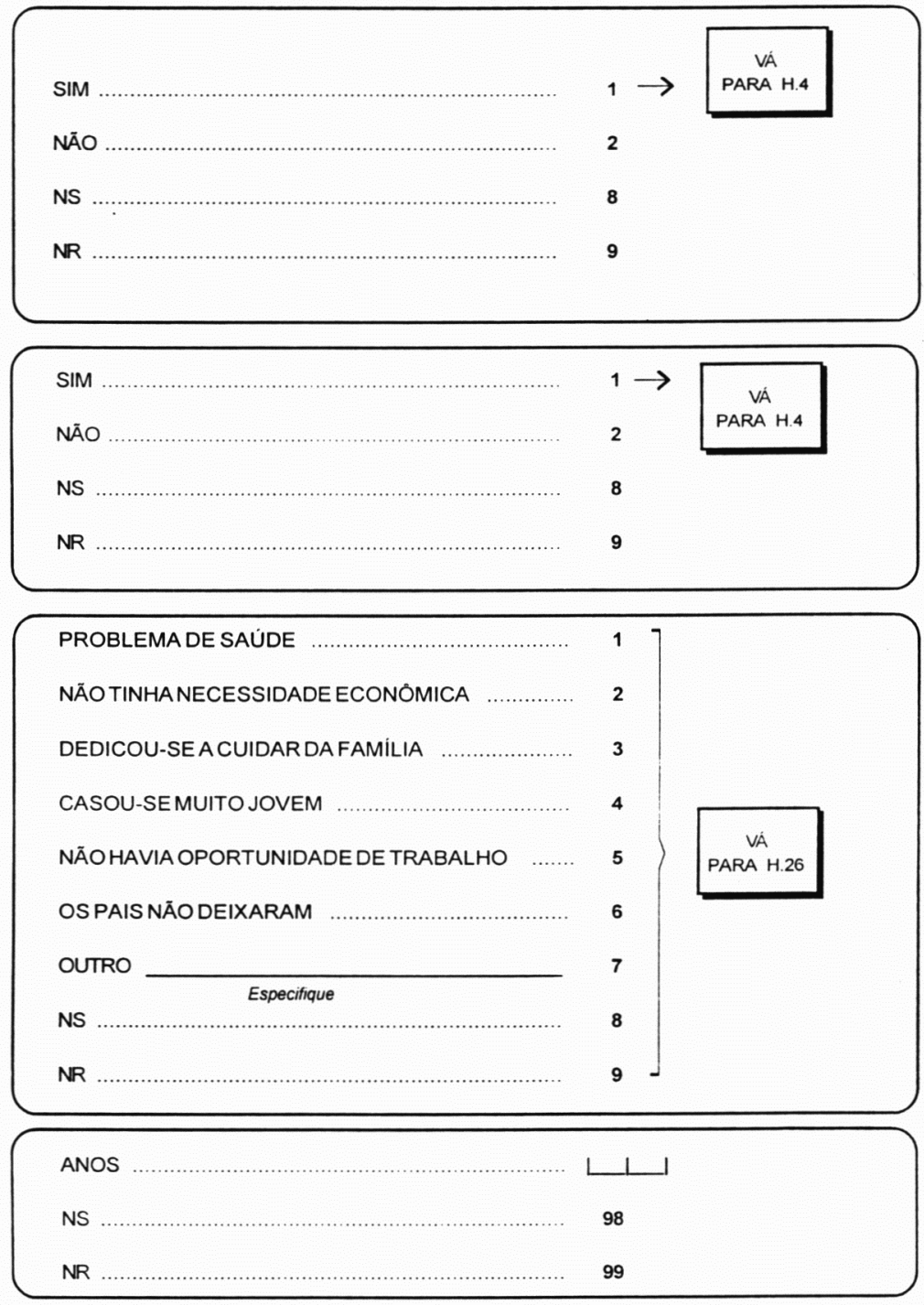

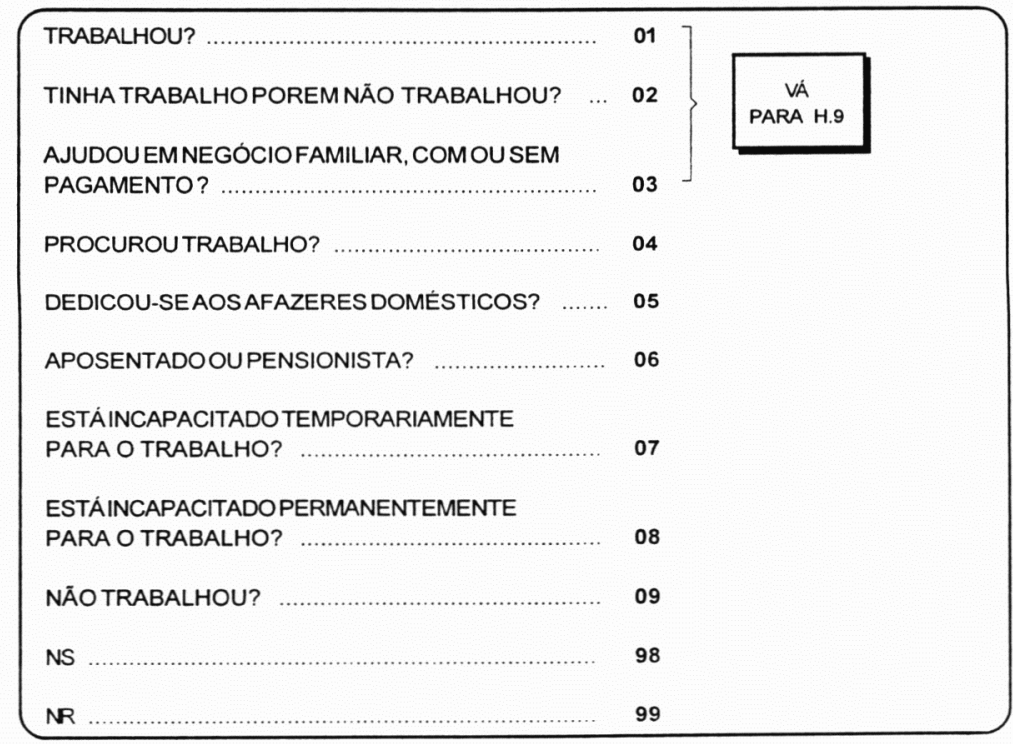


SEÇÃO H - HISTÓRIA DE TRABALHO E FONTES DE RECEITA

H.6

Além desta atividade, (condição em H.5), na semana passada o(a) Sr.(a)...

\section{LEIA AS OPÇOEES ATE OBTER UMA} RESPOSTAAFIRMATIVA

Com que idade deixou de trabalhar?

Qual a principal razão pela qual o(a) Sr.(a) não trabalha atualmente?

\section{ANOTE SOMENTE UMA RESPOSTA}

H.9

Agora, vou me referir ao seu trabalho atual ou ao último que o(a) $\mathrm{Sr}(\mathrm{a})$ teve.

Qual é o nome da ocupação ou ofício que o(a) Sr.(a) desempenhou no seu trabalho principal, na semana passada (ou a última vez que trabalhou)?

H.10

Quais foram as atividades ou tarefas mais importantes que o(a) Sr.(a) desenvolveu no seu trabalho principal, na semana passada (ou a última vez que trabalhou)?
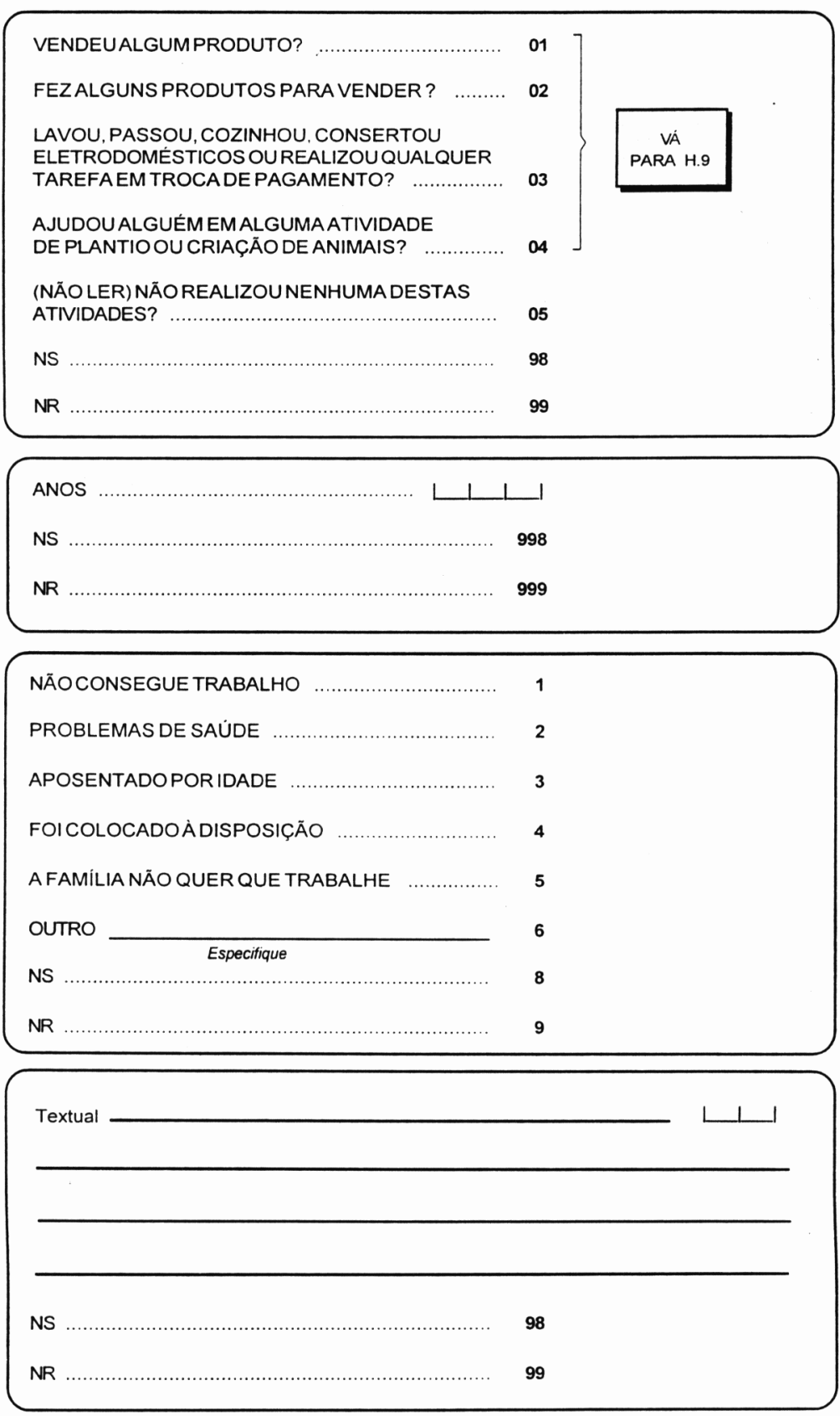

Textual

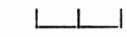

NS

98

NR 
SEÇÃO H - HISTÓRIA DE TRABALHO E FONTES DE RECEITA

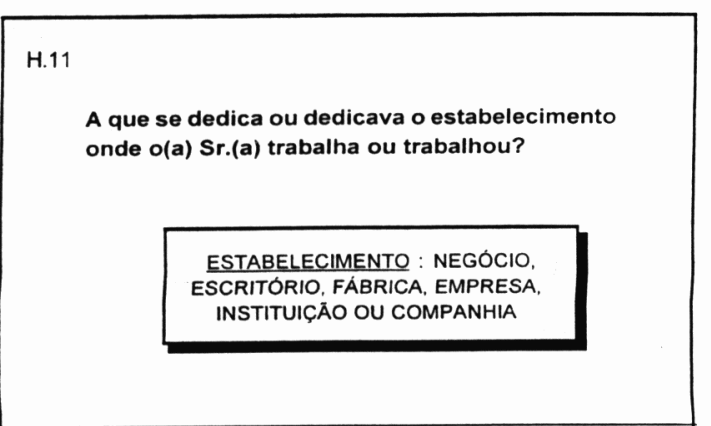

H.12

Com relaçăo ao seu trabalho principal, o Sr.(a) é ou era...?

LEIA AS OPÇÓES ATÉ OBTER UMA RESPOSTAAFIRMATIVA

H.13

Quantas horas o(a) Sr.(a) dedica ou dedicava ao seu trabalho principal ou atividade?

H.14a

Quantos dias por semana o(a) Sr.(a) trabalhou, na semana passada, em sua ocupação principal (ou na última vez que trabalhou)?

H.14b

Quantas semanas por ano trabalhou (no seu trabalho principal) nos últimos 12 meses (ou a última vez que trabalhou)?
Textual

1

NS

NR

99

OPERÁRIO OUEMPREGADONÃO

AGROPECUÁRIO? ............................................ 01

DIARISTARURAL OUPEÄODO CAMPO? ........... 02

PATRÃO, EMPREGADOROUPROPRIETÁRIO

(COM 1 A 5 EMPREGADOS)? …....................... 03

PATRÃO, EMPREGADOROUPROPRIETÁRIO

(COM 6 OU MAIS EMPREGADOS)? .................. 04

TRABALHADOR POR CONTA PRÓPRIA? ............. 05

TRABALHADORFAMILIAR, SEM PAGAMENTO? ... 06

TRABALHADORNÄOFAMILIAR, SEM

PAGAMENTO? …..................................... 07

TRABALHADORPOREMPREITADA? ................ 08

OUTRO

\begin{tabular}{|c|c|}
\hline & Especifique \\
\hline
\end{tabular}

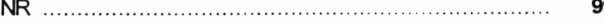
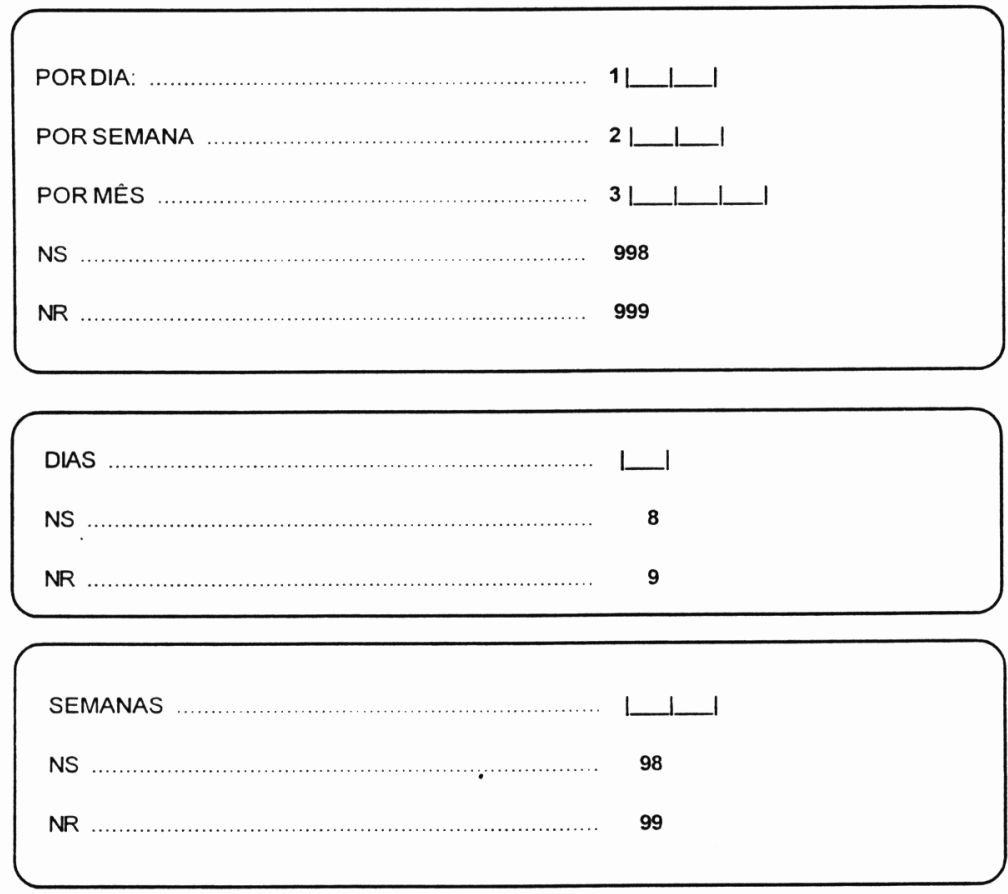
SEÇÃO H - HISTÓRIA DE TRABALHO E FONTES DE RECEITA

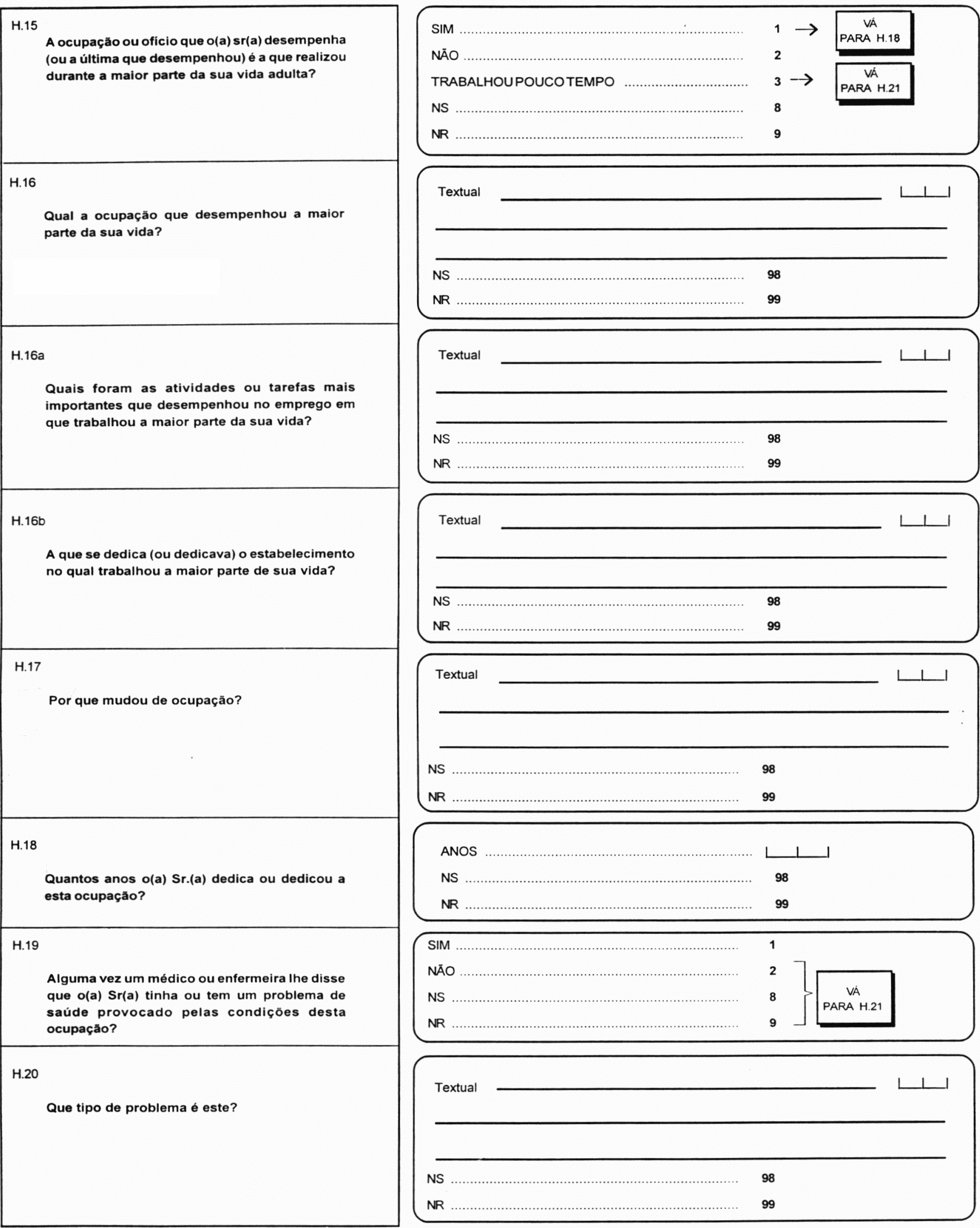


SEÇÃO H - HISTÓRIA DE TRABALHO E FONTES DE RECEITA

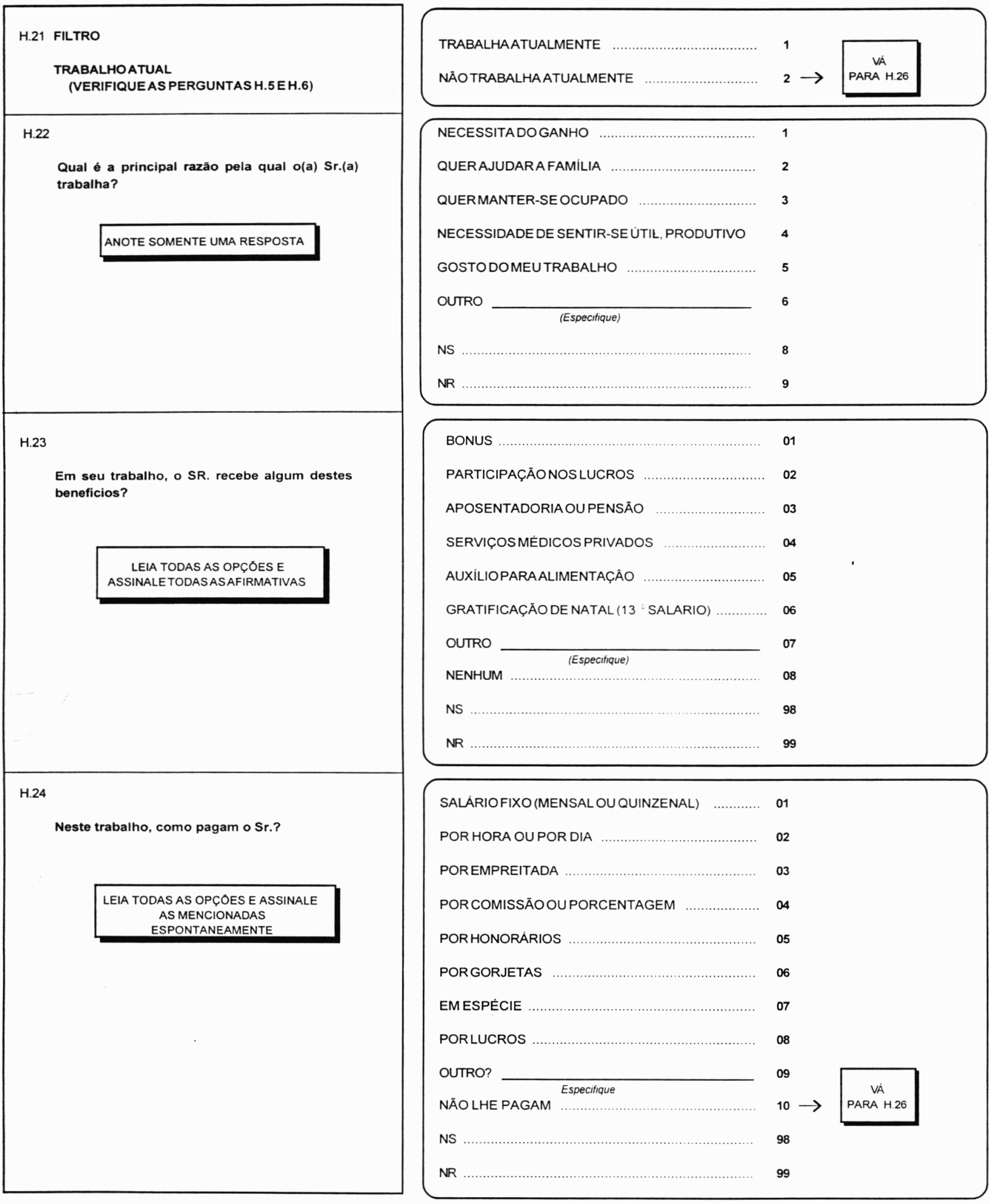


SEÇÃO H - HISTÓRIA DE TRABALHO E FONTES DE RECEITA

H.25

No total, quanto o SR: ganha por este e outros trabalhos que realiza e com que freqüência?

ESCOLHAAALTERNATIVA QUE MAIS SEAJUSTAR

POR SEMANA

\begin{tabular}{|c|c|c|c|}
\hline \multicolumn{2}{|l|}{ H.26 } & $\begin{array}{c}\text { H.27a } \\
\text { QUANTIA }\end{array}$ & $\begin{array}{l}\text { H.27b } \\
\text { FREQUENNCIA }\end{array}$ \\
\hline O(a) Sr.(a) recebe receita por... & & $\begin{array}{l}\text { Quanto o(a) Sr.(a) recebe } \\
\text { por....(beneficios em H.26) }\end{array}$ & $\begin{array}{l}\text { ¿Com que FREQUÊNCIA o recebe } \\
\text { (BENEFICIO em H.26)? }\end{array}$ \\
\hline $\begin{array}{l}\text { LEIA TODAS AS OPÇŌES E } \\
\text { ASSINALEAS AFIRMATIVAS }\end{array}$ & & $\begin{array}{l}\text { PARA CADA RESPOSTA } \\
\text { AFIRMATIVAEM H.26, } \\
\text { PERGUNTE H.27AE H27B }\end{array}$ & \begin{tabular}{|l|l|} 
Por semana $\ldots \ldots \ldots \ldots . . . .$. & 1 \\
Pormes...................... & $\mathbf{2}$ \\
Por quinzena $\ldots \ldots \ldots . .$. & $\mathbf{3}$ \\
por ano & \\
\end{tabular} \\
\hline & & & Periodo \\
\hline 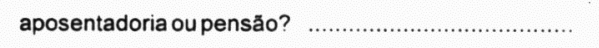 & 1 & $\begin{array}{llllllllllll}\perp & \perp & \perp & \perp & \perp\end{array}$ & $\mathrm{L}$ \\
\hline ajuda de familiares que estão em outro pais? ........... & 2 & $\sqcup \perp \perp \perp \perp$ & 1 \\
\hline ajuda de familiares que estão no pais? & 3 & 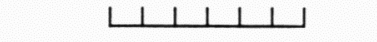 & $\mathrm{L}$ \\
\hline aluguel (renda) ou aplicaçőes bancárias? & 4 & $\begin{array}{lllllllllllll}1 & \perp & \perp & \perp & 1 & 1\end{array}$ & 1 \\
\hline ajuda do bem estar social? & 5 & $\begin{array}{llllllllllll}1 & 1 & 1 & 1 & 1 & 1\end{array}$ & $\mathrm{~L}$ \\
\hline outro? & 6 & $\begin{array}{llllllllll}1 & \perp & \perp & \perp & 1\end{array}$ & 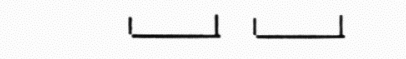 \\
\hline nada ... & 7 & 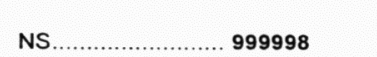 & NS.. \\
\hline 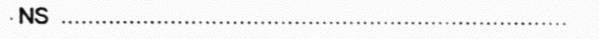 & 8 & 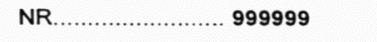 & NR \\
\hline NR & 9 & & \\
\hline
\end{tabular}

\section{H.27C FILTRO}

Recebe alguma receita.

(Ver perguntas H.23, H.24 e H.26.)

H.28

Quantas pessoas dependem dos seus ganhos?

INCLUA OENTREVISTADONOTOTALDE PESSOAS QUE DEPENDEMDESTES INGRESSOS
SIM

NĀO

SOOONTREVISTADO

01

NÚMERO DEPESSOAS …...........................

NS

98

NR

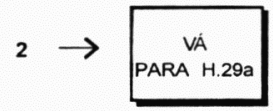


SECCIÓN K. ANTROPOMETRÍA

TOMAR TRÊS MEDIDAS PARA TODAS AS PERGUNTAS ABAIXO

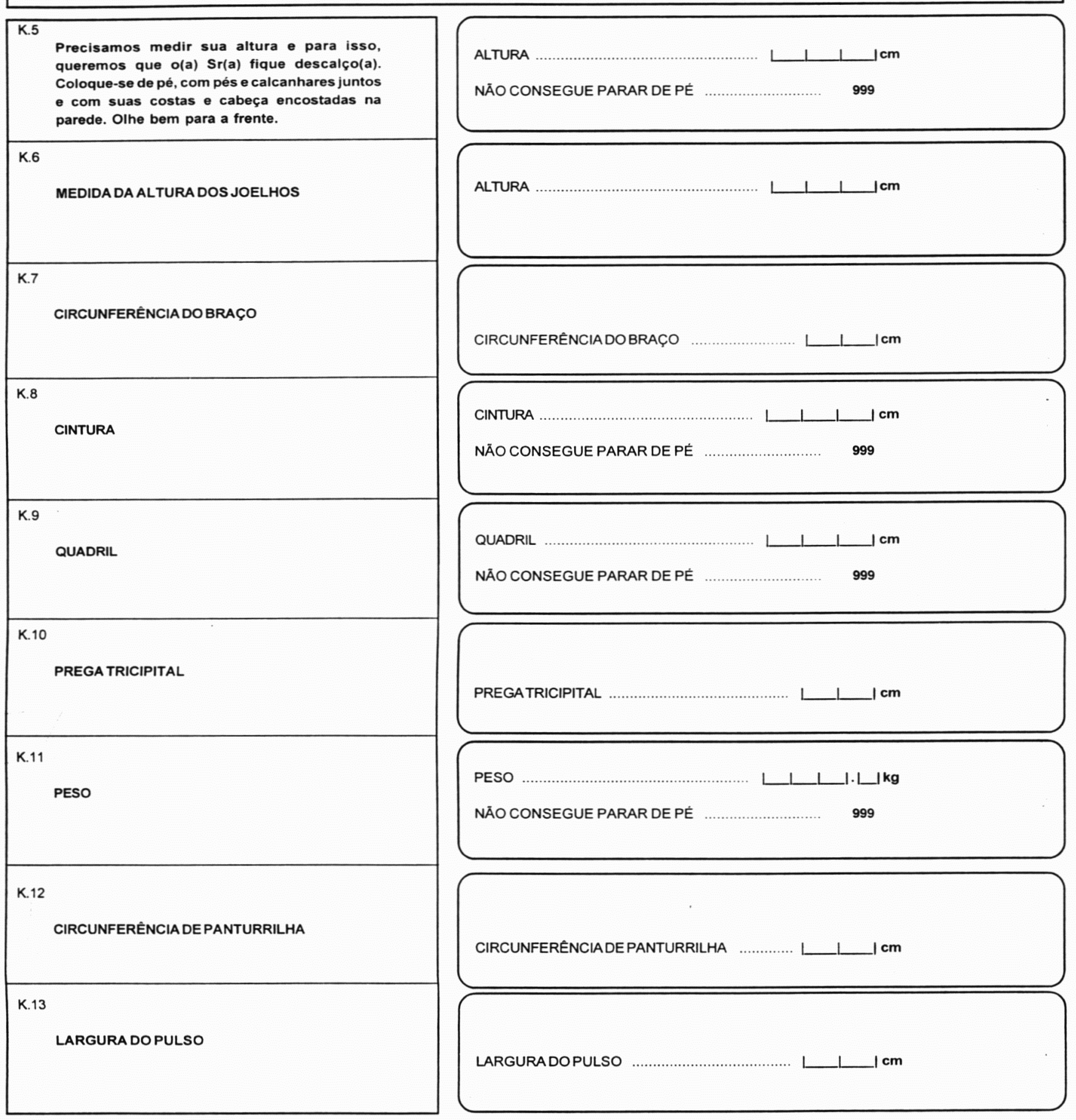


PERGUNTAS E COMENTÁRIOS FINAIS

\begin{tabular}{|c|c|}
\hline 1. & $\begin{array}{l}\text { Observou situação de violência, } \\
\text { abandono ou maus tratos de algum } \\
\text { integrante da casa com relação ao } \\
\text { entrevistado? }\end{array}$ \\
\hline 2. & Descreva a situação: \\
\hline 3. & $\begin{array}{l}\text { Teve dificuldades para completar o } \\
\text { questionário individual? }\end{array}$ \\
\hline 4. & De que tipo? \\
\hline 5. & $\begin{array}{l}\text { Ocorreu alguma situação especial que } \\
\text { tenha dificultado seu trabalho durante } \\
\text { a entrevista? }\end{array}$ \\
\hline 6. & Descreva a situação: \\
\hline
\end{tabular}

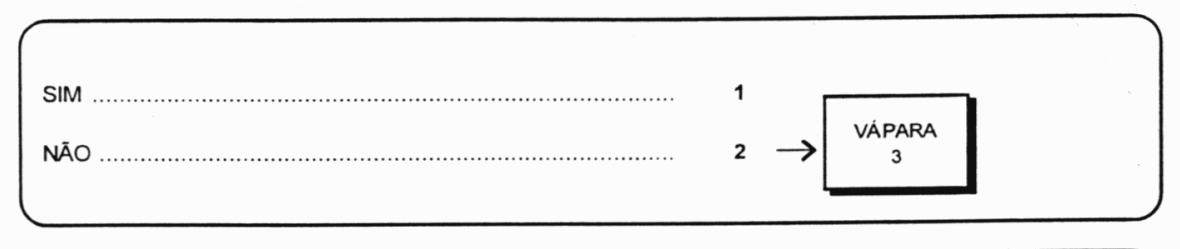

Textual
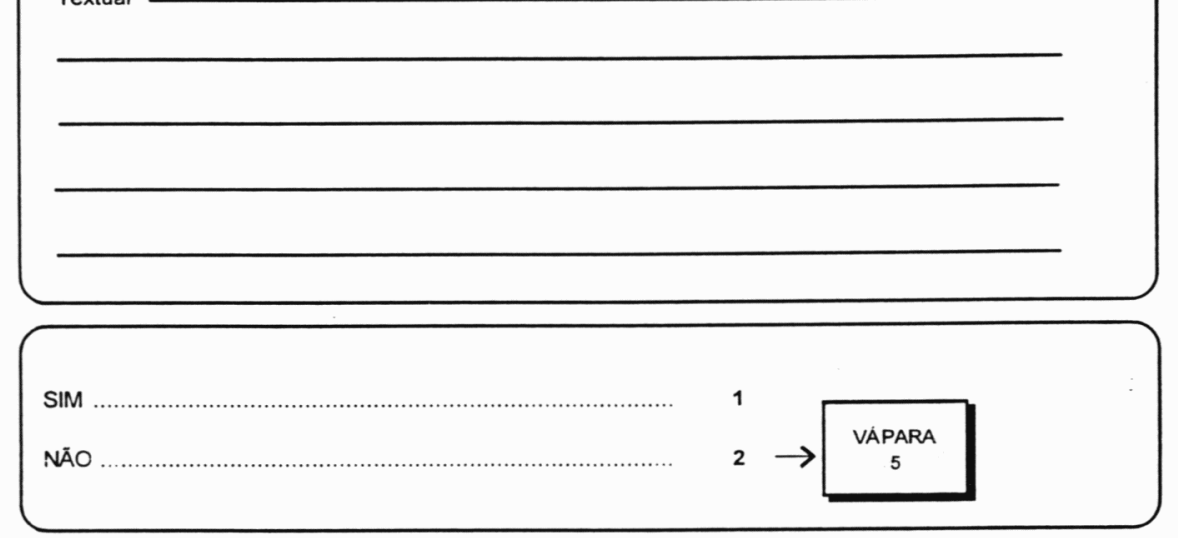

Textual

NÃO
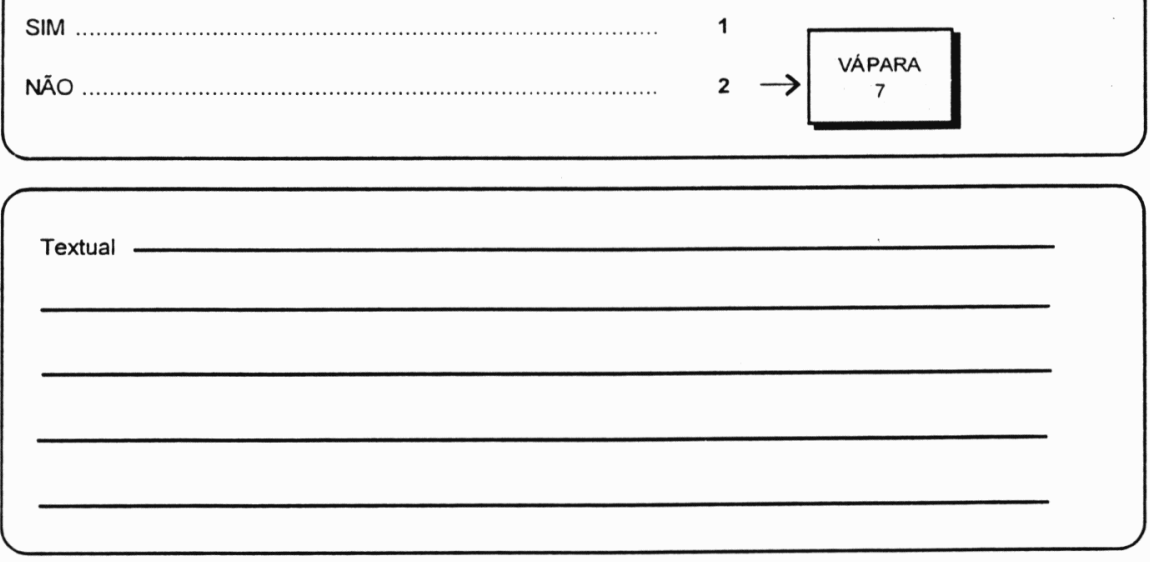